\title{
Lancet Oncology Commission on Sustainable Care for Children with
}

\section{Cancer}

Rifat Atun*, Nickhill Bhakta^, Avram Denburg^^, A. Lindsay Frazier\#^, Paola Friedrich^, Sumit Gupta\#^, Catherine G. Lam^^, Zachary Ward^ ${ }^{\wedge}$, Jennifer Yeh^^, Claudia Allemani $\sim$, Michel P. Coleman, Veronica di Carlo , Eva Loucaides , Elizabeth Fitchett , Fabio Girardi , Sue Horton , Freddie Bray, Eva SteliarovaFoucher , Richard Sullivan , Joanne Aitken, Shripad Banavali, Agnes Binagwaho, Patricia Alcasabas, Federico Antillon, Ramandeep Arora, Ronald D. Barr, Eric Bouffet, Julia Challinor, Soad Fuentes-Alabi, Thomas Gross, Lars Hagander, Ruth Hoffman, Cristian Herrera, Tezer Kutluk, Karen Marcus, Claude Moreira, Kathy Pritchard-Jones, Oscar Ramirez Lorna Renner, Leslie L. Robison, Jaime Shalkow, Lillian Sung, Allen Yeoh, Carlos Rodriguez-Galindo*

* Co-corresponding authors and Co-Chairs

\# Associate co-chairs

$\wedge$ Analytic Working Group Leaders

$\sim$ Core Analytic Team Member

\section{Pre-publication pre-proofed version}




\section{Introduction}

Worldwide, there are unacceptable inequities in access to cancer prevention, treatment and care for adults and children with wide disparities in mortality and survival. While the low-income and middle-income countries (LMIC) account for around $80 \%$ of the global cancer burden, the financing for cancer in these countries only amount to $5 \%$ of the resources allocated to cancer care globally. ${ }^{1}$

Many misconceptions have perpetuated these disparities, and created a 'cancer divide' in access to treatment and thus in survival, ${ }^{2}$ with false perceptions that cancer care is: (i) unnecessary because the burden of cancer is not large in LMIC (ii) unaffordable, for most LMIC (iii) unattainable because LMIC do not have adequate human or physical resources to support treatment and care, and (iv) inappropriate in LMIC because it takes resources away from high-burden diseases that have proven treatments and interventions. ${ }^{2}$

The stark inequities in financing and access to care have translated to wide disparities in the survival of children with cancer. The five-year net survival for acute lymphoblastic leukemia, the most common childhood cancer, range from less than $50 \%$ in Ecuador to more than $90 \%$ in many high-income countries. However, beyond a handful of countries the magnitude of these inequities in relation to the overall survival gap has not been reliably quantified in LMICs. ${ }^{3}$ 
Yet, these misconceptions are unfounded. For most children, a diagnosis of cancer was once a death sentence. However, the last six decades have produced scientific advances in the diagnosis, treatment and supportive care of children diagnosed with cancer (ages 0-14 years). In high-income countries, for many cancers, these advances have produced remarkable improvements in five-year net survival, for example from less than $5 \%$ to $80 \%$ for childhood leukaemia. ${ }^{4}$ However, these advances have not similarly benefited children with cancer in LMICs to anything like the same extent. ${ }^{5}$

Multiple factors account for the global inequities in cancer outcomes, including: disparities in access to effective diagnostics ${ }^{6}$, medicines, ${ }^{7}$ surgery ${ }^{8}$, radiotherapy ${ }^{9}$, and advanced stages of disease when cancer is diagnosed ${ }^{10}$. Even when there is access to medicines and treatment, financial unaffordability compels many children to abandon treatment prematurely ${ }^{11}$, or lack of supportive care leads to treatment interruptions or even death ${ }^{12}$. In addition, poor quality care delivered in weak health systems in LMICs adversely affects outcomes for cancer and other conditions that are amenable to treatment. ${ }^{13}$ In many LMICs children with cancer face multiple barriers in every step of care to survive (panel 1).

\section{Panel 1: The child with cancer in resource-limited settings}

In LMIC (we define LMIC according to World Bank income group classification in 2016 appendix page 28) unacceptable excess in treatment failure for children with cancer results from a malfunction of every step in the care cascade from diagnosis, to referral to treatment, follow up and palliative care. ${ }^{14}$ Inadequate healthcare infrastructure and service delivery networks, limited access to quality medicines, lack of multidisciplinary health workforce, 
low-quality of care adverse socio-economic environment, cultural and educational barriers, and lack of awareness both at the societal level as well as within the medical community result in missed diagnosis, under-ascertainment, delayed and under diagnosis and suboptimal care of childhood cancer in LMIC.15,16,17 Other factors also contribute to suboptimal care and poor outcomes, including:

(i) Refusal and abandonment of therapy: refusal and abandonment of therapy is a major cause of therapeutic failure in countries with limited resources, where children and families incur unaffordable direct and indirect costs of care ${ }^{18,19}$, and affect up to $50-60 \%$ of children in some world regions - often exceeding all other causes of treatment failure. ${ }^{11}$ Most children abandon early, usually after induction remission in leukaemias or at the time of radical surgeries (e.g. enucleation of the eye or amputation) in solid malignancies. ${ }^{20,21}$

(ii) Malnutrition: the prevalence of malnutrition in children with cancer in LMIC, which is associated with higher toxicity rates, reaches $50 \%$ to $70 \%$ in some regions of the world and is a major cause of decreased survival. ${ }^{22,23}$

(iii) Lack of supportive care: the ability to provide state of the art curative treatments for children with cancer in LMIC is severely limited by the lack of supportive care programmes, most notably nutrition, and infection control. Death from infection during neutropaenic episodes is much higher in countries with limited resources. ${ }^{24,25,26}$

(iv) Lack of blood products and transfusion support: availability of safe blood products is 
another major limitation to successful cancer care in LMICs - a problem worsened by the high seroprevalence of HIV and Hepatitis B, which can be as high as $10 \%$ to $25 \%$ among blood donors in Africa. ${ }^{27}$ Only $13 \%$ of LMICs have a national hemovigilance system to monitor and improve the safety of transfusions, and only $53 \%$ of blood donations are appropriately screened. ${ }^{28}$

(v) Reliance on traditional and complementary medicine: while a lack of awareness of the population in about cancer is a serious obstacle to access to treatment, it is also part of the reason why parents bring their children to traditional healers even when they have access to cancer care. This leads to delayed diagnosis but also a higher incidence of use of traditional and complementary medicine, for which often there is no evidence of effectiveness, among children undergoing cancer treatment in LMICs, with adverse consequences related to drug interactions, adherence to therapy, and treatment-related toxicities. ${ }^{29}$

(vi) Lack of palliative and survivorship care: most LMIC lack properly developed and implemented palliative care programmes. ${ }^{30}$ Lack of adequate pain control is at the core of deficient palliation in LMIC, where pain management may be available in less than $50 \%$ of paediatric oncology units, and high-potency opiates and adjuvant medications for neuropathic pain are available in less than $15 \%$ of the countries. ${ }^{31}$

The world is clearly failing to meet the needs of children with cancer in LMIC. Yet, there is hope. There are many cost-effective interventions that could be used to expand access to cancer prevention, treatment and care. ${ }^{32}$ However, as with many other technologies for 
global health (including diagnostics, medicines, medical devices and therapies) are challenges related to (i) availability - the technology is either not available to people in LMICs, (ii) accessibility - technology exists but is not accessible (due to unaffordability, distribution challenges or lack of human resources) or, (iii) acceptability - technology is available and accessible but not used due to inertia or lack of acceptability to users. ${ }^{33}$

New evidence and several recent developments worldwide have created an impetus to eliminate these disparities in treatment and outcome for children with cancer. The Third Edition of Disease Control Priorities (DCP3), a worldwide collaboration involving leading academic institutions, countries and development agencies, has identified cost-effective interventions for childhood cancer in LMICs to show that treating cancers such as Burkitt lymphoma, and Hodgkin lymphoma is very cost effective and can be delivered even in medical centres with the least capability, while treating Wilms tumour and acute lymphoblastic leukaemia is either cost-effective or very cost-effective and along with intraocular retinoblastoma could be delivered in medical centres with greater capability. DCP3 also suggested that effective treatment for sarcomas, brain tumors, acute myeloid leukemia, high-risk neuroblastoma, and other retinoblastomas could be delivered in medical centres with the highest level of capability. ${ }^{34}$ DCP3 has also identified healthcare delivery platforms, such as primary health care centres, district hospitals, teaching hospitals and specialist hospitals for children, which could be used to deliver cost-effective interventions. $^{35}$ 
Further, the Lancet Commission on Global Health 2035 has highlighted the "enormous payoff from investing in health" in terms of health and economic benefits for individuals, household and countries, arguing that it is possible to achieve "dramatic health gains" and to achieve convergence in health outcomes between low-income countries and uppermiddle-income countries within a generation. The Commission concluded: "progressive universalism would yield high health gains per dollar spent and poor people would gain the most in terms of health and financial protection". ${ }^{36}$ While the Lancet Commission on Global Health 2035 did not focus on childhood cancer, it made a strong case for 'investing in health' to realise health and economic benefits. A similar case could be made for expanding coverage of cost-effective interventions to tackle childhood cancer and to eliminate unacceptable worldwide inequities in access to care and health outcomes. The timing is right for a global push to expand the coverage of care for childhood cancers. There is a strong global momentum to achieve the universal health coverage (UHC) - a target (Target 3.7) of the third Sustainable Development Goal. ${ }^{37}$

In 2017, the World Health Assembly Resolution on Cancer Prevention and Control called on Member States to implement health promotion and risk factor reduction for cancer, and to address inequity in access to early detection and appropriate treatment, including pain relief and palliative care. ${ }^{38}$ With this mandate, in 2018, the World Health Organisation (WHO) launched the Global Initiative for Childhood Cancer to support governments in building and sustaining high-quality childhood cancer programmes to reach at least a $60 \%$ five-year overall survival for children with the six commonest childhood cancers globally by $2030 .{ }^{39}$ Achieving this goal will require prioritisation of childhood cancers at global and 
national levels, increased funding and stronger health systems..$^{40}$ This is especially in the case of sub-Saharan Africa where health systems are weak, and the population of children is projected to grow from 320 million in 2015 to more than 720 million in 2050.41

However, evidence is needed to demonstrate the opportunities for reducing disparities in access and outcomes, and to make a case for investing in worldwide scale-up of costeffective interventions for childhood cancer, and for their inclusion in UHC.

The aim of the Lancet Oncology Commission on Sustainable Cancer Care for Children (the Commission) is to present new evidence to justify investments in scale-up of interventions for childhood cancers in LMICs to reduce disparities and improve outcomes. The Commission provides a comprehensive analysis of the challenges and opportunities in relation to childhood cancers and costs and benefits of scaling up cost-effective interventions and their inclusion in UHC. It identifies examples of good practice in different settings and potential solutions with packages of care that could be scaled up globally. It quantifies the investment needed to scale evidence-based interventions and the health and economic benefits of such investments globally to develop a compelling case for investing in management of childhood cancers.

The Commission report is organised in seven sections. Section one provides an analysis of the global challenge of childhood cancer by providing a review of published literature and estimates for incidence and survival of childhood cancers. This section also presents new analyses on the current and projected incidence of childhood cancers and survival in 
different countries globally. Section two provides an analysis of the current service coverage levels for childhood cancers, funding allocated to childhood cancers in national cancer plans and global research funding. Section three examines the current evidence on the cost of providing cancer services in different settings and case studies of successful examples of LMICs that have developed cancer services. Section four presents a new analysis of costs, health and economic benefits of expanding cancer services and the economic returns to investing in childhood cancer care. Section five provides new analyses on the package of services that are necessary for providing care to children with cancer in varied settings, and capabilities needed to deliver them. Section six discusses actions for expansion of services for children with cancer, potential funding that could be mobilised to support expansion of care to children with cancer globally, and the roles different stakeholders could play in this expansion process. Finally, we propose ambitious but achievable targets and a call to action for sustainable care for children with cancer around the world. 


\section{SECTION 1: THE CHALLENGE}

Accurate estimates of childhood cancer incidence are critical for understanding the current and future burden of disease and the demand for health services, and to inform policymakers in priority setting and planning decisions to ensure development of appropriate responses at global and country level.

The Commission undertook a series of reviews of published literature and examined existing data to identify studies on global and national estimates of incidence, survival and mortality, as well as composite measures of the burden of childhood cancer (such as disability-adjusted life-years [DALYs] ${ }^{42}$ ).

A scoping review of studies of childhood cancer burden undertaken by the Commission and published in 2000-2018 (details of which are published elsewhere) ${ }^{43}$ identified four major studies: (i) International Incidence of Childhood Cancer (IICC-3) ${ }^{44,45}$ (ii) GLOBOCAN 2012, published in $2015^{46}$ (iii) CONCORD (CONCORD-3), ${ }^{3}$ and (iv) Global Burden of Disease Study (GBD) 2016 on cancer covering the period 1990-2016 ${ }^{47}$. These studies differ in data sources, the criteria for assessing data quality and inclusion of data in the analyses, the analytical and modelling approaches used to estimate the burden of cancer, and the subsets of childhood malignancies and countries. Their estimates of incidence and mortality also differ (panel 2). ${ }^{43}$ 


\section{Panel 2: Comparison of published studies measuring incidence, survival and mortality, and the burden of disease for childhood cancer}

The International Agency for Research on Cancer (IARC), in collaboration with the International Association of Cancer Registries, used population-level data collected by cancer registries to estimate the incidence of childhood cancer. The findings of the study were published in the Lancet Oncology in $2017,{ }^{44}$ coinciding with the publication of the International Incidence of Childhood Cancer, volume 3 (IICC-3) ${ }^{45}$.

IICC-3, published in 2017, included data from 153 registries in 62 countries to examine the incidence rates in children and adolescents aged 0-19 years, diagnosed during 2001-2010 with leukaemias, lymphomas, central nervous system tumours, neuroblastoma, retinoblastoma, soft tissue sarcoma, germ cell tumours, epithelial tumours, cancers of kidney, liver or bone, or a residual category of 'other and unspecified' malignancies. Only $11 \%$ of included registries were from LMICs. ${ }^{44}$

GLOBOCAN 2012, published in 2015, used data from 375 registries to model incidence and mortality rates for leukaemias, Hodgkin lymphoma, non-Hodgkin lymphoma, cancers of central nervous system, kidney and liver, and Kaposi sarcoma in children aged 0-14 years for 184 countries in 2012. Just 7\% of the registries were from LMICs. ${ }^{46}$

CONCORD-3, published in 2018, used individual patient data from 322 registries in 71 countries to examine 5-year net survival (cumulative probability of surviving up to 5-years since diagnosis after correcting for other causes of death) from acute lymphoblastic 
leukaemia, lymphomas, and central nervous system tumours among children (aged 0-14) for $2000-2014$. Only $5 \%$ of the registries were from LMICs. ${ }^{3}$

GBD 2016, published in 2017, used data from 562 registries in 93 countries to model incidence, prevalence, mortality and disability adjusted life-years for acute lymphoblastic leukaemia, acute myeloid leukaemia, Hodgkin lymphoma, non-Hodgkin lymphoma, and cancers of the central nervous system, kidney and liver, in children and adolescents aged 019 years for 195 countries over the period 1990-2016. Only 12\% of the registries were from LMICs. ${ }^{47}$

\section{Published studies on estimates of incidence of childhood cancers}

Worldwide regional estimates of childhood cancer incidence for the year 2018 undertaken by IARC for this Commission by modelling based on cancer registry data suggests agestandardised rates ranging from 59.5 per million person-years for children aged 0-14 years (95\% uncertainty interval [UI] 54.9-64.1) in sub-Saharan Africa to 175.1 (95\% UI 163.6186.5) in Southern Europe (table 1). The largest number of estimated new cases was in South Central Asia $(44,098)$ and the lowest in Oceania $(1,362)$. Age standardised incidence rates (ASR) for leukaemias were the highest (49.1 per million person-years for children aged 0-14 years; 95\% UI 47.9-50.4), followed by central nervous system tumours (ASR 30.4; 95\% UI 29.4-31.4) (table 1). 
Table 1: Estimated age-standardised incidence rates of childhood cancer per million population by world region, for 2018

\begin{tabular}{|l|c|c|c|}
\hline World Region & $\begin{array}{c}\text { Age-standardised } \\
\text { rate }\end{array}$ & $\begin{array}{c}\mathbf{9 5 \%} \\
\text { uncertainty } \\
\text { interval }\end{array}$ & $\begin{array}{c}\text { Number of } \\
\text { cases }\end{array}$ \\
\hline Africa, North & 105.4 & $83.2-127.6$ & 7,587 \\
\hline Africa, Sub-Saharan & 59.5 & $54.9-64.1$ & 24,584 \\
\hline America, Caribbean & 148.7 & $133.1-164.3$ & 8,780 \\
\hline America, South & 135.7 & $128.8-142.6$ & 13,500 \\
\hline America, North & 167.8 & $162.9-172.6$ & 10,781 \\
\hline Asia, Eastern & 163.2 & $156.9-169.4$ & 43,144 \\
\hline Asia, South Central & 79.9 & $70.7-89.1$ & 44,098 \\
\hline Asia, South Eastern & 122.9 & $108.5-137.4$ & 20,280 \\
\hline Asia, Western & 146.5 & $134.4-158.6$ & 11,162 \\
\hline Europe, Eastern & 159.1 & $150.0-168.2$ & 7,305 \\
\hline Europe, Northern & 150.6 & $142.0-159.2$ & 2,658 \\
\hline Europe, Southern & 175.1 & $163.6-186.5$ & 3,791 \\
\hline Europe, Western & 169.2 & $162.0-176.4$ & 4,852 \\
\hline Oceania & 152.0 & $137.2-166.8$ & 1,362 \\
\hline \hline
\end{tabular}

Data source: International Agency for Research in Cancer

For countries in each sub-region please refer to appendix page 2

There were an estimated 91,463 leukaemia cases in 2018, with an ASR of 49.1 per million population, followed by 57,457 central nervous system tumours (ASR 30.4; 95\% UI 29.431.4) (table 2). 
Table 2: Estimated age standardised incidence rates per million population for childhood cancers by cancer type

\begin{tabular}{|l|c|c|c|}
\hline Area & $\begin{array}{c}\text { Age-standardised } \\
\text { rate }\end{array}$ & $\begin{array}{c}\mathbf{9 5 \%} \\
\text { uncertainty } \\
\text { interval }\end{array}$ & $\begin{array}{c}\text { Number of } \\
\text { cases }\end{array}$ \\
\hline Leukaemia & 49.1 & $47.9-50.4$ & 91,463 \\
\hline Lymphomas & 15.5 & $14.7-16.3$ & 30,410 \\
\hline $\begin{array}{l}\text { Central nervous system } \\
\text { tumours }\end{array}$ & 30.4 & $29.4-31.4$ & 57,457 \\
\hline Sympathetic nervous system & 10.9 & $10.3-11.5$ & 19,235 \\
\hline Retinoblastoma & 4.7 & $4.2-5.1$ & 8,132 \\
\hline Renal tumours & 8.3 & $7.8-8.8$ & 14,871 \\
\hline Hepatic tumours & 2.6 & $2.2-2.9$ & 4,578 \\
\hline Bone tumours & 5.7 & $5.3-6.1$ & 11,597 \\
\hline Soft tissue sarcomas & 9.1 & $8.7-9.5$ & 17,327 \\
\hline Germ cell \& gonadal tumours & 5.3 & $5.0-5.7$ & 10,230 \\
\hline Epithelial tumours \& \\
melanoma
\end{tabular}

Data source: International Agency for Research in Cancer

However, as with earlier estimates, these figures are derived by modelling the number of observed and registry-reported cases, and projecting the rates to countries without cancer registries. They do not account for underreporting. ${ }^{43}$

The incidence estimates from GLOBOCAN 2012 and GBD 2016 were more comprehensive in their coverage, in terms of the cancer types and the number of countries for which estimates were made. However, for the many countries with missing data incidence and mortality rates were extrapolated from other sources. The incidence estimates for these 
two studies differed by between $5 \%$ and $47 \%$ depending on the cancer. For the number of deaths the differences varied between $5 \%$ and $52 \%$. The difference in the modelled estimates of the total number of cancers diagnosed worldwide each year in children and adolescents (aged 0-19 years) was large, estimated by GLOBOCAN as 163,284 cases and by GBD 2016 as 240,942 cases. $^{43}$

\section{Published Studies on Survival from Childhood Cancers}

In 2018, the CONCORD programme, led by the Cancer Survival Group at the London School of Hygiene and Tropical Medicine in England, published its third report (CONCORD-3), ${ }^{3}$ covering global trends in population-based cancer survival based on individual records for over 37 million patients diagnosed with one of 18 common cancers during 2000-2014. ${ }^{3}$

These 18 cancers represent 75\% of the global cancer burden. Data were provided by 322 population-based cancer registries in 71 countries and territories that are home to $67 \%$ of the world's population. CONCORD-3 reported age-standardised five-year net survival, which is corrected for competing causes of death (background mortality) and the higher competing risks of death in the elderly. ${ }^{48}$ Information on background mortality was derived from complete life tables of all-cause mortality in the general population, specific for country or region, single year of age, sex, single calendar year and, where relevant, race/ethnicity. ${ }^{3}$

CONCORD-3 included the three most common childhood cancers: acute lymphoblastic leukaemia, lymphomas and brain tumours. The second cycle of the CONCORD programme 
(CONCORD-2) ${ }^{49}$, including children (0-14 years) diagnosed in 1995-2009, had reported five-year net survival for childhood leukaemias. ${ }^{50}$ Combined results from CONCORD-2 and CONCORD-3 indicated that during the 20-year period from 1995-1999 to 2010-2014, agestandardised 5 -year net survival for acute lymphoblastic leukemia had increased by $10 \%$ or more in 14 countries, including three upper-middle-income countries (China, Turkey and Lithuania). ${ }^{3}$

The CONCORD Central Analytic Team performed more detailed analyses of survival by morphologic sub-type for this Commission. Age-standardised 5-year net survival for childhood cancers varied widely by country-income status (table 3). Only reliable, agestandardised estimates are shown in Table 3 with a range of lowest and highest values in LMIC where data are available to show the range and not report just a single 'outlier' that was either very high or very low. 
Table 3: Lowest and highest age-standardised 5-year net survival (\%) for children diagnosed with cancer during 2010-2014, by country and country-income group

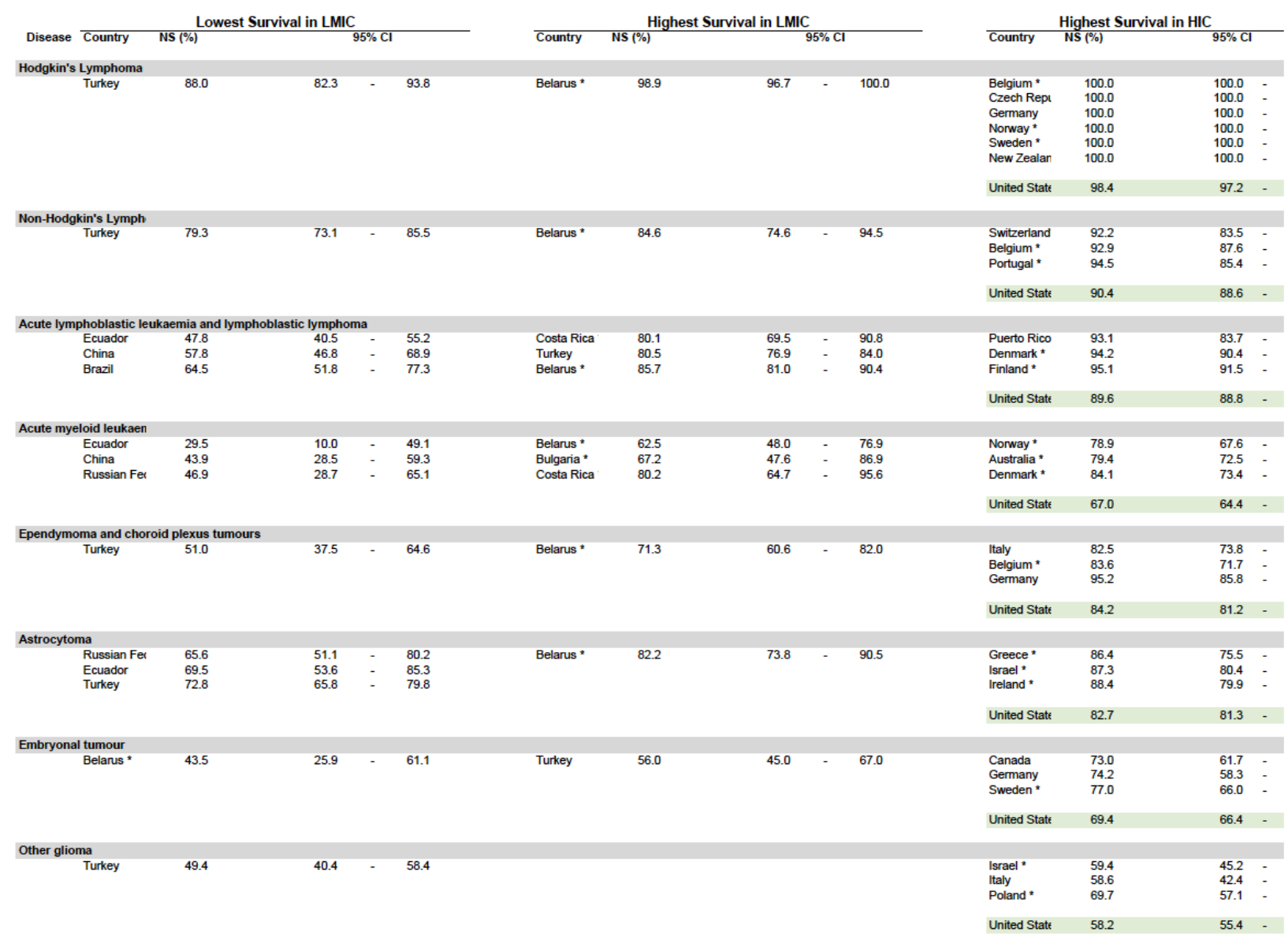

Source: Survival estimates provided by the Concord programme

* Data with $100 \%$ coverage of the national population

Note: Morphology groups included in Table 3 are based on the second tier of the International Classification of Childhood Cancer 3rd edition (ICCC-3). Therefore, agestandardised survival estimates are for all astrocytomas combined and for all embryonal tumours combined. ICCC-3 does include a third, more granular tier for embryonal tumours, but not for astrocytomas. We chose, however, not to estimate survival separately for embryonal tumour subtypes in this third tier (medullolastoma, primitive neuro-ectodermal tumour, medulloepithelioma, and atypical teratoid/rhabdoid tumour), because small numbers would not have allowed production of robust, age-standardised survival estimates.

Age-standardised five-year net survival for children diagnosed with acute lymphoblastic 
leukaemia in LMICs during 2010-2014 varied between $47.8 \%$ in Ecuador and $85.7 \%$ in Belarus. The highest value was seen in Finland (95.1\%). For acute myeloid leukaemia, fiveyear survival among LMICs during 2010-2014 ranged from 29.5\% in Ecuador to 80.2\% in Costa Rica. The highest value was seen in Denmark (84.1\%).

The global range of age-standardised five-year net survival for brain tumours was broad. For astrocytomas, age-standardised five-year net survival for 2010-2014 in LMICs ranged from 65.6\% in Russia to $82.2 \%$ in Belarus, and between $43.5 \%$ in Korea and $88.4 \%$ in Ireland among high-income countries. Age-standardised 5-year net survival for children diagnosed with embryonal tumours during 2010-2014 varied between 43.5\% in Belarus and 56.0\% in Turkey among LMICs, and from $48.6 \%$ in Finland to $77.0 \%$ in Sweden.

IICC-3, GLOBOCAN 2012 and GBD 2016 and the CONCORD-3 have all noted inherent limitations in their estimates of incidence, survival and mortality. These limitations, which are summarised in panel 3, need to be addressed. 3,44,45,46,47

\section{Panel 3: Limitations of published studies on estimates of global incidence, survival and mortality of childhood cancers}

The first limitation is the paucity of population-based cancer registries in LMICs. For example, in their estimates IICC- $3^{44}$ and CONCORD studies ${ }^{3,49}$ included data from reporting cancer registries in 50\% of high-income countries, $41 \%$ upper-middle-income countries, 
$21 \%$ of low-middle-income countries and only $10 \%$ of low-income countries. The "Global Initiative in Cancer Registration", launched by IARC and other global partners in 2011, is attempting to remedy this situation through provision of training and capacity building. 51

The second limitation is that the quality of the data that area available from population based cancer registries is variable. The iterative process of queries back and forth to submitting registries, used both by the IICC-3 and CONCORD studies to produce their reports, clearly improved the quality of the data. For IICC-3, IARC reported that of the 153 included registries, $47 \%$ (72) did not initially meet quality standards. CONCORD studies collected data to a common protocol and ran standardised quality control procedures on all data sets. ${ }^{3,44,49}$

The third limitation with the data at hand is that they only include children who have first been diagnosed, and then registered in the population based cancer registry. Some children who are treated in the private sector or in other countries might not be included in the cancer registry. As alluded to previously, the low incidence rates in sub-Saharan Africa and other world regions may well reflect under-ascertainment, not inherently lower rates of cancer. Both GLOBOCAN 201246,52,53 and the Global Burden of Disease studies ${ }^{47,54}$ have attempted to adjust for the presumed levels of under-diagnosis, or under-registration of cancers that are diagnosed, by modeling expected incidence, using the anticipated ratio of cancer mortality to cancer incidence. However, this is less than ideal, because it is inherently dependent on timely and accurate death registration, which may be at least as incomplete as cancer registration in many of these countries. ${ }^{55}$ 
The fourth limitation is the data needed for estimating survival, which is likewise dependent on accurate public data systems to ascertain vital status. Most cancer registries use a system of 'passive follow-up' to determine the date on which a cancer patient is last known to be alive, by linking tumour registration records to official data systems, such as a regional or national index of all deaths, or social insurance, health insurance, electoral registers, or hospital records. In the absence of efficient public record systems, or difficulty in accessing them, a high proportion of registered patients may be lost-to-follow up. In Morocco, for instance, 33\% of patients included in CONCORD-3 report were lost to followup and $35 \%$ were censored, in contrast for US registries, $1.5 \%$ of patients were lost to follow-up and none were censored. ${ }^{3}$

A further limitation in examining the current status of childhood cancer survival was that while CONCORD -3 included brain tumours, it did not include the other solid tumours that represent about one-third of childhood malignancies.

Many of the childhood solid tumors, such as Wilms tumor, germ cell tumors and retinoblastoma, are highly curable with surgery and chemotherapy. In an attempt to assess the current status of survival of children with solid tumors, the Commission undertook a systematic review of the literature published between January 2011 and December 2016 to assemble current literature on survival for solid tumors of childhood that were not included in the CONCORD-3 (appendix pp. 3-8). 
The search identified 4,695 articles; only 59 fulfilled the inclusion criteria during the 5-year period (see appendix page 8 for PRISMA diagram). Among these publications, 11 uppermiddle-income countries, nine lower-middle-income countries, and four low-income countries were represented. China contributed the most studies (13); reports from lowincome countries Malawi (4 studies), Botswana (1 study), Senegal (1 study), and Uganda (1 study) were included. The distribution of articles by disease was as follows: retinoblastoma (17), germ cell tumors (2), hepatoblastoma (3), rhabdomyosarcoma (7), osteosarcoma (5), Ewing sarcoma (2), Kaposi sarcoma (3), neuroblastoma (6), soft tissue sarcoma (2) and Wilms tumor (12) (appendix pp. 8-15).

In the studies included, inconsistent methodology on censoring, minimal follow-up times, and only reporting results by risk group made overall survival estimates difficult to summarise but estimates varied greatly from $10 \%$ at 5 -years in soft tissue sarcoma (Cambodia) to $98 \%$ at 5 years in retinoblastoma (China).

\section{Modelling to estimate global incidence, survival and mortality of childhood cancers}

The available studies on incidence and survival of childhood cancers have limitations. Both IICC-3 and CONCORD-3 were based on the analysis of individual records of children diagnosed with cancer, but they could include relatively few registries from LMICs. The three groups of childhood cancer included in CONCORD-3 (leukaemias, lymphomas and brain tumours) account for about 66\% of all childhood tumours. While GLOBOCAN 2012 and the GBD 2016 provided incidence estimates for a larger number of countries than IICC3 , but they used models and projections to estimate incidence where registry data were not 
available, and did not take into account health system weaknesses that might have led to under-diagnosis or under-reporting of cancer cases where registries do exist. Given these limitations the Commission developed its own modelling approach to develop countrylevel and global estimates of cancer incidence, survival and mortality from childhood cancer in LMICs.

\section{Estimating the Global Incidence of Childhood Cancers}

Development of meaningful policies to effectively address the burden of childhood cancer in LMICs requires reliable estimates of the current incidence of childhood cancer, deaths from cancer and net survival in countries, just as a global response requires global estimates.

We developed a proprietary model, the Global Childhood Cancer (GCC) microsimulation model; an individual level simulation model described in detail elsewhere ${ }^{56}$ and briefly in appendix (pp. 16-17).

The model synthesizes demographic, epidemiologic, and health system data from wellestablished data sources to estimate childhood cancer incidence for the following World Bank income groups: low-income countries, lower-middle-income countries, uppermiddle-income countries, and high-income countries ${ }^{57}$ This analytic framework leverages informative, albeit incomplete data from cancer registries in combination with countrylevel data on health systems related to access to primary health care and appropriate referral, to provide estimates of the total incidence of childhood cancer globally for children 
aged 0-14 years.

Using the Global Childhood Cancer model and the incidence rates that have been computed and published elsewhere using this model, ${ }^{56}$ we estimate that there will be 413,000 (95\% UI 389,000 to 444,000 ) incident cases of childhood cancer worldwide in 2020, of which 232,000 (95\% UI 223,000 to 246,000 ) cases will be diagnosed and 181,000 cases undiagnosed (95\% UI, 163,000 to 200,000) (table 4).

Table 4: Projected number of children diagnosed with cancer in 2020

\begin{tabular}{|c|c|c|c|c|}
\hline $\begin{array}{l}\text { Income } \\
\text { Group }\end{array}$ & $\begin{array}{c}\text { Total } \\
(95 \% \text { UI) }\end{array}$ & $\begin{array}{c}\text { Number } \\
\text { diagnosed } \\
(95 \% \text { UI })\end{array}$ & $\begin{array}{c}\text { Number } \\
\text { undiagnosed } \\
(95 \% \text { UI) }\end{array}$ & $\begin{array}{c}\text { Proportion of } \\
\text { total who are } \\
\text { undiagnosed } \\
(95 \% \mathrm{UI}) \\
\end{array}$ \\
\hline Global & $\begin{array}{c}413,000 \\
(389,000-444,000)\end{array}$ & $\begin{array}{c}232,000 \\
(223,000- \\
246,000)\end{array}$ & $\begin{array}{c}181,000 \\
(163,000- \\
200,000)\end{array}$ & $\begin{array}{c}44 \% \\
(42 \%-46 \%)\end{array}$ \\
\hline LIC & $\begin{array}{c}85,000 \\
(75,000-98,000)\end{array}$ & $\begin{array}{c}38,000 \\
(34,000-42,000)\end{array}$ & $\begin{array}{c}47,000 \\
(41,000-56,000) \\
\end{array}$ & $\begin{array}{c}55 \% \\
(54 \%-57 \%) \\
\end{array}$ \\
\hline LMIC & $\begin{array}{c}208,000 \\
(191,000-228,000)\end{array}$ & $\begin{array}{c}102,000 \\
(96,000-109,000)\end{array}$ & $\begin{array}{c}106,000 \\
(94,000-119,000)\end{array}$ & $\begin{array}{c}51 \% \\
(49 \%-54 \%)\end{array}$ \\
\hline UMIC & $\begin{array}{c}90,000 \\
(83,000-98,000)\end{array}$ & $\begin{array}{c}64,000 \\
(62,000-66,000)\end{array}$ & $\begin{array}{c}26,000 \\
(19,000-34,000)\end{array}$ & $\begin{array}{c}29 \% \\
(23 \%-35 \%)\end{array}$ \\
\hline HIC & $\begin{array}{c}31,000 \\
(30,000-32,000)\end{array}$ & $\begin{array}{c}29,000 \\
(28,000-30,000)\end{array}$ & $\begin{array}{c}2,000 \\
(1,000-3,000)\end{array}$ & $\begin{array}{c}6 \% \\
(4 \%-9 \%) \\
\end{array}$ \\
\hline
\end{tabular}

The estimated magnitude of under-reporting varies substantially by income group: over $50 \%$ in low-income countries (55\%, 95\% UI, 54 to 57\%) and lower-middle-income countries (51\%, UI 49 to 54\%), less than 30\% in upper-middle-income countries (29\%, 95\% UI 23 to 35\%), and approximately 5\% for high-income countries (6\%, 95\% UI, 4 to 9\%) (figure 1).

These findings suggest that health system barriers to access and referral, especially in low- 
income countries and lower-middle-income countries, lead to substantial under-diagnosis of childhood cancer with $44 \%$ of cases undiagnosed.

For every child with cancer who is diagnosed and reported in a cancer registry in these settings, another child with cancer may be missed.

Figure 1: Projected numbers of incident childhood cancer cases - total, diagnosed and undiagnosed for 2020, by World Bank income group (based on 2016 classification)

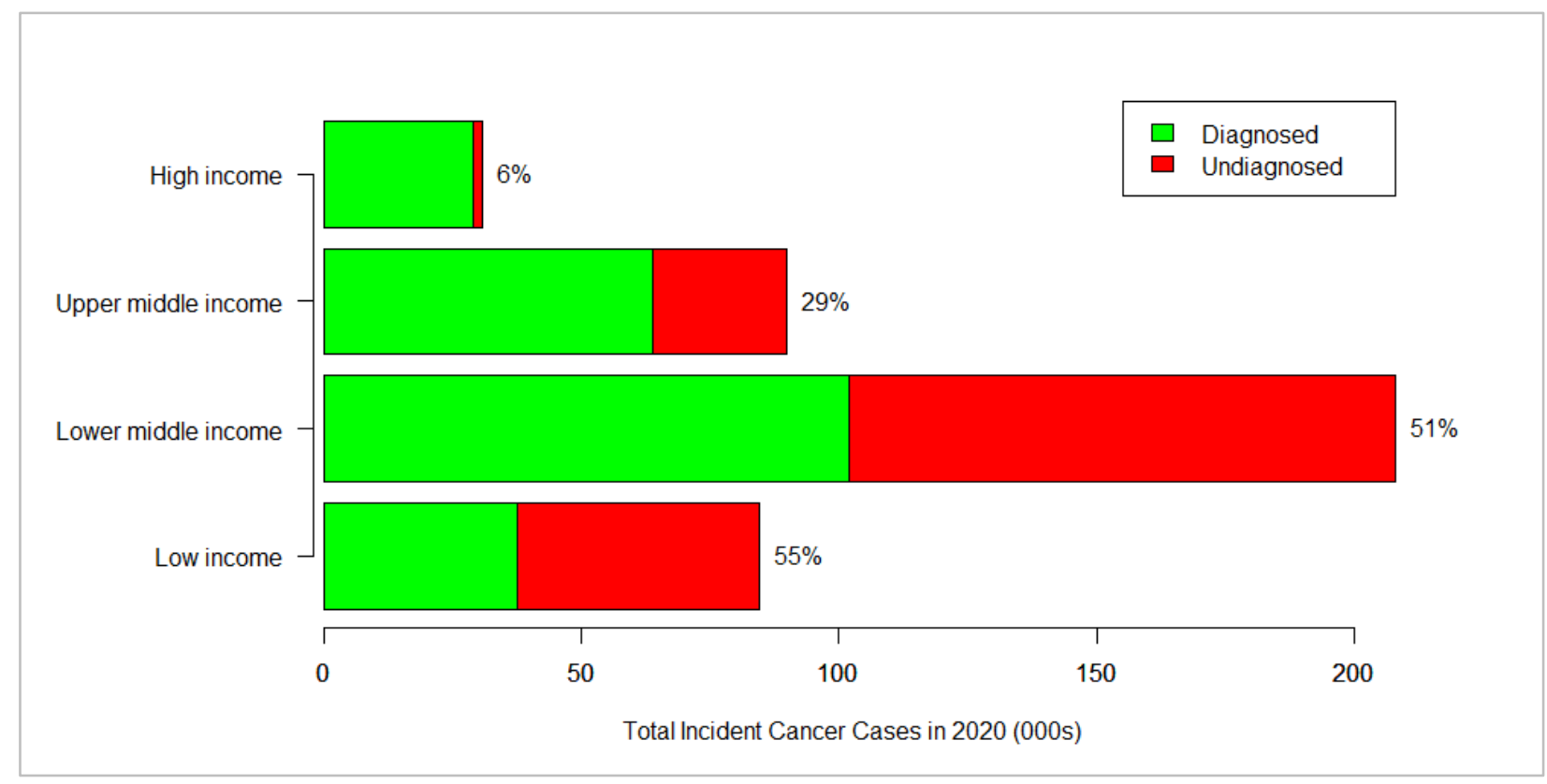

Taking into account current projections of population growth, we estimate that globally there will be 13.7 (95\% UI 12.5 to 15.0) million new cases of childhood cancer from 2020 to 2050 , of which around 3.4 million (95\% UI 2.9-4.0) will be in low-income countries and an estimated 6.9 million (95\% UI 6.0-7.8) in low-middle-income countries. In 2020 to 2050, the projected number of new cases of childhood cancer in upper-middle income countries 
will be 2,509,000 (95\% UI 2,239,000-2,801,000) and 939,000 (95\% UI 884,000-999,000)

in high-income countries (table 5).

At current levels of health system performance (access and referral), the model estimates that 6.1 (95\% UI, 5.4 to 6.9 ) million cases of childhood cancers, accounting for $44.9 \%$ of total cases (95\% UI 42.9\%-46.7\%) of childhood cancers, will be undiagnosed in 2020-2050. In low-income and lower-middle income countries, the number of children with cancer who are undiagnosed will exceed those who are diagnosed. With the current projected demographic trends, the annual number of childhood cancer incident cases is projected to diverge by country income groups, with high and upper-middle-income countries experiencing a decline in cases, while low-income and lower-middle-income countries experience continued increases due to population growth (figure 2).

Table 5: Projected number of new childhood cancer cases in 2020 to 2050 for children aged 0-14 years

\begin{tabular}{|l|c|c|c|}
\hline \multirow{2}{*}{$\begin{array}{l}\text { Income } \\
\text { Group }\end{array}$} & \multicolumn{3}{|c|}{ Projected number of childhood cancer incident cases (95\% UI) } \\
\cline { 2 - 4 } & $\begin{array}{c}\text { Total } \\
(\mathbf{9 5 \%} \% \mathbf{U})\end{array}$ & $\begin{array}{c}\text { Diagnosed } \\
\text { (95\%UI) }\end{array}$ & $\begin{array}{c}\text { Undiagnosed } \\
\mathbf{( 9 5 \%} \text { UI) }\end{array}$ \\
\hline Global & $13,659,000$ & $7,532,000$ & $6,128,000$ \\
& $(12,542,000-15,002,000)$ & $(7,025,000-8,118,000)$ & $(5,445,000-6,937,000)$ \\
\hline LIC & $3,359,000$ & $1,518,000$ & $1,842,000$ \\
\hline
\end{tabular}




\begin{tabular}{|l|c|c|c|} 
& $(2,923,000-3,951,000)$ & $(1,335,000-1,744,000)$ & $(1,571,000-2,228,000)$ \\
\hline \multirow{2}{*}{ LMIC } & $6,852,000$ & $3,358,000$ & $3,494,000$ \\
& $(6,004,000-7,779,000)$ & $(2,971,000-3,773,000)$ & $(2,988,000-4,039,000)$ \\
\hline \multirow{2}{*}{ UMIC } & $2,509,000$ & $1,773,000$ & 736,000 \\
& $(2,239,000-2,801,000)$ & $(1,611,000-1,934,000)$ & $(557,000-975,000)$ \\
\hline \multirow{2}{*}{ HIC } & 939,000 & 883,000 & 56,000 \\
& $(884,000-999,000)$ & $(836,000-930,000)$ & $(38,000-83,000)$ \\
\hline
\end{tabular}

Figure 2: Projected new childhood cancer incident cases between 2020 and 2050 - by World Bank income group (based on 2016 classification)

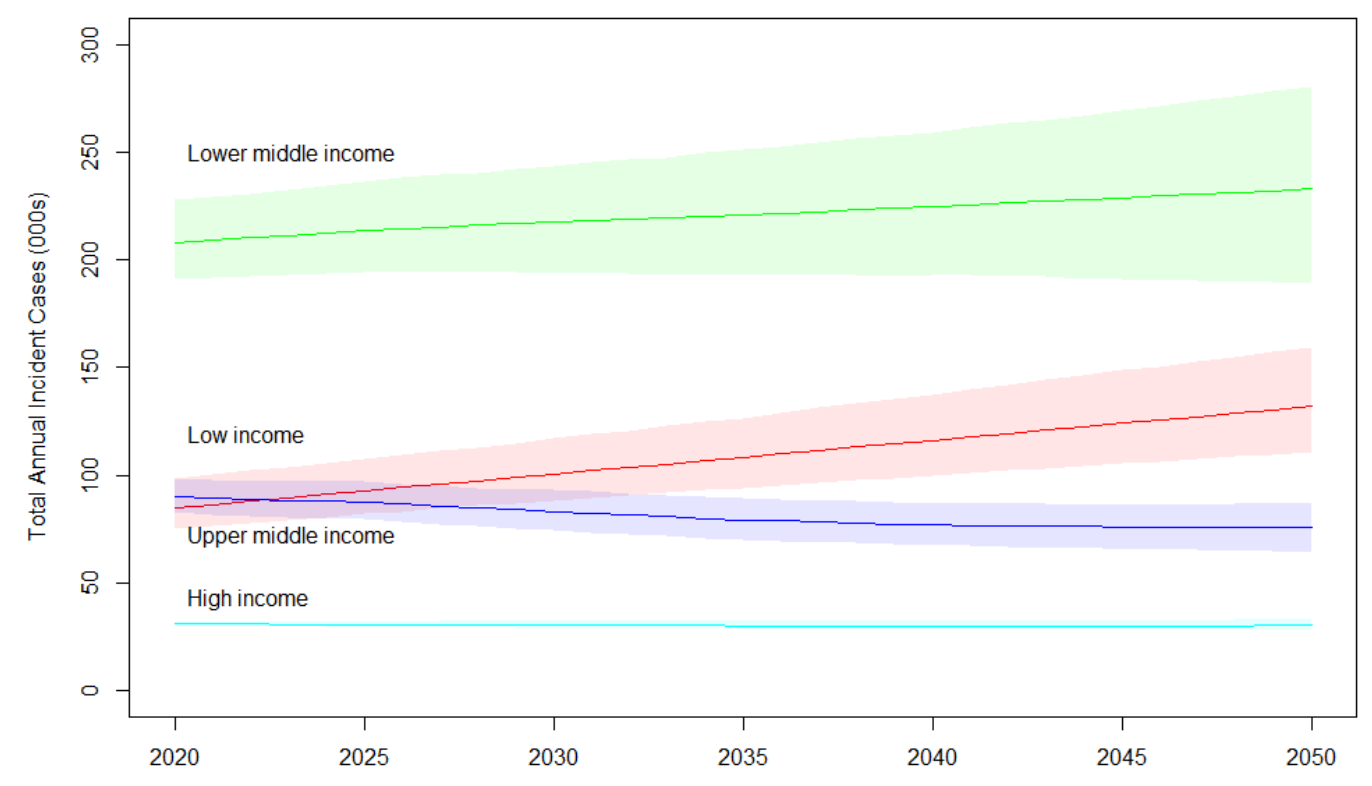

Our modelling suggests that childhood cancer is substantially under-diagnosed, especially in south Asia and sub-Saharan Africa (including western, eastern, and southern Africa). An estimated one in two new cases of childhood cancer in sub-Saharan Africa are missed due to health system constraints in access, diagnosis and referral. The findings indicate that in addition to improving treatment for childhood cancer, health systems, particularly in lowincome countries, low-middle-income countries and upper-middle-income countries must be strengthened to accurately diagnose and effectively care for all children with cancer - an important action we discuss in more detail later in the Commission report. 
Although our model-based estimates should be interpreted in light of data limitations in cancer registries and the various assumptions underlying or model, the model had a high level of accuracy compared with available observed data. For example, our model predictions of diagnosed incidence rates are consistent with country-specific registry data and they reflect geographical variation in cancer incidence and heterogeneity in health systems between and within countries, and our global estimates of the number of diagnosed cases are similar to estimates by IARC ${ }^{44}$ and GBD $2016^{47}$. Furthermore, our model accurately predicted the total number of childhood cancer cases reported from several high-income countries with national data.

\section{Modelling to estimate the number of deaths from childhood cancers}

We extended the Global Childhood Cancer microsimulation model, described in detail elsewhere ${ }^{56}$ and briefly in appendix panels 1 and 2 (pp. 16-19), to project the number of childhood cancer deaths worldwide between 2020 and 2050 for children diagnosed and undiagnosed with cancer.

Using the Global Childhood Cancer microsimulation model, we projected the annual number of childhood cancer deaths between 2020 and 2050 in children diagnosed and undiagnosed with cancer (figure 3).

Figure 3: Projected childhood cancer deaths between 2020 and 2050 (diagnosed and undiagnosed) 


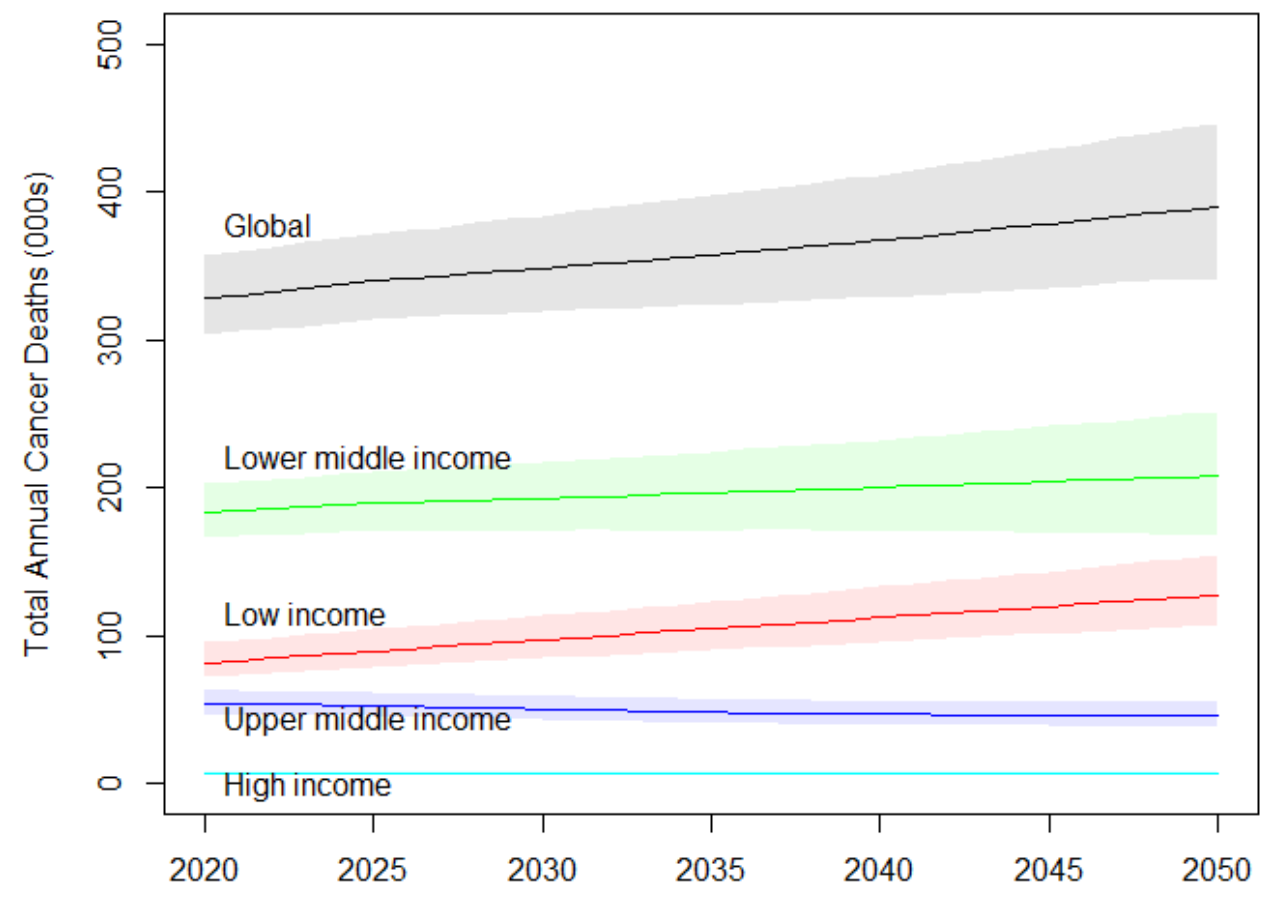

We estimated that in 2020 there would be 328,000 deaths (95\% UI 304-357,000) from childhood cancers globally (diagnosed and undiagnosed), projected to rise to 390,000 a year by 2050 (95\% CI 342,000-446,000). The largest number of deaths is projected to occur in lower-middle-income countries (208,000 in 2050 (95\% UI 168,000-252,000), but the largest increase is projected to be in low-income countries from 82,000 (95\% UI $(72,000-96,000)$ to 128,000 (95\% UI $(107,000-154,000)$ (table 6).

We estimate that between 2020 and 2050, cumulatively, 11,108,000 children (95\% UI, $10,067,000-12,351,000$ ) will die from childhood cancer if no additional investments are made to improve access to healthcare services or childhood cancer treatment (table 6). These estimates reflect deaths from all cancer cases (diagnosed and undiagnosed). 
The total number of deaths from childhood cancer between 2020 and 2050 is projected to be highest in lower-middle-income countries, with 6,095,000 deaths (95\% UI 5,301,000$6,960,000$ ) followed by low-income countries where the number is projected to reach 3,249,000 (95\% UI 2,806,000-3,826,000). A staggering 9,344,000 (95\% UI 8,338,000 $10,461,000$ ) children, accounting for $84.1 \%$ (95\% UI $81.6 \%-86.2 \%$ ) of the total deaths, is projected to occur in low-income and lower-middle-income countries (table 6).

Table 6: Projected numbers of childhood cancer deaths (cumulative, 2020 to 2050) in children aged 0-14 years diagnosed and undiagnosed with cancer

\begin{tabular}{|c|c|c|c|}
\hline $\begin{array}{l}\text { Income } \\
\text { Group }\end{array}$ & $\begin{array}{c}\text { Projected number of } \\
\text { annual childhood } \\
\text { cancer deaths } 2020 \\
(95 \% \mathrm{UI})\end{array}$ & $\begin{array}{c}\text { Projected number of } \\
\text { annual childhood } \\
\text { cancer deaths } 2050 \\
(95 \% \mathrm{UI})\end{array}$ & $\begin{array}{c}\text { Projected cumulative } \\
\text { number of childhood } \\
\text { cancer deaths 2020-2050 } \\
(95 \% \text { UI) }\end{array}$ \\
\hline Global & $\begin{array}{c}328,000 \\
(304,000-357,000)\end{array}$ & $\begin{array}{c}390,000 \\
(342,000-446,000)\end{array}$ & $\begin{array}{c}11,108,000 \\
(10,067,000-12,351,000)\end{array}$ \\
\hline LIC & $\begin{array}{c}82,000 \\
(72,000-96,000)\end{array}$ & $\begin{array}{c}128,000 \\
(107,000-154,000)\end{array}$ & $\begin{array}{c}3,249,000 \\
(2,806,000-3,826,000)\end{array}$ \\
\hline LMIC & $\begin{array}{c}184,000 \\
(167,000-203,000)\end{array}$ & $\begin{array}{c}208,000 \\
(168,000-252,000)\end{array}$ & $\begin{array}{c}6,095,000 \\
(5,301,000-6,960,000)\end{array}$ \\
\hline UMIC & $\begin{array}{c}54,000 \\
(47,000-63,000)\end{array}$ & $\begin{array}{c}46,000 \\
(39,000-55,000)\end{array}$ & $\begin{array}{c}1,531,000 \\
(1,305,000-1,799,000)\end{array}$ \\
\hline HIC & $\begin{array}{c}8,000 \\
(7,000-9,000)\end{array}$ & $\begin{array}{c}7,000 \\
(6,000-9,000)\end{array}$ & $\begin{array}{c}233,000 \\
(209,000-264,000)\end{array}$ \\
\hline
\end{tabular}

\section{Estimating the global survival levels for childhood cancers}

To ascertain current survival levels from childhood cancers globally, especially in lowincome countries and middle-income countries, for which comprehensive estimates are lacking, the Commission used the Global Childhood Cancer microsimulation model to simulate childhood cancer survival for 200 countries/territories worldwide for 2015 . The 
Global Childhood Cancer microsimulation model is described in detail elsewhere ${ }^{56}$ and briefly in appendix panels 1 and 2 (pp. 16-19).

We developed a survival module to model 5-year net survival for all childhood cancers diagnosed, taking into account clinical and epidemiologic factors, including country-specific treatment variables, such as the availability of chemotherapy, radiation and surgery. The detailed methodology for the survival module is provided in the Lancet Oncology publication on survival for children's cancers. ${ }^{58}$

To develop and parameterise the survival module of the Global Childhood Cancer microsimulation model, the CONCORD program provided 5-year net survival estimates for each of the three main childhood cancer types (leukaemias, lymphomas, and brain tumors), which were disaggregated into the subtypes within each broader category, as specified by the International Classification of Childhood Cancer third edition. ${ }^{45}$ These were acute lymphoblastic leukaemia/lymphoblastic leukaemia and acute myelogenous leukaemia, Hodgkin lymphoma and Non-Hodgkin lymphoma, ependymoma/choroid plexus tumours, embryonal brain tumours, astrocytomas, and other types of glioma.

These modelled estimates, reported in detail elsewhere, ${ }^{58}$ suggest very wide variation between countries and world regions in 5-year net survival for all cancer combined (figure 4). Survival estimates are reported for all of the continents. 
In 2015-2019, average global five-year net survival was 37.4\% (95\% UI 34.7\%-39.8\%), but it ranged from $11.6 \%$ (95\% UI 8.7\%-14.8\%) in Africa to 39.6\% (95\% UI 35.1\%-43.6\%) in Asia, 55.0\% (95\% UI 51.2-58.7\%) in Latin America and the Caribbean, 64.4\% (95\% UI 58.9-69.2) in Oceania, 74.3\% (95\% UI 71.9\%-76.4\%) in Europe, and 83.0\% (95\% UI 81.6\%-84.4\%) in North America. In sub-continental regions, the modelled estimates of 5year net survival were lowest in Eastern Africa at 8.1\% (95\% UI 4.4\%-13.7\%) and Western Africa at $8.5 \%(95 \%$ UI $4.9 \%-13.0 \%){ }^{58}$

Figure 4: Estimated 5-year net survival for childhood cancers diagnosed (all cancer types; 2015-2019)

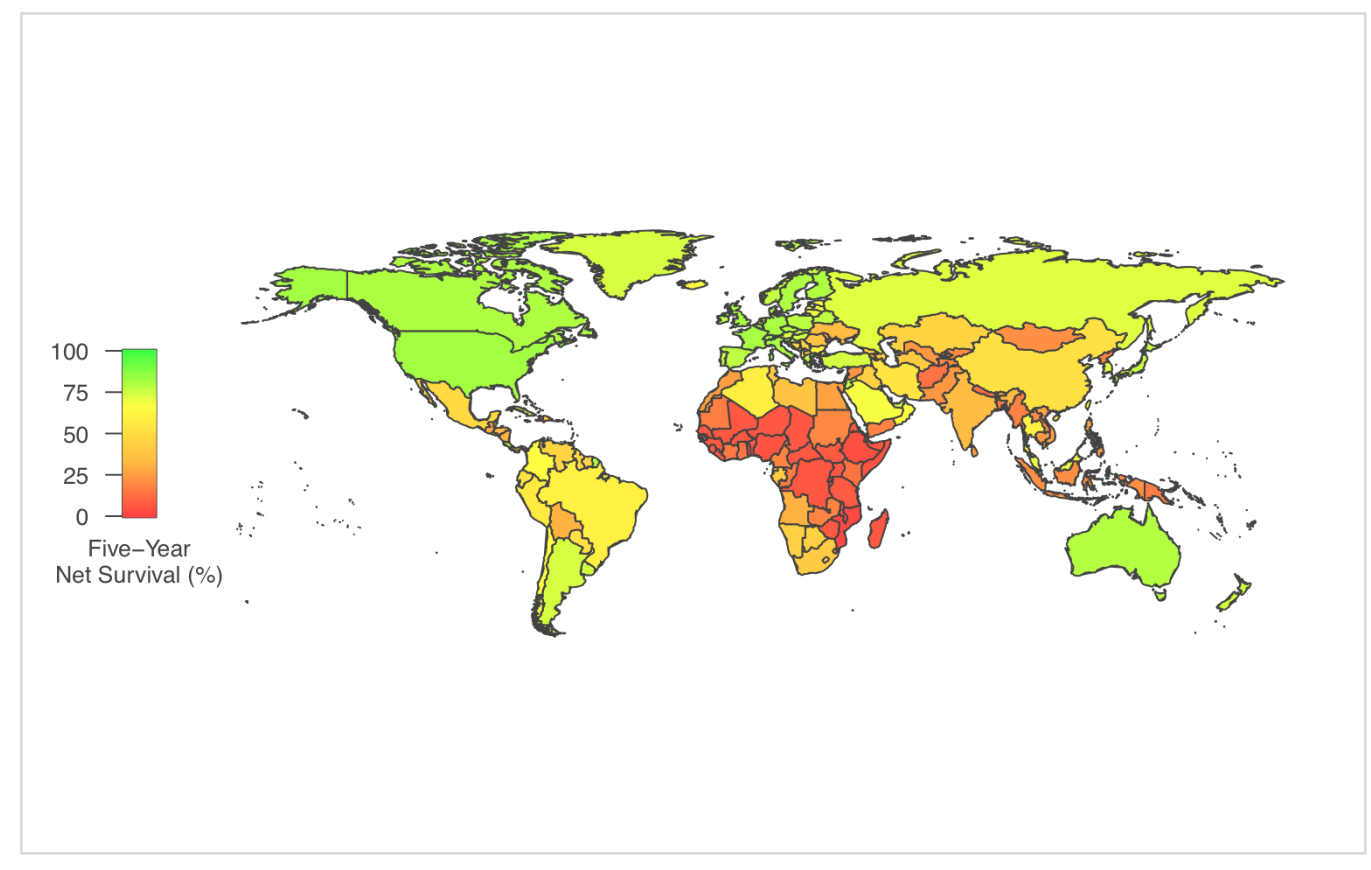

Source: Ward et al. Lancet Oncology 2019

There was a large difference between the modelled estimates of 5-year net survival for all cancers combined of 7.4\% (95\% UI 5.0\%-10.7\%) for low-income countries and 79.8\% (95\% UI 78.7\%-80.8\%) in high-income countries. The modelled estimates of 5-year net survival in Africa were less than 25\% (range 2.3\% to 24.1\%) for each tumour type 
examined, whereas for North America the estimates for almost every tumour type were greater than $60 \%$, ranging from $57.8 \%$ for hepatic carcinoma to $98.2 \%$ for malignant melanoma. For some tumour types, the difference between world regions in 5-year net survival for tumour types was huge. For example, in Africa, estimate for 5-year net survival for central nervous system germ-cell tumour was 2.3\% (95\% UI 0.8\%-5.3\%), compared with $80.9 \%$ (95\% UI 69.4-89.9\%) in North America. 58

The analysis undertaken by the Commission reveals large variation in incidence rates, death rates, and 5-year net survival for childhood cancers between countries, world regions, and World Bank country-income groups, with a clear gradient of high death rates and poor survival in low-income countries and lower-middle-income countries. The analysis also highlights the paucity of high quality cancer registry data for children's cancers in LMICs.

In section two we explore the current global and country-level financing and coverage of healthcare services for childhood cancers. We provide new analyses of global funding for research from public and philanthropic sources for childhood cancers. Using country-level case studies this section also examines in depth how childhood cancer diagnosis, treatment and care is funded, provided and incorporated in priority setting process in selected LMICs.

\section{SECTION 2: CURRENT FINANCING FOR CHILDHOOD CANCER SERVICES AND RESEARCH AND COVERAGE OF CHILDHOOD CANCER CARE}


We examined published studies on financing and coverage of healthcare services for childhood cancers. We also examined publicly available databases on national health budgets, country studies on national health accounts on health financing, as well as published studies on national health plans or national cancer plans, to ascertain the level of funding allocated to childhood cancers. Further, we undertook a detailed analysis of research funding for childhood cancers using publicly available data and bibliometric analysis. We also undertook detailed analysis in five LMICs to ascertain how childhood cancer services were prioritised, financed and delivered. We present the findings below.

\section{Current Financing of Childhood Cancer Programs}

The WHO Global Health Expenditure Database (which utilises data from publicly available national health budgets, budget related documentation, or National Health Accounts studies and generates estimates when data are not available) is the "global reference for health expenditure estimates in all WHO Member States". However, it has no data on funding for childhood cancers either from domestic or external sources. ${ }^{59}$ Nor does the Organization for Economic Cooperation and Development (OECD) Health Statistics, "the most comprehensive source of comparable statistics on health and health systems across OECD countries", which has data on International Disease Category of 'Neoplasms', but with no breakdown of figures for children. ${ }^{60}$ Similarly, the OECD data on Development Finance, which has the most comprehensive data on Official Development Assistance, and collates funding from donor countries, multinational organizations, private donors, and foundations, provides no data financing for childhood cancers. ${ }^{61}$ Thus we know little on country-level or global financing for childhood cancers. 


\section{Analysis of National Health and Cancer Control Plans}

Well-designed and implemented national cancer control plans are an important tool for improving cancer care.62 In 2017, the World Health Assembly Resolution 70.12 (2017) affirmed the commitment of the WHO member states to developing and implementing national cancer control plans "inclusive of all age groups". 63

However, a recent published analysis of 527 national cancer plans (or cancer-related plans) from 156 countries found that childhood cancer care was mentioned in plans of only 65 (42\%) countries, but no data were provided on financing childhood cancers. There were regional differences: $53 \%$ of the countries in the WHO European and Eastern Mediterranean regions and $43 \%$ of the countries in the Western Pacific region had plans that included childhood cancer, but only a quarter to a third of the countries in other world regions had plans with any mention of childhood cancer. ${ }^{64}$ Further analysis of the data available from 154 countries included in the study, ${ }^{64}$ showed that of the 90 countries with a national cancer control plan, 61 (68\%) mentioned childhood cancer in at least one national plan; in contrast, of the 64 countries that did not have a national cancer control plan but had an NCD plan, only 5 (8\%) mentioned childhood cancer. The plans in high-income countries were twice as likely to include childhood cancer as those in LMICs. Altogether, plans were twice as likely to mention cancer in adults than in children. However, although childhood cancer is mentioned in these plans, few details are provided about proposed actions or the financing of these actions across the care continuum, or about the monitoring 
and evaluation of their effects. ${ }^{64}$ This is similar to findings in an earlier analysis of national cancer control plans and childhood cancer in Africa. 65

\section{Health Service Coverage for Childhood Cancers}

There are no systematic global data on the availability of childhood cancer services or country capacities to manage childhood cancer. In LMICs, government, private sector and not-for-profit foundations have created cancer centres with varying scope and capacity. National cancer centres are typically located in tertiary hospitals university teaching hospitals. These institutes tend to be in capitals or major cities, providing different levels of comprehensive services and coverage, but dedicated childhood cancer centres also exist. ${ }^{66}$ In most low-income countries, private sector centres, which provide care for children with cancer, have evolved without adequate regulatory standards. ${ }^{67}$

\section{Research Funding for Childhood Cancers}

The Commission undertook a detailed analysis of research funding from public and philanthropic sources for childhood cancers for the period 2008-2016 using Dimensions database (https://www.dimensions.ai), which is an inter-linked research information system that uses automated methods to collate monthly data on research funding from open-access web-based sources, and manually sourced information directly from funders. The methodology for the analysis is described elsewhere and briefly presented in appendix panel 3 (p 20). ${ }^{68}$ 
The analysis of Dimensions database data revealed that during the period 2008-2016, total global funding for all childhood cancer research was $\$ 2.0$ billion, with average funding of $\$ 226 \cdot 8$ million per year over the nine-years; with an additional $\$ 80.3$ million dollars estimated per year from other major funders not included in the Dimensions database.

Based on trends within the Dimensions data, excluding a research infrastructure investment of $\$ 24$ million in 2011-13, overall yearly funding of childhood cancer research fell from $\$ 222.9$ million in 2011 to $\$ 215.3$ million in 2015 . New funding awarded each year varied substantially from a high of $\$ 256 \cdot 0$ million in 2014 to $\$ 160 \cdot 0$ million in 2015.68

Of the $\$ 2.0$ billion of total research funding identified for the nine-year study period, around $\$ 771.8$ million (37.9\%) was for 'general paediatric oncology' (including $\$ 181.6$ of investment in research infrastructure to support new research centres and networks). When funding was evaluated by tumour type, leukaemia (and other myeloproliferative and myelodysplastic diseases) received $\$ 448 \cdot 8$ million $(22 \cdot 0 \%)$ of the total funding followed by $\$ 329.6$ million for central nervous system tumours (16.2\%). The funding for neuroblastoma and peripheral nerve cell tumours was $\$ 181 \cdot 2$ million (8.9\%). A further $\$ 309 \cdot 0$ million $(15 \cdot 2 \%)$ was awarded for research into all other tumour types, with $\$ 86.4$ million awarded for malignant bone tumours (4.2\%), \$85.9 million for soft tissue and extraosseous sarcomas (4.2\%), but just $\$ 16.9$ million for retinoblastomas $(0.8 \%)$ and $\$ 10 \cdot 3$ million for germ cell tumours $(0.5 \%) .{ }^{68}$ 
When the funding was compared to the burden of childhood cancers (as measured by agestandardised incidence per million person-years in children) there was relative underfunding of research for lymphomas (including Burkitt lymphoma which accounts for a large proportion of childhood cancers in sub-Saharan Africa), retinoblastomas, renal tumours and germ cell and gonadal tumours. ${ }^{68}$

In terms of funding for stages of research (pre clinical, Phase I, II, III, and phase IV posttrial/healthcare delivery research), $\$ 1 \cdot 2$ billion (59.3\%)) was awarded for pre-clinical research $(\$ 643.8$ million of which went towards investigating the biology and aetiology of childhood cancers), $\$ 525 \cdot 3$ million (25.7\%) for Phase I, II or III clinical trials or 'cross disciplinary' (i.e. research that included several stages of the research pipeline, and $\$ 193$ million (9.5\%) for infrastructure but just $\$ 113 \cdot 0$ million (5.5\%) was spent on improving healthcare delivery for children with cancer. ${ }^{68}$

By area of research focus $\$ 806 \cdot 4$ million (39.5\%) of the total research spend was awarded to research on the biology and aetiology of childhood cancers, $\$ 236 \cdot 8$ million $(11 \cdot 6 \%)$ for survivorship research, $\$ 111.4$ million (5.5\%) for diagnosis and prognosis research, with just $\$ 18 \cdot 1$ million $(0 \cdot 9 \%)$ on research related to the prevention of childhood cancers. ${ }^{68}$

Around $\$ 1.6$ billion of the funding (77.7\%) was awarded to USA-based institutions, $\$ 105.4$ million (5.2\%) to institutions based in the United Kingdom, \$98.1 million (4.8\%) in Canada, \$37.8 million in Australia, \$31.5 million (1.6\%) in France, \$24.3 million (1.2\%) in Germany 
and $\$ 23.9$ million (1.2\%) in Sweden. Less than $0.1 \%$ of the funding was allocated to institutions based in LMICs. ${ }^{68}$

The annual amount of research funding for childhood cancers of $\$ 226.8$ million per year, of which less than $0.1 \%$ is awarded to LMICs on average, is relatively low, compared to $\$ 4.8$ billion of research funding from 58 public and philanthropic sources awarded to cancer research for all ages in the single year 2008,69 and $\$ 5.45$ billion in 2011 and $\$ 5.39$ billion in 2015 allocated to cancer research for all ages by the National Institutes of Health in the United States ${ }^{70}$, and the $\$ 1.3$ billion awarded to HIV (in LMICs) and the $\$ 611$ million for malaria related research in 2017 alone ${ }^{68}$.

\section{Priority setting for childhood cancers: case studies from five countries}

As part of the Commission, we examined the political, social, and economic factors which influence health system priority-setting on childhood cancer funding and care in five LMICs, namely El Salvador, Ghana, Guatemala, India and the Philippines. The methodology is presented in detail elsewhere and summarised in appendix panel 4 (pp. 21-22) 71,72

In each of the five countries studied, philanthropic organizations, foundations or private institutions had been the first to establish services for childhood cancer, often working with international partners (panel 4). Childhood cancer had not been a priority in the publicly funded health systems of these countries due to political instability and competing policy priorities. However, the respondents in the study countries noted that the global momentum for UHC, a target for SDG 3,35 had created, particularly in El Salvador and the 
Philippines, a window of opportunity to include childhood cancers in the political discourse for priority setting and incorporate childhood cancer care in essential benefits package (panel 4).

\section{Panel 4: Prioritisation of childhood cancers in universal health coverage}

In El Salvador, the 2010-2014 National Strategic Program for the Promotion of Health:

Prevention and Control of Non-Communicable Chronic Diseases, and the 2015 National

Policy on Integrative Care for People with Cancer includes cancer prevention and screening as a priority does not mention childhood cancers. ${ }^{73,74}$ Funding for cancer care for children is largely from local philanthropic and private contributions mobilised by Fundacion Ayudame a Vivir, a local foundation, and channeled to the national childhood cancer programme, which received only one third of its budget from the government. ${ }^{75}$ Childhood cancer care is provided through a collaboration established in 1993 involving the publicly funded Hospital Nacional de Niños Benjamin Bloom, St Jude Children's Research Hospital in the US, and Fundacion Ayudame a Vivir. ${ }^{76}$ In 2008, the creation of a separate day-clinic, Centro Medico Ayudame a Vivir, financed by the Fundacion Ayudame a Vivir, next to Hospital Bloom, has expanded capacity to care for children with cancer.

In Guatemala, however, there is no discernable national plan that includes childhood or adult cancers as a priority. ${ }^{77,78}$ Childhood cancer care is provided through a children's cancer hospital, Unidad Nacional de Oncologia Pediatrica (UNOP). UNOP is a public-private partnership established in 2000 involving Guatemala's Ministerio de Salud Publica y Asistencia Social, St. Jude Children's Research Hospital in the USA, and Fundacion Ayudame 
a Vivir Guatemala, a local foundation..$^{79}$ UNOP covers an estimated $47 \%$ of expected cases, mainly from Guatemala City. Although, health insurance coverage, provided by the Instituto Guatemalteco del Seguro Social, does benefit a small proportion of the population, most families of children with cancer incur high out-of-pocket costs for care. To address major gaps in access and funding of treatment and associated costs, Ayudame a Vivir Guatemala actively mobilises, pools and channels funds from philanthropic donations, civil society, academia, private industry and external partners to Unidad Nacional de Oncologia Pediatrica.

In the Philippines, which has a highly decentralised health system with more than 7,000 islands communities, care for children with cancer is provided through more than 30 centres with varied levels of capacity, but just three of these centres have designated units and multidisciplinary teams that can provide comprehensive cancer care. ${ }^{80,81}$ The Philippines is expanding UHC, which now includes standard risk acute lymphoblastic leukemia in the benefits package, with commensurate expansion of insurance coverage and treatment capacity to expand access. ${ }^{82}$ The 'Z Benefits' programme, created by PhilHealth Insurance Corporation, provides comprehensive coverage to children diagnosed with acute lymphoblastic leukaemia for children admitted to hospital but unable to meet high out-ofpocket care costs. ${ }^{83}$ In addition, the Medicine Access Program, which operates in conjunction with the Z Benefit, provides free chemotherapy for all solid tumours and for patients diagnosed with acute lymphoblastic leukaemia who are not enrolled in the Z benefits package. ${ }^{84}$ Further, the 'no-balance billing' system created for those admitted to hospitals for care helps to absorb additional costs for the patients entitled to the Z Benefits 
programme. ${ }^{85}$ However, despite these developments, financial and physical access barriers remain due to the highly fragmented funding and service delivery system in the Philippines. The National Cancer Control Act and the Universal Health Care Act enacted as laws in February, 2019, and provide for further increase in financing, extension of the benefits package to include additional cancer types, and expansion of service coverage by developing a nationwide network of comprehensive cancer centres that will provide, beyond the urban hubs, high quality services for children with cancer across the country in accordance with clinical guidelines and an accountability framework for safety and quality .86

In India, the National Programme for Prevention and Control of Cancers, Diabetes, Cardiovascular Diseases, and Stroke, and the National Cancer Control Programme of the Ministry of Health and Family Welfare does not prioritise childhood cancer ${ }^{87}$ Hence, alternative governance and care delivery models have emerged for childhood cancers, which include a mix of public, private, philanthropic and state actors. For example, the Tata Memorial Hospital in Mumbai, in the state of Maharashtra, which was established in 1941 by the Sir Dorabji Tata Trust. It was initially managed independently then transferred in 1957 to the Ministry of Health and Family Welfare. In 1962, the management of the hospital and its Cancer Research Institute, established as the Tata Memorial Centre, was transferred to the Department of Atomic Energy, responsible to the Prime Minister's Office.

The Tata Memorial Centre operates as a centre of excellence, with state-of-the-art facilities, which provides high quality clinical services as well as research pertaining to children with 
cancer. It receives funding from multiple sources, including Tata Trust, the federal government through the Department of Atomic Energy (a more stable source of funding compared to state funds for health), private and public insurance schemes for providing care, corporate donations, and philanthropy from individual donors and non-governmental organizations. Tata Memorial Centre's Improving Pediatric Cancer Care and Treatment (ImPaCCT) Foundation, funded from philanthropic sources, enables access to comprehensive cancer care for children regardless of socioeconomic background by defraying medical costs, provides nutritional support for patients and organises free accommodation with psychosocial services for caregivers - an holistic approach that helps to reduce abandonment of treatment. ${ }^{88}$

In Ghana, Ghana Health Services, an autonomous Public Service institution, is responsible for providing most of the public healthcare services, according to polices and direction of the ministry. Healthcare services for childhood cancers are provided through two public tertiary-care teaching hospitals, which are independent of Ghana Health Service. This independence from the ministry of health means that the teaching hospitals have limited influence on priority setting. ${ }^{89}$ National Health Insurance Fund, financed by general taxation, does not provide coverage for all treatments and drug costs related to childhood cancer. ${ }^{90}$ There is no dedicated financing of childhood cancer in the Non-Communicable Disease Control Program or National Cancer Plan..$^{91}$ Instead, the little funding available for childhood cancers comes from international agencies or external philanthropic organisations, who typically allocate their funds to communicable disease and general health services for women and children, but for whom childhood cancer is not a priority. ${ }^{92}$ 
The case studies reveal the considerable variation in the governance, financing, organizational design and service provision for childhood cancers in the countries examined. Prioritisation of childhood cancers in national health policy agendas also varies across the countries studied. Arguably, childhood cancer is a national priority only in the Philippines, which has included acute lymphoblastic leukaemia in the health insurance benefits package, with plans to extend the number of conditions covered as part of the UHC expansion, combined with the development of a network of services to expand access to high-quality cancer care beyond urban settings. This experience is not shared by the other four countries studied, however, where childhood cancers are not part of health insurance benefits, and service coverage, access and financial protection benefit a few. Instead, in these countries, foundations and philanthropic institutions have taken the lead to establish services for children with cancer, often through innovative partnerships involving government, private sector, civil society, external funders, and external institutions involved in childhood cancer care in high-income countries.

In LMICs collaborations and 'twinning' arrangements have undoubtedly helped in expansion of cancer care for some children..$^{93}$ There are examples of successful initiatives aimed at addressing gaps in childhood cancer care, but these tend to be selective (e.g. focusing on a single cancer) or benefit selected populations (e.g. those able to access cancer centres in urban areas) (panel 5). These collaborations, which tend to establish dedicated centres located in urban centres, and benefit those who can access them, have not reached scale to convincingly impact on mortality and survival at population level, particularly in 
large and populous countries. ${ }^{94,95}$ As a result, in LMICs, where childhood cancer care is not incorporated into UHC, disparities in coverage and access exist.

\section{Panel 5: Examples of successful initiatives addressing gaps in childhood cancer care}

Despite the global gaps in access to care, quality of treatment, and outcomes for children with cancer, there are examples of initiatives aimed at addressing policy, financing, global advocacy, psychosocial, and workforce gaps, which provide models that can be integrated into global and national solutions. For example, in El Salvador, Guatemala, and India, prioritisation of the development of programs to address refusal and abandonment of care, has resulted in a substantial improvements on treatment outcomes, highlighting the critical role of psychosocial packages in comprehensive childhood cancer care. ${ }^{96,97,98}$

A key principle of successful paediatric cancer treatment is the delivery of care by skilled professional nurses. However, specialized education and training is generally unavailable for nurses in LMICs; this lack of training, coupled with high workload and cultural and organizational barriers contribute to the disparity in outcomes and overall survival. ${ }^{99}$ However, there are examples of cost-effective and sustainable educational initiatives to address this workforce gap, as illustrated by an internationally supported programme designed to implement global nursing standards in Guatemala that has shown to promote the provision of quality nursing care..$^{100}$

Optimization of care has shown to be possible even in the poorest countries as exemplified by the design of effective regimens for Burkitt lymphoma, one of the most common cancers 
in Africa, adapted to the socioeconomic conditions, the available supportive care, and the patients' co-morbidities. ${ }^{101}$ For example, in Malawi, a simple protocol costing less than $\$ 50$ per 28-day cycle resulted in 1-year survival of $48 \%{ }^{102}$ And in Uganda, the cost per Disability Adjusted Life Year (DALY) averted in a cohort of children with Burkitt lymphoma was $\$ 97.103$

The long-term commitment intrinsic to twinning relationships is critical to their success, as it provides a strong framework to facilitate the development of scalable strategies that incorporate dedicated initiatives in education, capacity building and research. ${ }^{104,105,106}$

The availability of childhood cancer services in countries of low-income and middleincome

There is no systematic analysis of the availability, capacity and quality of services, care delivery models and financing of childhood cancers in all LMICs. However, findings of selected surveys involving a few countries reveal substantial variation in the availability of paediatric cancer units, and overall management of childhood cancers. ${ }^{107}$

In LMICs, incorporation of childhood cancers in benefits packages varies. For example, starting with acute lymphoblastic leukaemia, Mexico has gradually incorporated childhood cancers in its health insurance for poor populations (Seguro Popular) ${ }^{108}$, whereas when expanding UHC Turkey was able to provide health insurance coverage and a network of cancer centres for all cancer types in children. ${ }^{109,110}$ Similarly, Chile and China have incorporated childhood cancer treatment packages within the framework of UHC together 
with the development of nationwide networks for their implementation and monitoring, to achieve population-based advances and to demonstrate national models for effective scaleup. ${ }^{111,112}$ However, even with limitations and resource constraints, experience from LMICs suggests that when services are accessed, demonstrable improvements in survival from childhood cancers is possible. For example, 5 -year event-free survival of $60.8 \%$ was achieved in five countries of Central America (Costa Rica, El Salvador, Guatemala, Honduras, Nicaragua) in children with Hodgkin lymphoma despite no access to radiotherapy, ${ }^{113}$ which is a critical treatment modality for some children with this cancer in high-income countries. Similarly, 3-year event-free survival of 59.4\% was achieved in children with acute lymphoblastic leukaemia in five countries of Central America (Costa Rica, El Salvador, Honduras, Nicaragua and Panama). ${ }^{114} \mathrm{At}$ select treatment centres in India and China 5-year event-free survival for acute lymphoblastic leukaemia was even higher, at $72.1 \%$ and $72.7 \%$ respectively. ${ }^{115,116}$

Selected sub-Saharan African centres in Kenya, Nigeria, Tanzania have achieved 52\% 2year event-free survival in children with Burkitt lymphoma, and Burkina-Faso, Cameroon, Ivory Coast, Madagascar, Mali and Senegal 51\% 2-year overall survival, despite lack of capabilities for 'supportive care', which constrains the intensity of treatment provided.117,118 In Malawi, one of the poorest countries in sub-Saharan Africa, selected centres have achieved 5-year overall survival of $46 \%$ for Wilms tumour. ${ }^{119}$

Many LMICs have benefited from twinning arrangements, which have helped to strengthen capacity for clinical services, improve research and education, expand access to healthcare 
services and improve service quality - and contributed to improved outcomes. ${ }^{120}$

,121,122,123,124,125,126,127 However, local capacity can and should be built to achieve scale and population level impact. Given the potential to achieve demonstrable improvements in survival for childhood cancer in resource-constrained settings, we next examine the cost and cost-effective interventions for managing childhood cancers in LMICs.

SECTION 3: THE OPPORTUNITY - COST-EFFECTIVE SOLUTIONS FOR CHILDHOOD CANCERS 
Competing health priorities and limited resources mean that policymakers in LMICs must set priorities in order to allocate the available resources, including for childhood cancers.

Multiple factors must be taken into account when setting priorities in health systems, including, the values of citizens and policymakers, the burden of disease and risk, the expected goals and outcomes, equity, the efficiency effectiveness and responsiveness of services to deliver services, and the cost and cost-effectiveness of interventions. ${ }^{128}$ However, whatever the criteria used for priority setting, a clear, transparent and deliberative process should inform decision-making. ${ }^{129}$

\section{Cost and cost-effectiveness of treatments for childhood cancers}

To date, few studies have examined the cost and cost-effectiveness of childhood cancer treatments. A systematic review undertaken in 2012, which analysed cost-effectiveness of treatments for childhood cancers in high-income countries, found only 40 studies, but the vast majority of these studies had focused on specific interventions, such as individual supportive care measures (e.g. infection management) or specific aspects of cancerdirected treatment (such as stem cell transplantation). ${ }^{130}$ Even a smaller number of studies have examined costs and cost-effectiveness of interventions for childhood cancers in LMIC settings. One study, which suggested that treating childhood cancers in LMICs should be cost-effective, did not use real-world data to support this assertion. ${ }^{131}$ Other economic evaluation or costing studies, which have adopted a narrow definition of cost, either examined the cost of chemotherapeutic agents alone, ${ }^{132}$ or did not include the costs of outpatient care ${ }^{133,134,135}$, or fixed direct costs ${ }^{136}$. Other studies have not adequately 
described data sources or provide detailed elements of costs. ${ }^{137}$ So far, only two methodologically rigorous and comprehensive micro-costing studies of childhood cancer treatment or care have been published. One of these studies estimated that, in China, the direct cost of treating retinoblastoma per patient was $\$ 9,442.138$ The other study estimated the direct cost of treating Burkitt lymphoma in Uganda was $\$ 1312.139$

Given the paucity of published studies in LMICs on the costs and cost-effectiveness of interventions for childhood cancers, we undertook a multi-center micro-costing analysis to determine the cost of delivering childhood cancer care. The methodology is presented in appendix panel 5, which also identifies the limitations of the costing study (pp. 23-26).

The annual operating cost and cost per new diagnosis for each of the three LMIC childhood cancer treatment units studied are shown in figure 5 with further detail provided in appendix table 2 ( $\mathrm{p}$ 27). Of note, the ratio of cost per new diagnosis to per capita GDP was remarkably consistent across centers: namely 6.5xGDP in Ghana, 6.8xGDP in El Salvador, and 6.3xGDP in Jalisco, Mexico. Personnel and pharmacy (i.e. chemotherapy and supportive care) represented two of the top three cost items in all three centers (figure 6). Although radiation is essential for the treatment of some cancers, it only accounted for $1 \%$ of costs in each of the three centres studied.

Figure 5: Cost of childhood cancer services per newly diagnosed case at three cancer centres in Ghana, El Salvador and Mexico 


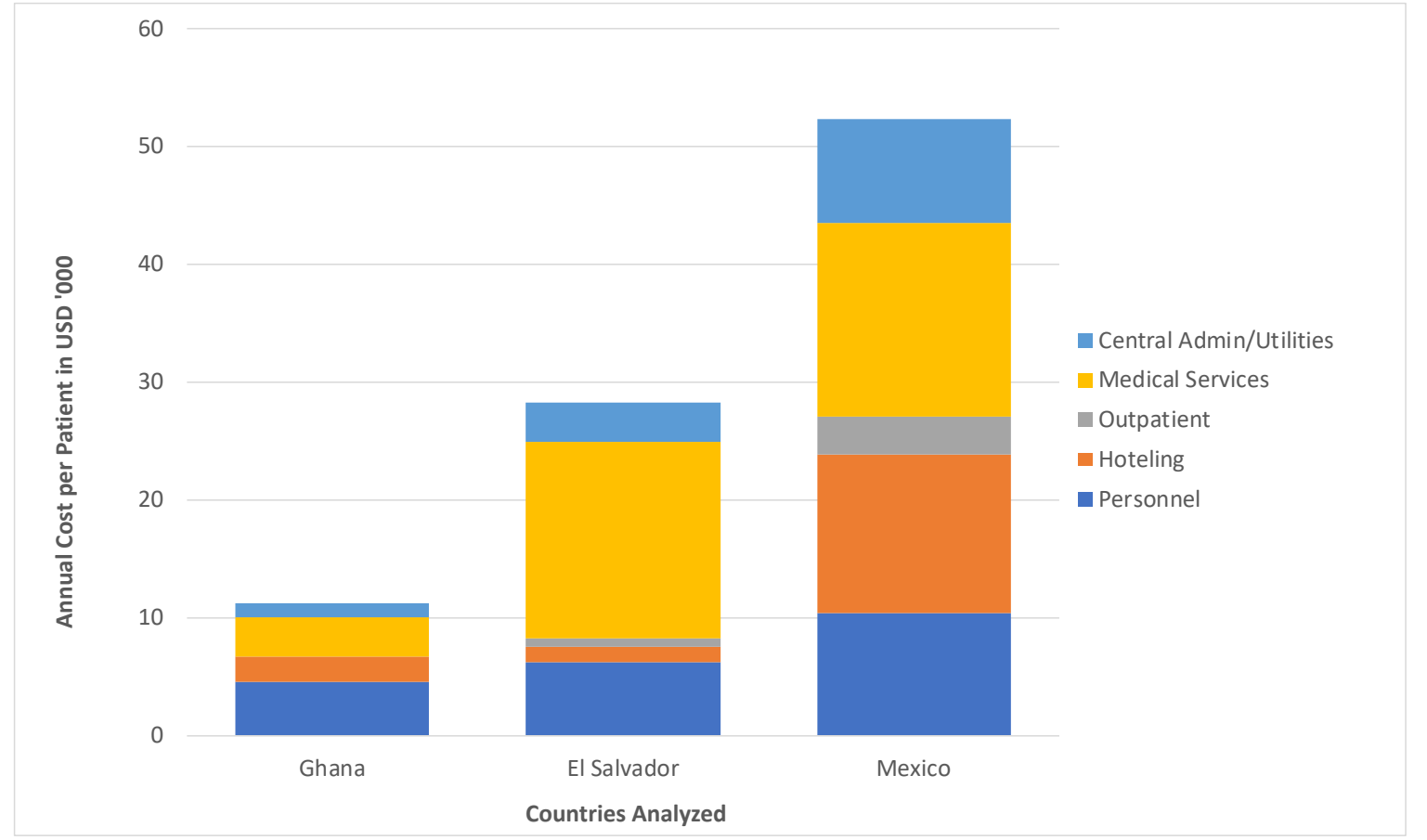

Figure 6: Components of annual budget by cost in selected childhood cancer centres in Ghana, El Salvador and Mexico

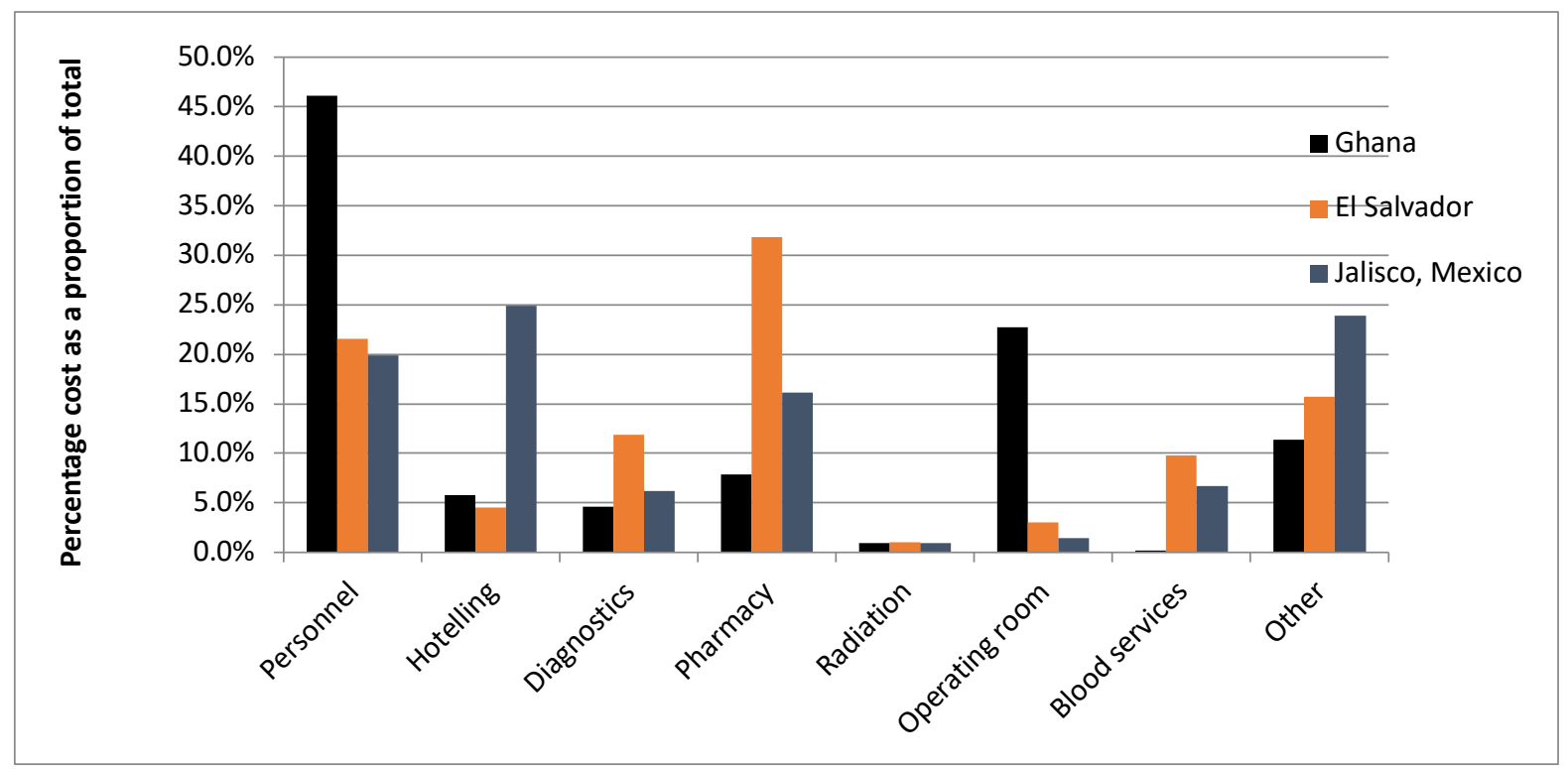

In each country, the cost per DALY averted through cancer treatment in each centre (\$1,034 in Ghana with GDP per capita of \$1,513 in 2016; \$1,624 in El Salvador with GDP 
per capita of $\$ 3920$ in 2016, and; $\$ 3039$ in Mexico with a GDP per capita of $\$ 8,208$ in 2016) was cost-effective (3 times GDP per capita income) or very-cost effective (1 times GDP per capita income).

The consistency of this finding in the three centres, despite substantial differences in the services provided and the outcomes achieved, highlights an important aspect of childhood cancer treatment. Historically, improvements in outcomes for many childhood cancers in high-income countries have been achieved through advances in diagnostic capabilities allowing for refined risk stratification, increases in treatment intensity for those with aggressive disease, and improvements in supportive care to manage treatment complications.

The steady progression of costs and outcomes in Ghana, El Salvador and Mexico suggests that even with basic diagnostics, low treatment intensity, and simple supportive care measures, a proportion of children with cancer can still be cured. For example, in highincome countries, childhood acute lymphocytic leukaemia protocols in the 1980's demonstrated that with far less intensive (and less costly) treatment than is currently standard in high-income countries, 60-70\% of children achieved long-term survival. ${ }^{140} 141$ Similarly, in high-income countries, Burkitt lymphoma is treated with multiple courses of highly intensive multi-agent chemotherapy associated with numerous treatment complications, long inpatient stays, and intensive care unit support, resulting in cure rates of $90 \%{ }^{142}$ However, data from sub-Saharan African clinicians and researchers indicate that 
with single agent cyclophosphamide and minimal supportive care, close to $50 \%$ of children can still be cured..$^{143}$

These results suggest that at least across the spectrum of resource settings studied here, a particular level of childhood cancer services will represent a very cost-effective investment. However, to achieve excellent cure rates and improved survival on par with high-income countries new investments are needed in LMICs to expand access to effective and more comprehensive cancer services with supportive care. Hence, a comprehensive analysis of costs and benefits of scaling services for childhood cancer globally is warranted to quantify the costs of such a scale up and the health benefits in terms of enhanced survival and life years saved that could be achieved and to ascertain whether the economic benefits outweigh the costs. 
To estimate worldwide costs and benefits of scale up of policies and health interventions across the care cascade (from access to health services, to diagnosis, referral and treatment) to manage more effectively the burden of childhood cancers globally we extended the Global Childhood Cancer microsimulation model (appendix panels 1 and 2, pp. 16-19) by including modules on costs and long-term outcomes. We used this to examine alternative policy options.

To estimate the global costs of expanding treatment of new cancer cases, we utilised the cost estimates generated by the Commission in the costing studies undertaken by the Commission in Ghana, El Salvador and Mexico. To estimate the health benefits of various policy and health interventions, we computed long-term outcomes in relation to life expectancy and life years gained. To estimate the economic benefits we estimated future potential contributions of children who are treated successfully and survive into adulthood to enter into productive employment. We then compared economic benefits to costs for alternative policy options and health interventions to estimate potential returns to investing in scale up of effective management of childhood cancers worldwide.

We examined the effect of several interventions across the care cascade, both individually and in combination ('Comprehensive Scale-up' policy). These interventions included (i) improved access to primary care and referral to specialty care (Access/Referral) (ii) social support services to reduce treatment abandonment (Abandon) (iii) availability of treatment (including chemotherapy drugs for a given regimen, access to radiotherapy, 
access to surgical services) and improvements in quality of care (Treatment), and (iv) concurrent implementation of all interventions ((i)-(iii)) together (Comprehensive Scaleup).

We assumed that quality of care, which depends on a functioning health system with supportive services (e.g., nursing standards, integrated referral, and record-keeping) and facility-level activities (e.g., infection control and nutritional support), affects survival.

Recognizing that scale-up of interventions will take time to implement in each country, we assumed that for all the health interventions examined, country-specific model parameters would increase linearly between 2020 and 2030 to converge with the mean value among all 63 high-income countries (mean values based on cancer-case weighted estimates).

Figure 7 shows the parameter values for low-income countries, low-middle-income countries, upper-middle-income countries and high-income countries for chemotherapy, radiotherapy, and surgery for children that require a particular modality, (model parameters are specified inputs that govern processes in the model. Because we use a Bayesian approach these are considered random variables and are not known which certainty, but follow a probability distribution that is summarized in the figures). The mean values of the model parameters for the health interventions with $95 \%$ uncertainty intervals are shown in appendix table 3 (p 28). 
Figure 7: Mean values of the model parameters for health interventions for countries by World Bank Income Group
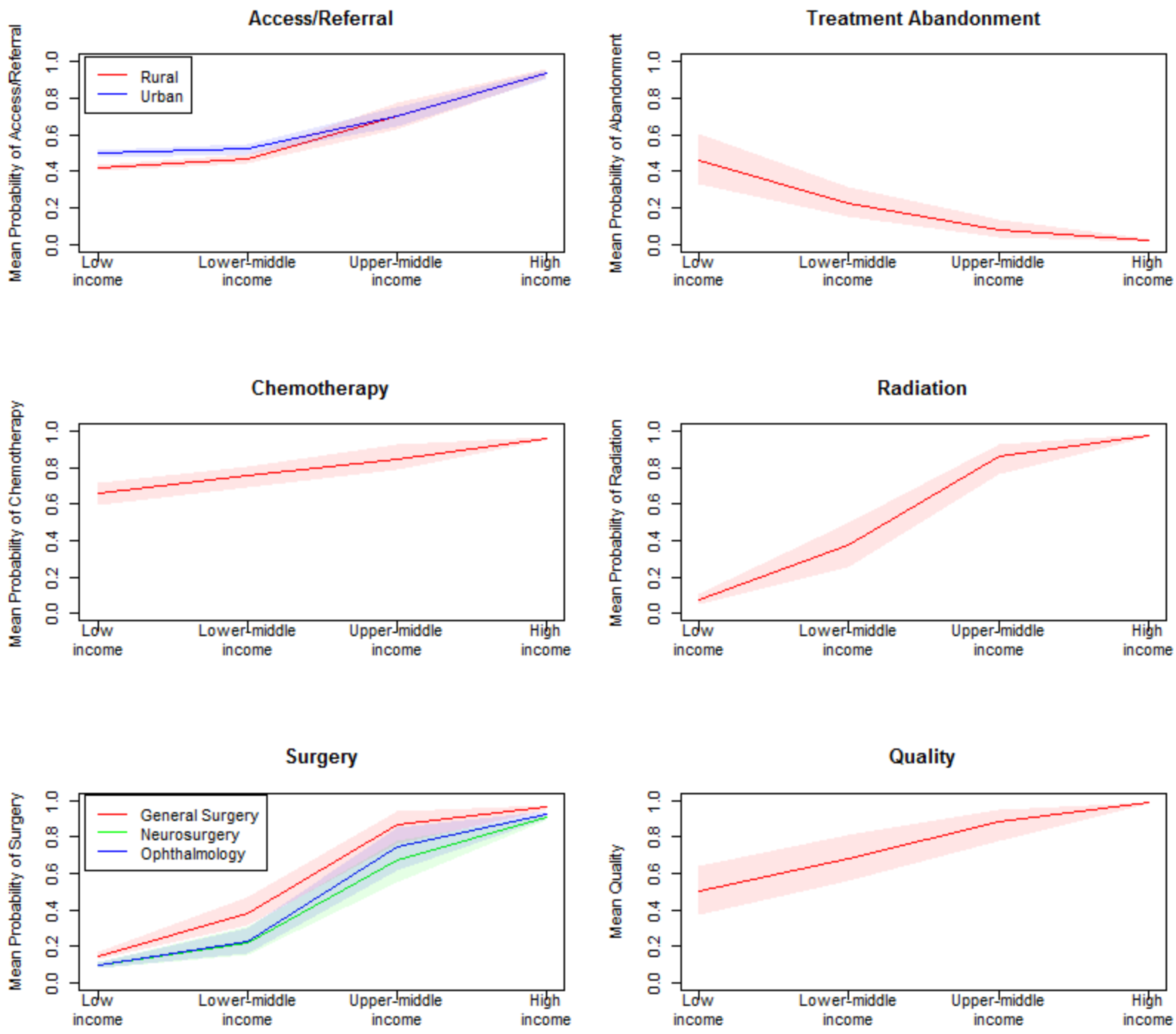

Using the Global Childhood Cancer microsimulation model and the projected 'pathway to scale-up', as described above and depicted in Figure 7, we simulated alternative scenarios of scaling up interventions either 'alone' or 'all combined' to estimate the potential effect in reducing the global number of childhood cancer deaths and improving global childhood 
cancer survival. We incorporated country-specific WHO life tables ${ }^{144,145}$ to account for background mortality rates, and assumed that sex-specific and age-specific mortality rates would decline between 2015 and 2030 (based on the average annual percentage reduction achieved between 2000 and 2016). The model also incorporated excess late mortality risk among childhood cancer survivors. After achieving initial disease cure, childhood cancer survivors continue to face health risks related to their original cancer diagnosis and treatment. We therefore assumed that survivors continue to face excess late mortality risks in addition to country-specific background mortality risks. ${ }^{146,147}$

\section{Health benefits of scaling health interventions globally to manage childhood cancers}

We present in Figure 8 the projected effect on deaths and survival globally by each intervention along the care cascade and all interventions combined. When scaled up as a stand-alone intervention increased access to primary care and referral (Access/Referral) is projected to avert 905,117 deaths (95\% UI, 728,835 to $1,104,700$ ), improved social support services to reduce treatment abandonment (Abandon) 237,641 deaths (95\% UI, 150,591 to $367,746)$, and expanded treatment availability with improved quality of care (Treatment) 2,020,000 (95\% UI, 11,715,800 to 1,715,800) childhood cancer deaths between 2020 and 2050 (figure 8 and table 7).

However, the effect is substantially magnified with Comprehensive Scale-up areas when these three interventions are combined and scaled up simultaneously. In that situation an estimated 6,235,100 (95\% UI 5,547,800 to 7,053,900) deaths could be averted in children with cancer (56.1\% of total deaths; 95\% UI, 53.6\% to 58.4\%) between 2020 and 2050. This 
figure is 3 -fold greater than what could be achieved with expanding treatment availability with improved quality of care alone (figure 8 and table 7), and it indicates the interdependent and sequential nature of the care cascade.

Figure 8: Projected effect of scaling up interventions individually and in combination on global childhood cancer deaths and overall survival for all childhood cancers (2020-2050)
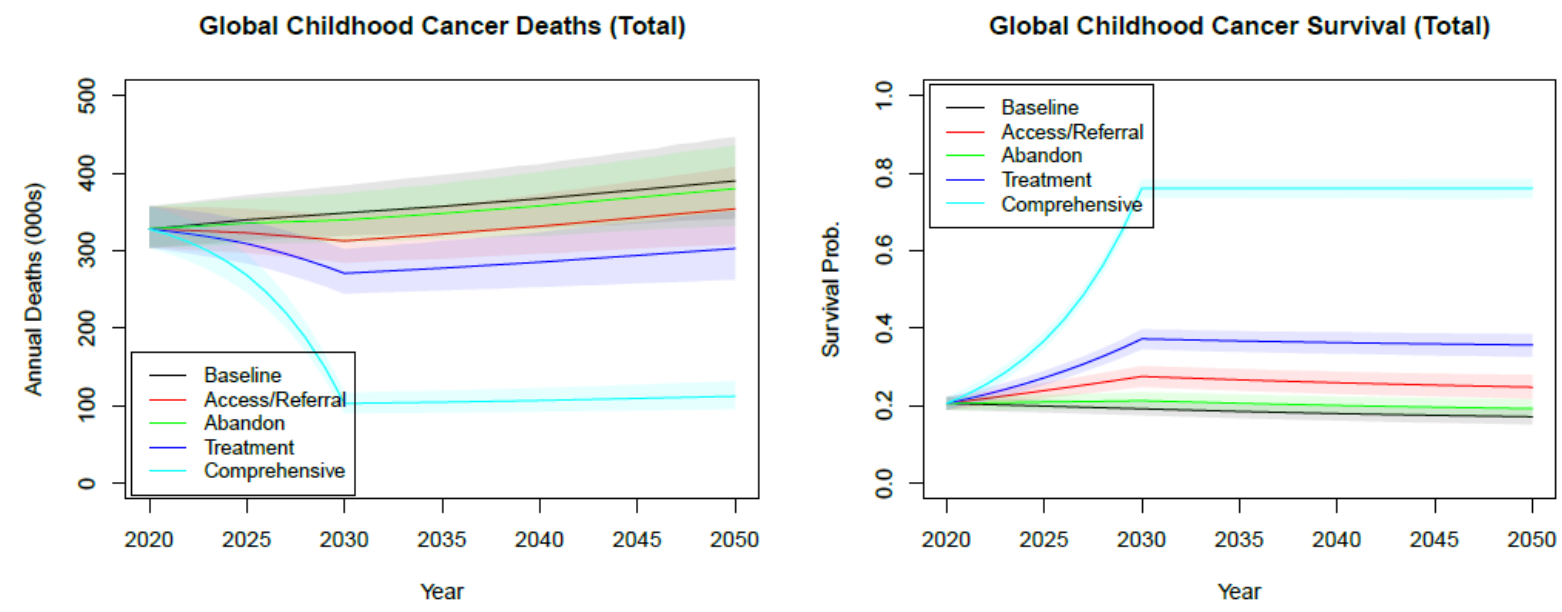

Table 7: Projected total number of childhood cancer deaths averted between 2020 and 2050, and life-years gained - lifetime

\begin{tabular}{|c|c|c|c|c|c|}
\hline \multirow{2}{*}{$\begin{array}{l}\text { Income } \\
\text { Group }\end{array}$} & \multirow{2}{*}{$\begin{array}{l}\text { Intervention } \\
\text { Scenario }\end{array}$} & \multicolumn{2}{|c|}{$\begin{array}{l}\text { Childhood Cancer Deaths Averted } \\
\text { between } 2020 \text { and } 2050 \text { ( } 95 \% \text { UI) }\end{array}$} & \multicolumn{2}{|c|}{$\begin{array}{l}\text { Projected Life Years Gained } \\
\text { (Lifetime), millions ( } 95 \% \text { UI) }\end{array}$} \\
\hline & & Number & Percent & Undiscounted & $\begin{array}{c}\text { Discounted } \\
(3 \%)\end{array}$ \\
\hline \multirow{4}{*}{ Global } & Access/Referral & $\begin{array}{c}905117 \\
(728835-1104708)\end{array}$ & $\begin{array}{c}8.2 \% \\
(6.7 \%-9.8 \%)\end{array}$ & $\begin{array}{c}52.22 \\
(42.79-63.11)\end{array}$ & $\begin{array}{c}15.22 \\
(12.61-18.21)\end{array}$ \\
\hline & Abandon & $\begin{array}{c}237461 \\
(150591-367746)\end{array}$ & $\begin{array}{c}2.1 \% \\
(1.3 \%-3.3 \%)\end{array}$ & $\begin{array}{c}12.05 \\
(7.76-18.72)\end{array}$ & $\begin{array}{c}3.39 \\
(2.17-5.3)\end{array}$ \\
\hline & Treatment & $\begin{array}{c}2020167 \\
(1715794- \\
2360370) \\
\end{array}$ & $\begin{array}{c}18.2 \% \\
(15.9 \%- \\
20.6 \%) \\
\end{array}$ & $\begin{array}{c}102.25 \\
(87.3-119.24)\end{array}$ & $\begin{array}{c}28.21 \\
(24.07-32.79) \\
\end{array}$ \\
\hline & Comprehensive & $\begin{array}{c}6235086 \\
(5547779- \\
7053927)\end{array}$ & $\begin{array}{c}56.1 \% \\
(53.6 \%- \\
58.4 \%) \\
\end{array}$ & $\begin{array}{c}318.4 \\
(284.21-359.65)\end{array}$ & $\begin{array}{c}87.93 \\
(78.74-99.08)\end{array}$ \\
\hline \multirow{2}{*}{ LIC } & Access/Referral & $\begin{array}{c}97975 \\
(61543-152146)\end{array}$ & $\begin{array}{c}3.0 \% \\
(1.9 \%-4.6 \%)\end{array}$ & $\begin{array}{c}6.51 \\
(4.62-9.34)\end{array}$ & $\begin{array}{c}2.02 \\
(1.48-2.79)\end{array}$ \\
\hline & Abandon & $\begin{array}{c}61915 \\
(34689-100701) \\
\end{array}$ & $\begin{array}{c}1.9 \% \\
(1.1 \%-3 \%) \\
\end{array}$ & $\begin{array}{c}3.09 \\
(1.77-5.07)\end{array}$ & $\begin{array}{c}0.86 \\
(0.5-1.41)\end{array}$ \\
\hline
\end{tabular}




\begin{tabular}{|c|c|c|c|c|c|}
\hline & Treatment & $\begin{array}{c}558863 \\
(442909-700484)\end{array}$ & $\begin{array}{c}17.2 \% \\
(14 \%-20.5 \%)\end{array}$ & $\begin{array}{c}27.61 \\
(22-34.59)\end{array}$ & $\begin{array}{c}7.51 \\
(5.99-9.37)\end{array}$ \\
\hline & Comprehensive & $\begin{array}{c}1951183 \\
(1666625- \\
2330863)\end{array}$ & $\begin{array}{c}60.0 \% \\
(56.9 \%- \\
62.8 \%)\end{array}$ & $\begin{array}{c}98.15 \\
(83.82-117.31)\end{array}$ & $\begin{array}{c}26.68 \\
(22.89-31.79)\end{array}$ \\
\hline \multirow{4}{*}{ LMIC } & Access/Referral & $\begin{array}{c}533115 \\
(385111-711422)\end{array}$ & $\begin{array}{c}8.8 \% \\
(6.4 \%-11.5 \%)\end{array}$ & $\begin{array}{c}30.18 \\
(22.49-39.66)\end{array}$ & $\begin{array}{c}8.86 \\
(6.69-11.53)\end{array}$ \\
\hline & Abandon & $\begin{array}{c}127837 \\
(58023-237512)\end{array}$ & $\begin{array}{c}2.1 \% \\
(0.9 \%-4 \%)\end{array}$ & $\begin{array}{c}6.35 \\
(2.92-11.81)\end{array}$ & $\begin{array}{c}1.81 \\
(0.83-3.38)\end{array}$ \\
\hline & Treatment & $\begin{array}{c}1150757 \\
(925912-1407416)\end{array}$ & $\begin{array}{c}18.9 \% \\
(15.6 \%- \\
22.1 \%)\end{array}$ & $\begin{array}{c}57.67 \\
(46.4-70.98)\end{array}$ & $\begin{array}{c}16.07 \\
(13.07-19.68)\end{array}$ \\
\hline & Comprehensive & $\begin{array}{c}3504948 \\
(2973584- \\
4079867)\end{array}$ & $\begin{array}{c}57.5 \% \\
(54.8 \%- \\
59.7 \%)\end{array}$ & $\begin{array}{c}177.25 \\
(150.64-205.99)\end{array}$ & $\begin{array}{c}49.46 \\
(42.28-57.15)\end{array}$ \\
\hline \multirow{4}{*}{ UMIC } & Access/Referral & $\begin{array}{c}257255 \\
(193174-344189)\end{array}$ & $\begin{array}{c}16.8 \% \\
(13.9 \%- \\
20.1 \%)\end{array}$ & $\begin{array}{c}14.56 \\
(10.87-19.54)\end{array}$ & $\begin{array}{c}4.08 \\
(3.06-5.47)\end{array}$ \\
\hline & Abandon & $\begin{array}{c}43457 \\
(16547-85437) \\
\end{array}$ & $\begin{array}{c}2.9 \% \\
(1.1 \%-5.7 \%) \\
\end{array}$ & $\begin{array}{c}2.37 \\
(0.89-4.76) \\
\end{array}$ & $\begin{array}{c}0.65 \\
(0.25-1.29) \\
\end{array}$ \\
\hline & Treatment & $\begin{array}{c}294053 \\
(217402-378494) \\
\end{array}$ & $\begin{array}{c}19.2 \% \\
(14.3 \%- \\
23.9 \%) \\
\end{array}$ & $\begin{array}{c}16.04 \\
(11.77-20.83)\end{array}$ & $\begin{array}{c}4.39 \\
(3.25-5.65) \\
\end{array}$ \\
\hline & Comprehensive & $\begin{array}{c}739317 \\
(615884-879019)\end{array}$ & $\begin{array}{c}48.3 \% \\
(45.7 \%- \\
50.7 \%)\end{array}$ & $\begin{array}{c}40.73 \\
(33.62-48.76)\end{array}$ & $\begin{array}{c}11.18 \\
(9.3-13.34)\end{array}$ \\
\hline \multirow{4}{*}{ HIC } & Access/Referral & $\begin{array}{c}16772 \\
(11737-22639)\end{array}$ & $\begin{array}{c}7.2 \% \\
(5 \%-9.6 \%)\end{array}$ & $\begin{array}{c}0.97 \\
(0.68-1.32)\end{array}$ & $\begin{array}{c}0.27 \\
(0.19-0.36)\end{array}$ \\
\hline & Abandon & $\begin{array}{c}4252 \\
(2704-6156)\end{array}$ & $\begin{array}{c}1.8 \% \\
(1.2 \%-2.6 \%)\end{array}$ & $\begin{array}{c}0.24 \\
(0.15-0.35)\end{array}$ & $\begin{array}{c}0.06 \\
(0.04-0.09)\end{array}$ \\
\hline & Treatment & $\begin{array}{c}16494 \\
(14027-19381)\end{array}$ & $\begin{array}{c}7.1 \% \\
(5.9 \%-8.4 \%)\end{array}$ & $\begin{array}{c}0.94 \\
(0.8-1.11)\end{array}$ & $\begin{array}{c}0.25 \\
(0.21-0.29)\end{array}$ \\
\hline & Comprehensive & $\begin{array}{c}39637 \\
(33012-47100)\end{array}$ & $\begin{array}{c}17.1 \% \\
(14 \%-19.8 \%)\end{array}$ & $\begin{array}{c}2.27 \\
(1.9-2.71)\end{array}$ & $\begin{array}{c}0.61 \\
(0.51-0.73)\end{array}$ \\
\hline
\end{tabular}

The substantially larger effect of Comprehensive Scale-up, compared with scaling up each intervention separately along the care cascade, was consistent for countries in all World Bank income groups. The health benefits of comprehensive scale-up of interventions, in terms of reduction in the number of childhood cancer deaths, are projected to be greatest in lower-middle-income countries, followed by low-income countries. In contrast, the greatest improvement in 5-year survival is projected for low-income countries (figure 9 and table 7). The model also projected improvements among high-income countries, 
where variability in death rates and survival exist. This improvement observed in highincome countries, where variability in death rates and survival does exist, but these gains are comparatively very small, since the model assumes that countries performing worse than the average for high-income countries would converge to the mean death rates and survival levels in high-income countries between 2020 and 2030.

Figure 9: Projected effect on comprehensive scale-up on childhood cancer deaths and overall survival in countries by World Bank income group
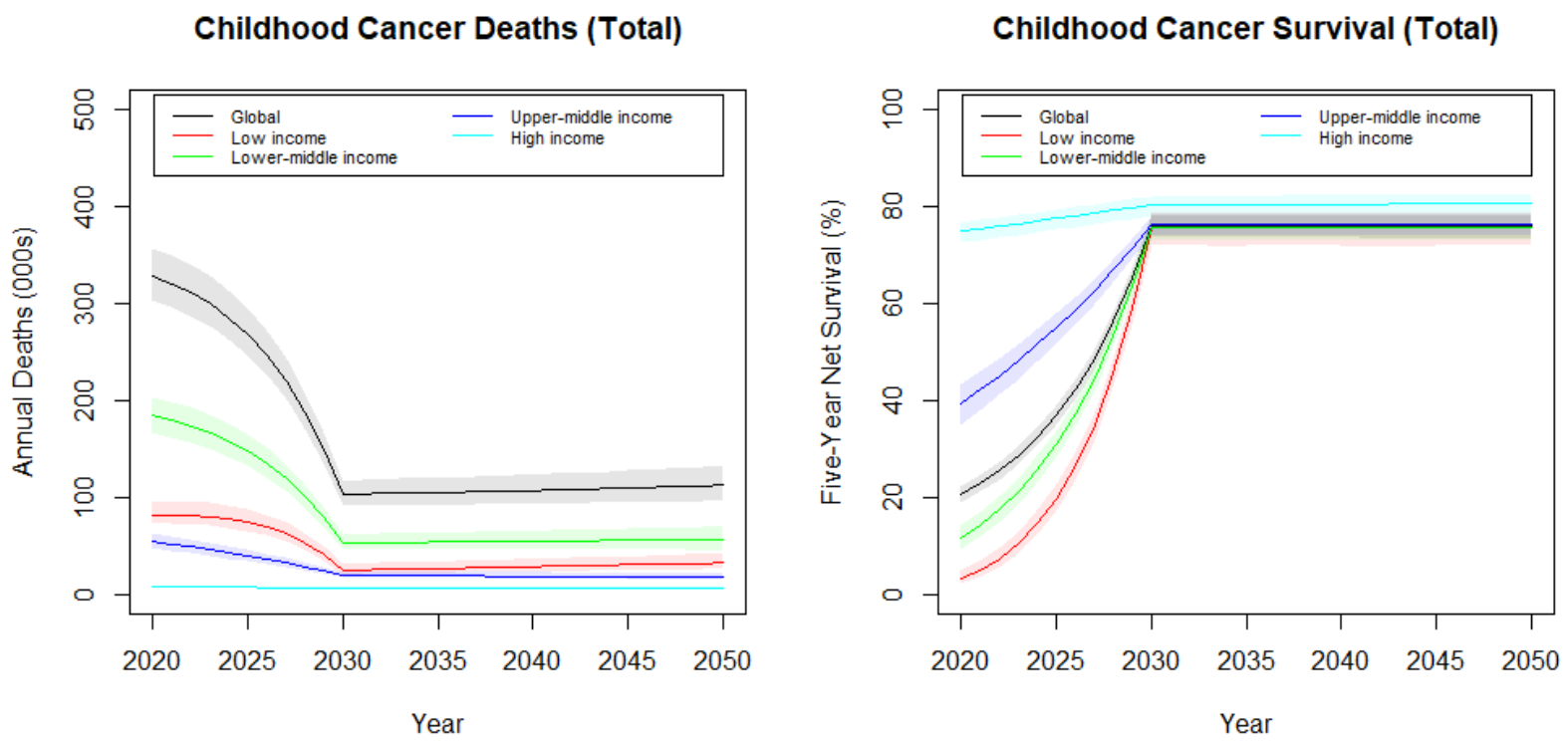

When excess mortality risks are considered, the model estimates for the projected number of life years gained showed similar results to those for averted childhood cancer deaths. Comprehensive scale-up had by far the greatest effect globally and in each World Bank country income group (table 7). 
The results show that, globally, the number of undiscounted life years gained was an estimated 318.4 million (95\% UI, 284.2 to 359.7 million) for Comprehensive Scale-up. This figure exceeds the total number of life years gained for each individual intervention is implemented separately and the effects combined (166.5 million life years gained (95\%UI, 137.2 to 201.0 million)). Results were largely unchanged if background mortality rates remained constant at current 2016 levels (appendix table 4, p 29).

\section{Costs and economic benefits of scaling-up health interventions globally to manage}

\section{childhood cancers}

To estimate global costs of scaling-up the health interventions required to manage childhood cancers effectively, we used the cost data generated in the study undertaken by the Commission in Mexico, Ghana and El Salvador. Based on these cost data, we assumed that the average treatment costs per-cancer-case-diagnosed was equivalent to 7-times GDP per capita income as a proxy for costs associated with Comprehensive Scale-up. This proxy cost for scale-up represents a conservative estimate based on the correlation between GDP per capita income and the observed average costs required to maintain a childhood cancer treatment unit in a low-income country and a middle-income country.

To estimate the economic benefits associated with Comprehensive Scale-up, we used the human-capital approach ${ }^{148} 149$ and the value-of-life-years approaches ${ }^{36}$ (also called the fullincome approach). For both methods, we used GDP to estimate the economic gains. In the human capital approach, the economic value of a life saved is based on a person's economic contribution. Based on the World Bank definition of working population (adjusted to 
reflect that some children diagnosed with cancer before age 14 may still be in treatment during adolescence) ${ }^{150}$, we assumed that a child who survived cancer would contribute to 1-times the GDP per capita starting at age 18 and until age 64 (or death, whichever occurs first).

The full-income approach, which accounts for the societal benefits, recognizing the intrinsic societal value of an intervention, even if the recipient is no longer able to contribute to the workforce, was based on 2.3-times the GDP per person in a given year, consistent with The Lancet Commission on Global Health 2035. ${ }^{36}$ As an upper bound, we used 3-times GDP, based on WHO-CHOICE (Choosing Interventions that are cost-effective) methodology developed by the WHO Commission on Macroeconomics and Health as the valuation metric. ${ }^{151}$ All GDP estimates were based on the International Monetary Fund data between 2015 and 2023, ${ }^{152}$ and projected to 2030 based on projections of the average percentage growth between 2015 and 2023 (with a minimum/maximum GDP growth rate of $8 \%$ to keep projections consistent with historical and anticipated trends).

Figure 10 (a) shows the cumulative treatment costs and productivity gains associated with Comprehensive Scale-up between 2020 and 2050 for all childhood cancers. Projected global cumulative treatment costs (discounted) with Comprehensive Scale-up amount to $\$ 17.3$ billion (95\% UI (16.9-17.6) in 2020, $\$ 228.8$ billion (95\% UI 220.7-237.0) by 2030 and $\$ 594.4$ billion (95\% UI 563.1-626.7) by 2050 (appendix table 5, p 30). We discounted both costs and benefits (as measured by life years gained which were then used to measure future productivity gains) using the same discount rate (individuals prefer to have benefits 
now and incur costs in the future - time-preference, which reflects the discount rate). As costs and benefits are realised at different times discounting is used to state both costs and benefits in terms of their net present value. While treatment costs are incurred at time of diagnosis for each incident cancer, productivity gains accrue only once a child survives cancer and reaches age 18. This leads to a lag in time before cumulative productivity gains are projected to exceed treatment costs. However, global cumulative productivity gains do exceed cumulative costs, which is projected to occur globally in 2043 at $2.3 x G D P$, or by 2045 if global treatment costs and productivity gains are discounted by 3\% (figure 10 (a)).

Figure 10 (b) and appendix table 5 (p 30) show discounted results by country income group. Projections show that cumulative productivity gains exceed cumulative costs in lower-middle income countries, middle-income countries and high-income countries at some point during the period 2020-2050, and after 2050 for low-income countries.

Figure 10: Projected cumulative costs and productivity gains with global Comprehensive Scale-up of health interventions for all childhood cancers Figure 10 (a) Global (Undiscounted and Discounted)
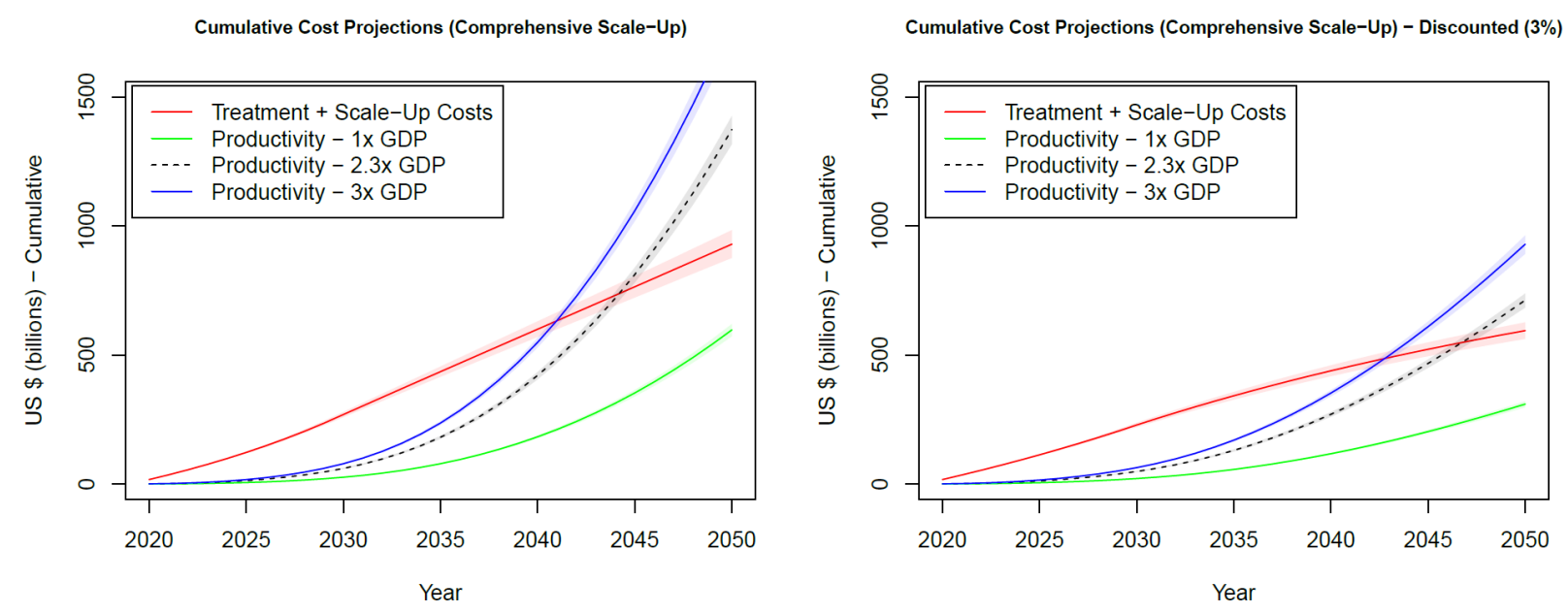
Figure 10 (b) By country income groups (Discounted)
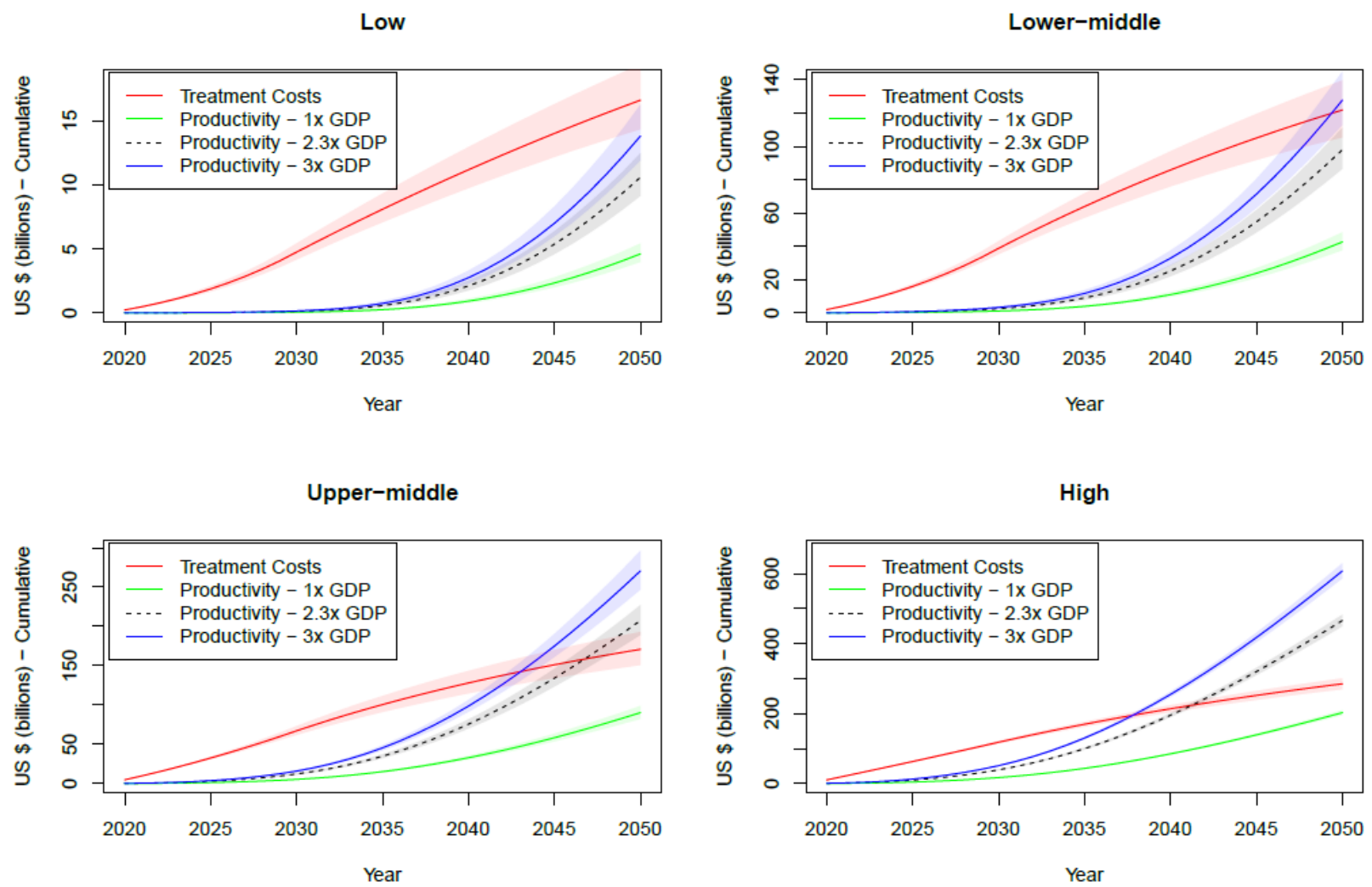

Estimates of net economic benefits and return on investment for global Comprehensive Scale-up of health interventions for all childhood cancers

To estimate the return on investment for global Comprehensive Scale-up of health interventions for childhood cancers, we compared global cumulative treatment costs with the global lifetime productivity gains among survivors for all cancers diagnosed in children between 2020 and 2050 (both costs and productivity were discounted at 3\% (appendix table 6 pp. 31-32). 
Using the 2.3-times GDP valuation metric, we estimate global lifetime productivity gains of $\$ 2,580$ billion ( $95 \%$ UI, $\$ 2,444.0$ to $\$ 2,726$ billion). This is four times greater than the cumulative treatment costs of $\$ 594.4$ billion (95\% UI, $\$ 563.1$ to $\$ 626$ billion). This suggests a a net benefit of $\$ 1,986.1$ billion (95\% UI, 1884 to 2101 ), and a net return on investment of more than 3-times - i.e. for each $\$ 1$ invested in improving care of childhood cancers a net return of $\$ 3$ is realised in the period 2020-2050.

Results by World Bank country income group (figure 11) show that in each country income group the global lifetime productivity gains exceed cumulative treatment costs. This would generate very substantial net benefits and a positive net return on investment.

Figure 11: Lifetime cumulative treatment costs, productivity gains and net benefits of comprehensive scale up for all childhood cancers diagnosed in 2020-2050
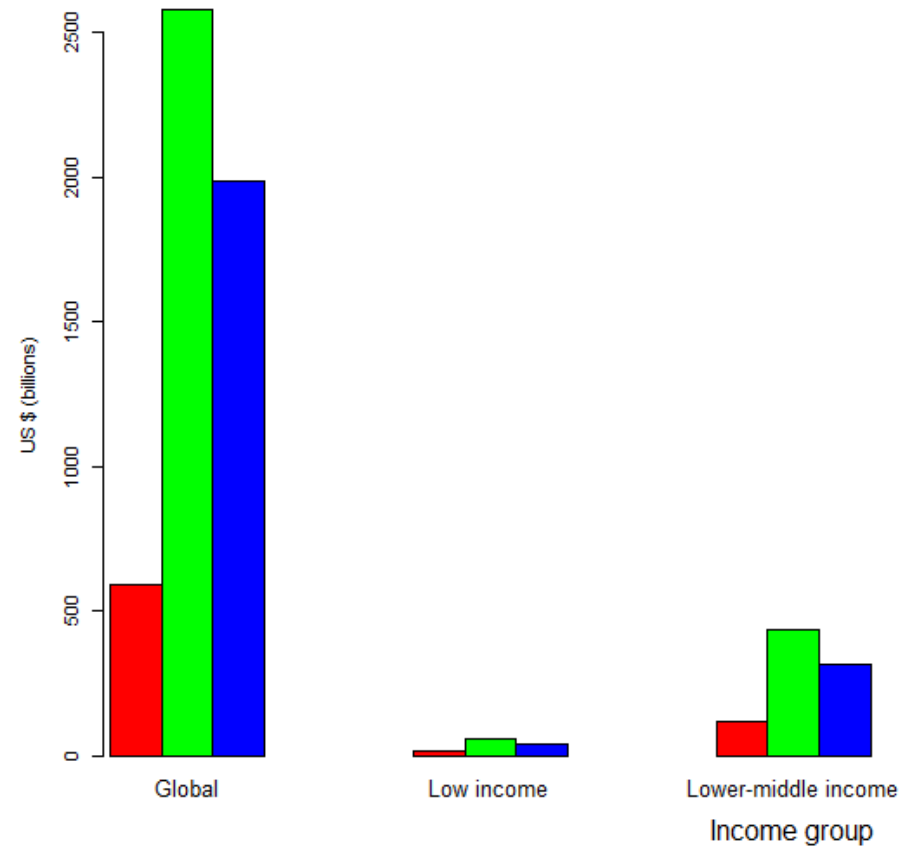

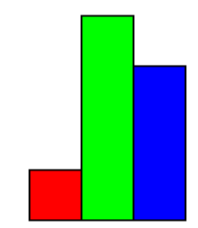

Upper-middle income $\square$ Treatment Costs

Productivity Gains

- Net Benefit (\$)

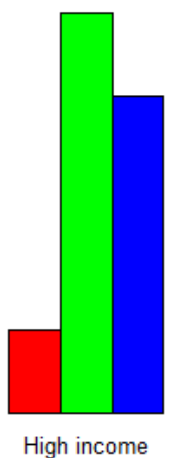

High income 
The projections with the Comprehensive Scale-up scenario assumed $100 \%$ scale up of the three groups of health interventions for childhood cancers along the care cascade to reach the high-income country mean targets. In some country settings, $100 \%$ scale up may be challenging due to health system weaknesses. Therefore, we varied the percentage of scaleup from $0 \%$ (no interventions) to 100\% (Comprehensive Scale-up). We then estimated net benefits realised from productivity gains at 1 xGDP, 2.3x GDP and 3xGDP based on the values used in the literature ${ }^{36}$ (appendix table 7, pp. 33-34).

The results show that globally, scaling-up health interventions to achieve improvements along the care cascade for childhood cancers is projected to produce productivity gains that exceed costs (figure 12). This would lead to positive net benefits at all levels of scale up (figure 13).

There were net benefits at all levels of scale up for each country income groups. However, for low-income countries, where a scale-up of at least $40 \%$ (e.g. all low-income countries moved $40 \%$ of the way between their current levels of health system performance and mean high-income country target levels) would be required for lifetime productivity gains to outweigh the cumulative treatment costs (figure 13 and appendix table 7, pp. 33-34). The longer time period and higher scale-up required in low-income countries to achieve lifetime productivity exceeding costs is because workforce productivity is lower in LIC, which accounts for some of this difference, and where salaries (as proxied by GDP per capita income) are relatively lower. In addition, higher competing mortality rates in lowincome countries means that childhood cancer survivors are less likely to survive as long as 
individuals in other countries, which also reduces the estimates of future productivity gains.

Figure 12: Lifetime costs and productivity gains (US\$ billions) at different levels of scale-up (global and by country income group)
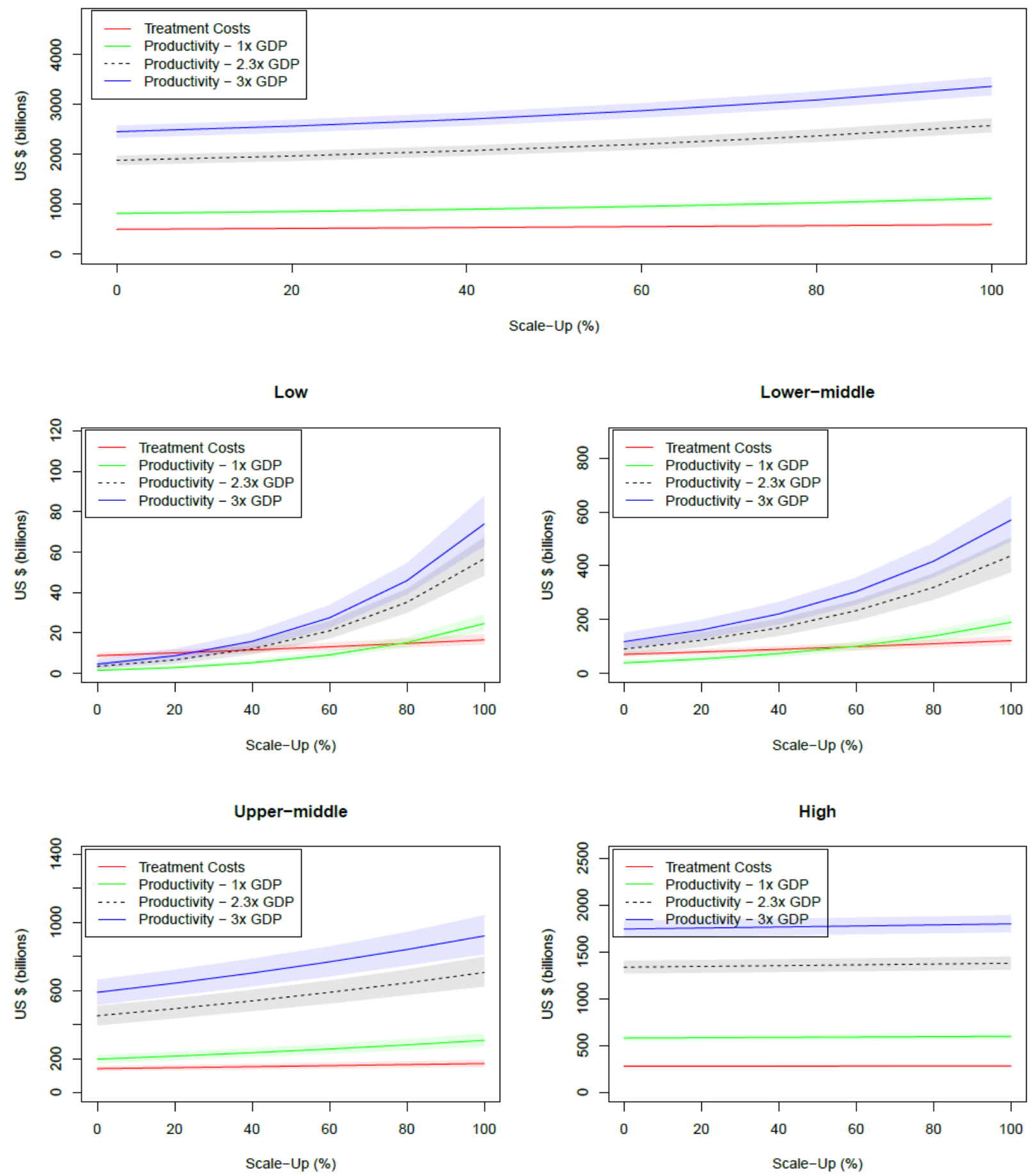
Figure 13: Net benefit from investments to scale-up health interventions for childhood cancers at different levels
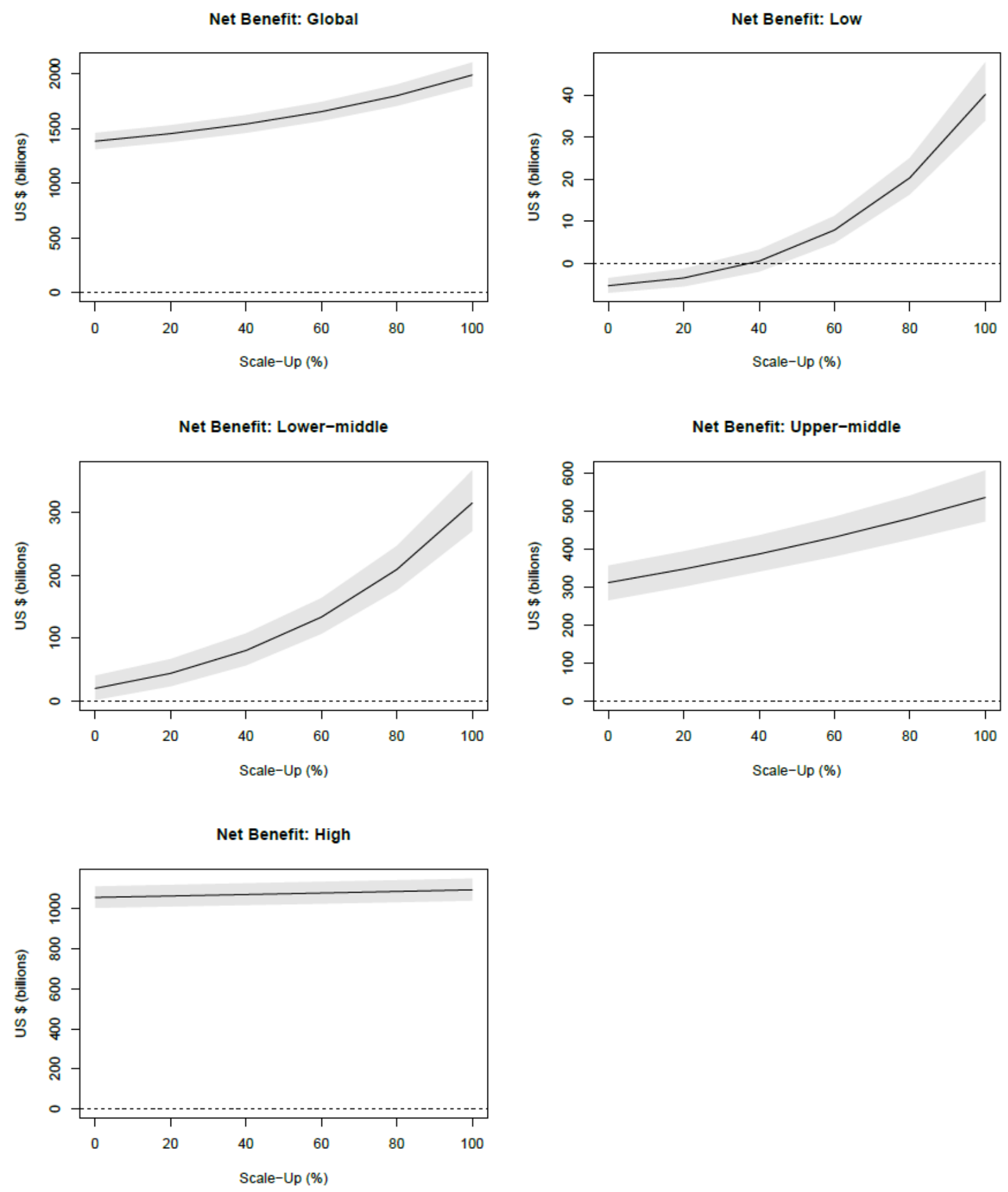
Given the complexity of implementing Comprehensive Scale-up, additional costs may be incurred to strengthen the health system over and above the costs for interventions for managing childhood cancers. We therefore undertook a sensitivity analysis on costs, productivity gains and net benefits, assuming some additional health system costs, ${ }^{153} 154$ which have been estimated as being necessary when scaling up other targeted health programmes globally. Our projections indicate that even if additional costs, equal to $20 \%$ of cancer treatment costs were included in overall costs, directionally, the results relating to benefits with scale up were largely unchanged (appendix tables 8, 9 and 10, pp. 35-38 and appendix figures 1 and 2 pp. 39-40).

The results clearly show the substantial health and economic benefits of comprehensive scale up of health and social interventions for childhood cancer to expand access to treatment, improve healthcare services, and reduce abandonment.

The economic benefits far exceed the costs of scale up of interventions globally. The net benefits are positive in each country income groups, and at all levels of scale up in middleincome and high-income countries. Only in in low-income countries where the relevant services are currently all but absent, would a scale-up of at least $40 \%$ or more would be required to achieve a net economic benefit. The projected net economic benefits would be greatest if interventions are scaled up in combination and simultaneously. This underlines the importance of a comprehensive and integrated response. 
These results provide a compelling case for investing in comprehensive scale-up of childhood cancer services. We next explore how global scale-up could be achieved, the preconditions for success and the potential roles and responsibilities of the main actors in realising the goal of comprehensive care for childhood cancers worldwide. 


\section{SECTION 5: SCALING UP COMPREHENSIVE CARE FOR CHILDHOOD CANCERS WORLDWIDE}

There is a compelling case for investing in the scale-up of diagnosis, treatment and care of children with cancer. This would prevent millions of needless deaths in children. It would address the unacceptable inequities in access to healthcare and health outcomes within and between countries. It would also help realise large economic returns for countries and families.

However, the magnitude and the speed of the global and country-level responses to the global needs of children with cancer will depend on far more than the evidence and health system capabilities. It will also require political will, leadership, understanding of the models of care that can be scaled up, human resource capability, and the availability of country-level (domestic) and external finances. In this section we discuss pathways to scale-up. We explore suitable service delivery models for providing childhood cancer care, how best to use existing service delivery platforms developed in low-income countries and middle-income countries, how to expand human resource capacity, and potential sources of funding.

Pathways to scaling up healthcare services for childhood cancer: country roadmaps, facility tiers, and intervention packages

Addressing childhood cancer requires the development of a specific framework that is integrated within national health systems, but is sensitive to the unique circumstances that 
define cancer in children, where comprehensive multidisciplinary care along the entire continuum of care is critical.

Context adaptation of guidelines for diagnosis and treatment provides an opportunity for policymakers to align the guidelines with the available resources and country priorities and to plan resource-appropriate cancer care programmes for children.155,156 The implementation of these tailored approaches will require the development and validation of levels of care that accurately reflect the status of regions, countries and paediatric oncology units of interest. $5,157,158$

The Commission explored this concept further, to develop a model of 'country roadmaps' and 'facility tiers' with integrated service packages for the development and implementation of childhood cancer care. Other health areas, such as maternal and neonatal health, and trauma medicine have successfully developed and implemented care models based on levels of care, ${ }^{159,160}$ to show the correlation of those models with quality indicators and outcomes. ${ }^{161,162,163}$

To develop a model of 'country roadmaps' and 'facility tiers' with integrated service packages, the Commission used a modified Delphi Process with three rounds of surveys to derive consensus on the care that could be provided at each level and the country capabilities needed to provide such care. The respondents to the Delphi study included commissioners and multidisciplinary experts (including paediatric oncologists and nurse specialists) representing all WHO regions and World Bank income groups. In addition, to contextualize 
the scoping review and complement the Delphi, working groups inclusive of multidisciplinary providers experienced with intervention needs in LMICs met in person and online over a period of more than 18 months to review evidence and refine key concepts for facility and country tiers, and childhood cancer packages.

Considering varied capabilities in countries the Commission identified country tiers and identified steps to progressively transition to higher capabilities while strengthening health systems in the process (panel 7).

Panel 7: Developing tiers of capability for childhood cancers and strengthening health systems

Not all countries are equally equipped to address the burden of childhood cancer, but all countries must consider how they can improve the quality of care and population-based outcomes for children with cancer within their resource constraints. The Commission considered that elements of a health system to guide the definition of country tiers in global pediatric oncology. Defining country capabilities can help develop models for health system strengthening of greater impact than achievable by focusing exclusively on strengthening individual facilities; better understand the country's capacity and the country's readiness to address and improve population-based childhood cancer outcomes; better evaluate and benchmark population-based childhood cancer outcomes; and understand the country's readiness to have more of its facilities ascend through facility tiers. Attentiveness to the country capabilities can improve a facility's understanding of its role in the health system and help foster communication, integration, and common purpose between facilities and 
with policy makers and government agencies, and prioritize areas in which a facility or network of facilities and its personnel should participate in advocacy.

The 'steps' illustrate how progressive acquisition of these capabilities and stepwise implementation of policy enablers, such as effective stewardship and governance, adequate financing, delivery of services with evidence-based interventions and essential medicines, equitable access to care and health information systems with suitable vital statistics and cancer registries that include childhood cancer, can accelerate progress by easing the facilities' delivery of childhood cancer care and monitoring and evaluation of progress. The proposed country tiers model needs to be interpreted as a roadmap towards a goal; the framework should serve as a consensus-derived step-by-step guide of health system policy enablers needed for optimal delivery of childhood cancer services in a given country, with downstream effects on facility capabilities (figure 14). 
Figure 14: Country roadmap to guide acquisition of capabilities for childhood cancer care

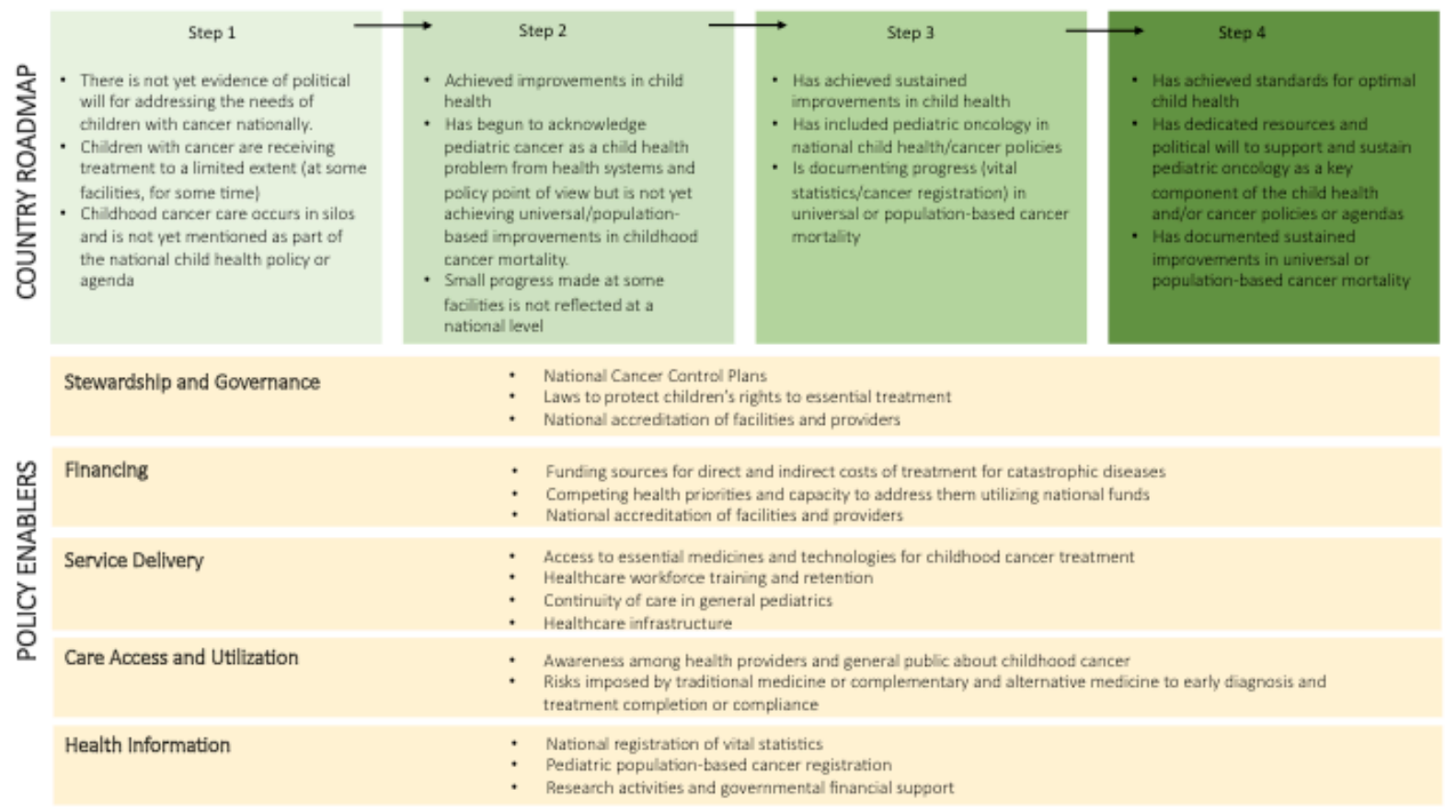

Context adaptation of diagnostic and treatment guidelines requires a detailed definition of the capabilities of the center where care is delivered. While the focus of guideline development has emphasised guidance for treatment decisions based on facility level resources, interconnectedness among facilities as a strategy to increase capabilities and treatment opportunities, or to improve outcomes has not been explored. In the proposed networked-tiers model, while it is understood that not all facilities are equally equipped to diagnose and treat all childhood cancers, all paediatric oncology units must consider their scope and role, determine how they can improve the quality of care and outcomes for all children with cancer within the resource constraints of their facility, and how to establish formal collaborations with other facilities in the country or region. Each level in the framework must provide the highest quality care possible for their scope and meet all 
capabilities defined in the preceding (lower) levels. Lower level facilities have unique care delivery and supportive care functions; they should not be perceived merely as referral centers to higher tier facilities. Higher facilities have unique education, consultative, and collaborative functions; they are not merely referral centers to lower tier facilities (figure 15).

Figure 15: Desirable capabilities at each level of care for childhood cancers

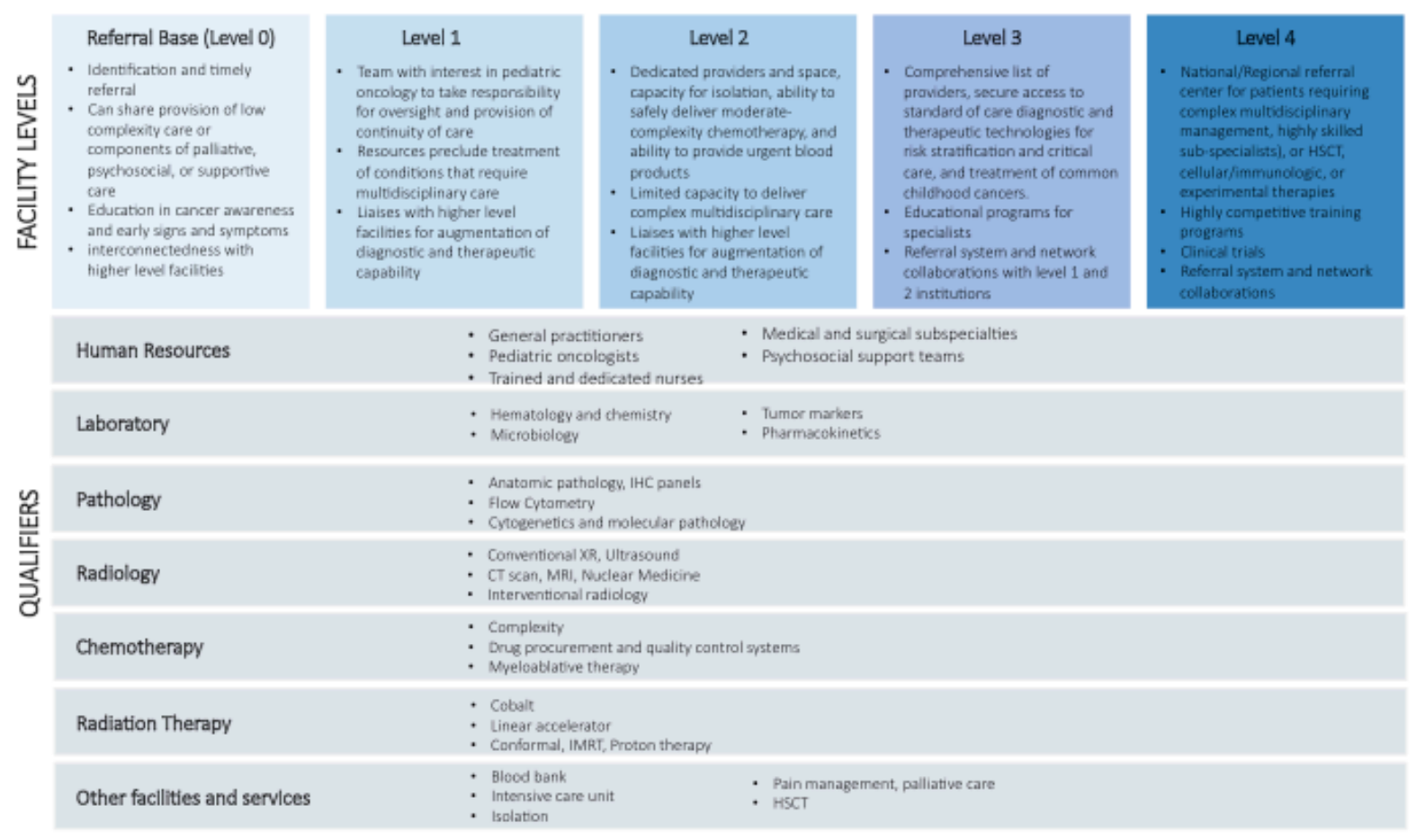

The Delphi study also helped to define the essential care packages most important for prioritization at a national level for sustainable paediatric cancer care, with integration in the country roadmap and facility tier models. Defining care packages at a national level allows priority setting for effective care and investment, promoting enhanced functioning 
and ultimately performance of the health system to achieve a patient-level positive impact that can be sustained.

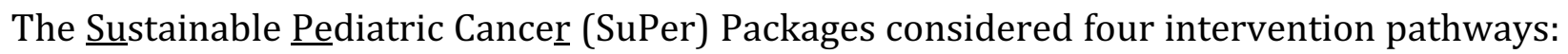
diagnosis, treatment, treatment completion, and integrated. The SuPer package framework included three overarching package sets connected to the proposed country roadmap and facility tiers. First, a Core Sustainable Pediatric Cancer (SuPer) Package, is expected to apply in most to nearly all settings, and which encompasses pediatric cancer needs broadly. Second, an Advanced SuPer Package, is expected to apply in many settings, and is typically introduced after the interventions in the Core Package. Third, a Maximal SuPer Package, expected to currently apply in a minority of settings, typically introduced after interventions outlined in the Advanced Package, and is most dependent on resource and capability levels, diagnoses, and outcomes.

This SuPer Package framework is outlined in figure 16. Given the overlapping and nuanced contextual differences, it was intentional for the boxes not to exactly line up horizontally with the facility levels. For instance, while the Core SuPer Package should be feasible including in settings with low resource capabilities (Level 1 Childhood Cancer Treatment Facilities) and starting in countries at Roadmap Step 1, the Advanced SuPer Package is typically feasible starting only in settings with moderate to high resource capabilities (Level 2 to 3 Facilities) and typically corresponding to countries that are at Roadmap Step 2 or above. The Maximal SuPer Package is typically considered feasible by settings with maximal 
resource capabilities (a few select Level 3 and mostly Level 4 Facilities), and typically corresponding to countries that are at Roadmap Step 3 or above (figure 16).

These three illustrative care packages offer an indicative framework for governments to identify and contextualize opportunities for scale-up, aligned to the tier system developed for facilities and the country roadmaps.

Figure 16: Sustainable Paediatric cancer-specific framework for essential intervention packages [SuPer Packages Framework]

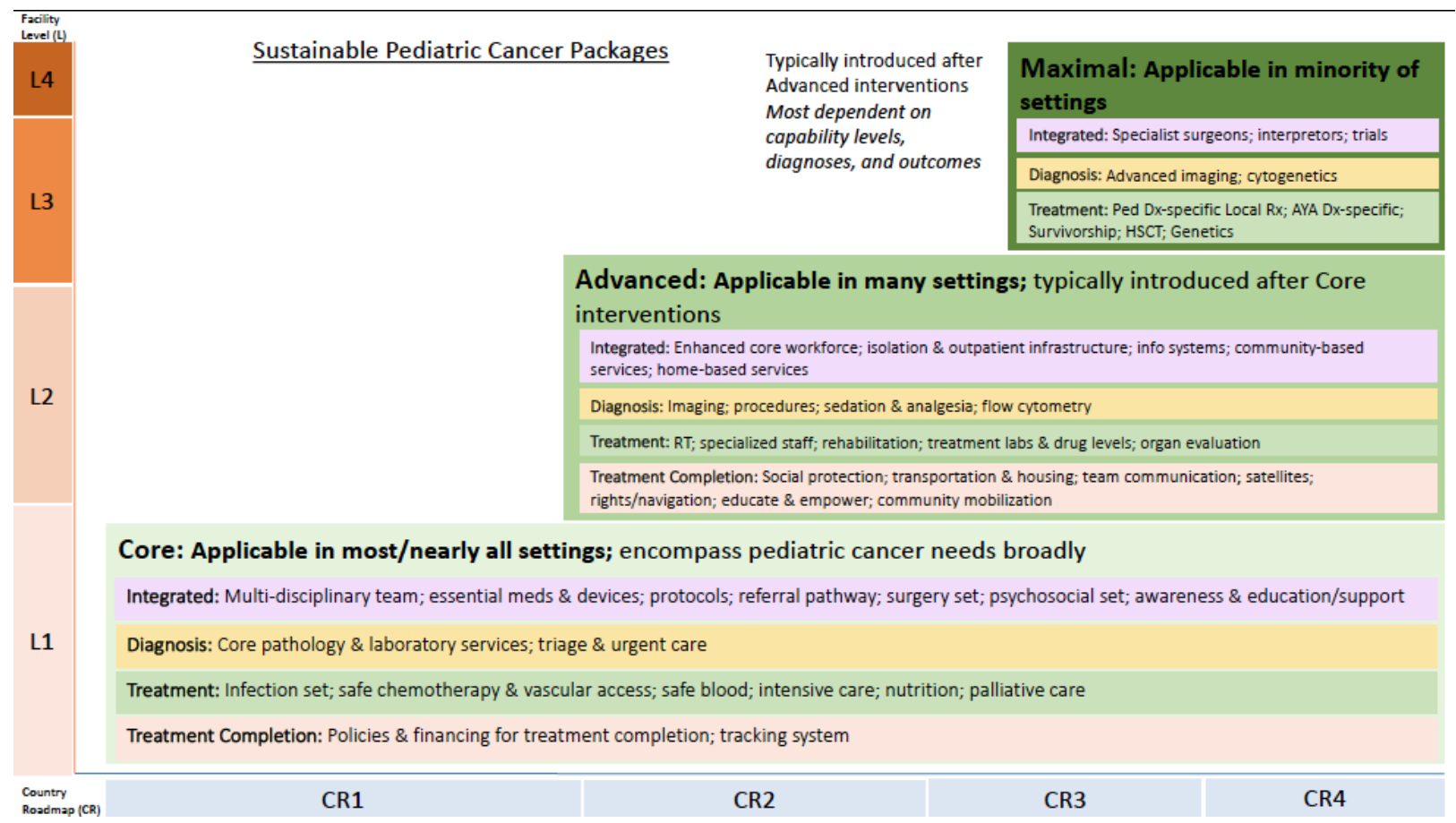

As countries have a heterogeneous mix of childhood cancer treatment facility levels, it is helpful to consider both facility levels and country roadmaps to contextualize how care packages could be developed. The Commission noted that the facility tiers and the packages 
provided should be sensitive to the country roadmap and each country should articulate a model that facilitate progression in a stepwise manner as capabilities are developed to manage different childhood cancers (figure 17). Part of the stepwise approach is also intended to highlight that more is not necessarily better. More advanced interventions without the appropriate health system context could unintentionally reduce patient survival and compromise health system efficiency and effectiveness because of increased treatment related morbidity, for example undertaking complex surgery or bone marrow transplant, without appropriate infrastructure for operation planning, blood transfusion, and infection control.

These capabilities can be developed in a stepwise manner in countries with differing resources, with a pathway for realization of these capabilities over time to provide services of increasing complexity and resource intensity to treat different childhood cancers (figure 17) as resources, competences and policies permit. 
Figure 17: Capabilities needed to provide interventions of differing complexity for childhood cancers

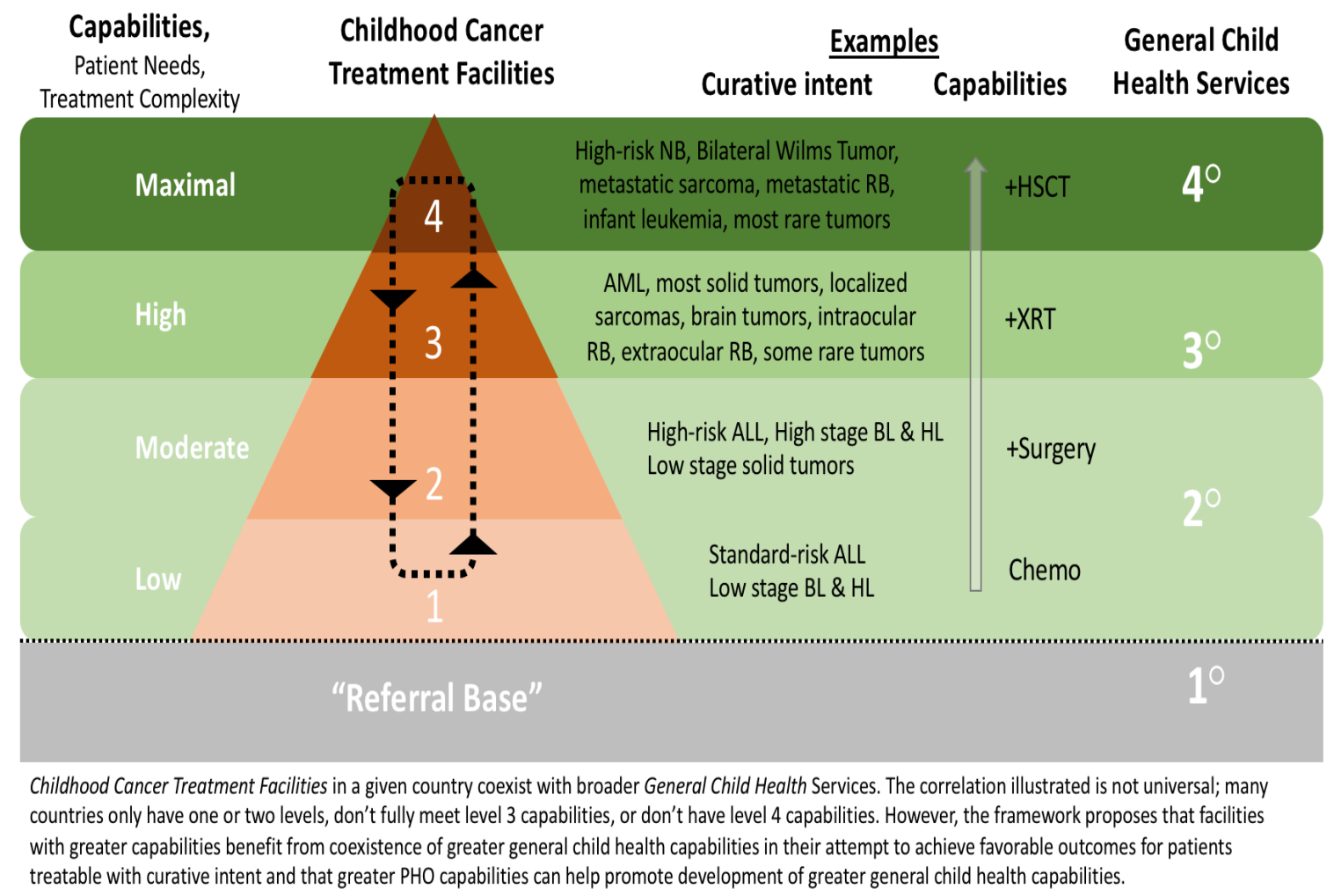

Through the Delphi process, the Commission also explored how networked models of care could be developed to facilitate access to best quality care possible within a health system, as proposed by other disciplines. ${ }^{164,165}$

Since most countries have more than one paediatric oncology facility and resources are always limited. Hence, there is strong argument for greater integration between facilities to strengthen health systems and ensure optimal delivery of equitable and patient-centered care. In countries with only one pediatric oncology care facility, improvements in health 
system can result from greater integration between paediatric oncology facilities and 'referral base' facilities.

\section{Alignment of scaling of services for childhood cancers with universal health coverage}

UHC is the top priority for WHO. ${ }^{166}$ Expansion of UHC offers a unique opportunity for LMICs to expand care for children with cancer. Funding for expansion of UHC will mainly come from domestic sources. In health systems that are funded predominantly from taxation, cancer care could be publicly funded from government health budget as part of the general health services, provided either by public providers or foundations.

In low-income countries, where there are fiscal space constraints, philanthropic funding and external financing through development assistance for health could be pooled and channeled to healthcare budgets to augment (but not displace) government funding. In countries where healthcare funding is a mixture of government funding and health insurance, publicly financed health insurance, funded through non-contributory schemes resources from the government budget, should be used to cover an essential benefits package that incorporates care for children with cancer. Children with cancer should be exempted from payment for care. This is crucial to ensure that the child's family is protected against financial risk.

The essential package of interventions and services for childhood cancer could be gradually expanded as financing and health system capabilities expand to extend UHC, and out-ofpocket payments are eliminated to provide financial risk protection and to stop the 
abandonment of treatment and care. It is important that essential package of interventions benefits all children equally. Research from Colombia suggests that disparities in mortality and 5-year survival in children with cancer persist even with UHC if the essential service packages differ for populations. Children who have access to greater healthcare benefits have better health outcomes compared to those with less benefits and those who are uninsured..$^{167}$

Incorporation of treatment and care for childhood cancers within essential benefits packages in health insurance funded systems, or as a core service in government-funded health systems, is a critically important step if the global expansion of childhood cancer services is to be achieved. This strategy of alignment and integration is fully aligned with the recommendations of the WHO Consultative Group on Equity and Universal Health Coverage. The recommendation of this group for the criteria to use in expanding UHC included cost-effectiveness, giving priority to the worse off, financial risk protection, eliminating out-of-pocket payments, and ensuring inclusion of priority groups. ${ }^{168}$

\section{Use of existing health system platforms to scale services for children with cancer}

Expansion of essential packages of interventions for children with cancer must be fully integrated within health system structures and use existing platforms. This defined in DCP3 as "logistically related delivery channels". 169

The Commission findings show that one of the major challenges in improving the management of childhood cancers on a global scale is interruption of care at various points 
along the care pathway, due to health system weaknesses and poor integration of care. Removing these barriers along the care pathway will require development of integrated care networks that seamlessly combine community-level services, health centres, first-level hospitals, and referral- and specialty-hospitals. These platforms for scale-up will enable the development of integrated care networks for the management of childhood cancers and help reduce interruptions of care in the care pathway. Such networks should also help to optimise use of available capacity for diagnostic imaging, surgery, radiotherapy, pathology and laboratory medicine services, infection control, transfusion services, and palliative care, which is particularly lacking in most LMICs. ${ }^{170}$

\section{Developing human resource capacity for scale up}

The global shortage of health professionals, especially in LMICs, is one of the major barriers to expanding services for childhood cancers. Shortage of well-trained health professionals is also a major barrier to the effective and safe operation of available capacity. New approaches are needed to meet these shortfalls in human resources.

The exact workforce needs will vary, depending on the current burden of cancer, the distribution of healthcare providers, the accessibility of alternative care settings, public demand and expectations and utilisation of different levels. The Commission considered, through the Delphi process, a 'reasonably achievable' target in LMICs for the number of newly diagnosed paediatric cancer patients that could be cared for each year by a physician with specific training for management of childhood cancer. The consensus for a reasonable number was 50 (approximately one new patient per week). Many respondents provided 
current examples from LMICs that in practice the current ratio staffing is typically more than 100 new children with cancer diagnosed per physician each year and that multidisciplinary teams were lacking.

The Commission strongly noted the need to develop multidisciplinary teams and specialised training for the health workforce dedicated to providing childhood cancer care (appendix pp. 41-44).

Workforce needs may be different in some settings where only a few cancer types are treated. For example, treatment of childhood leukemia may not require complex surgical services. Initial management of two-third of patients with solid malignancies, including highly curable conditions such as Wilms tumours, is feasible even in resource-limited settings. ${ }^{171,172}$ However, more advanced capabilities are needed for the management of some solid tumours, with investment in essential surgical services and pathology services. ${ }^{173,174}$

While rapid expansion in the numbers of health professionals in the near future is not realistic, given resource constraints, a multi-pronged approach could help expand the capacity needed to provide health services with optimal use of the health workforce.

The first of these approaches is 'task-sharing', which have been effectively used in LMICs to engage a broader group of health professionals in the provision of effective healthcare services, ${ }^{175,176}$ including for children, ${ }^{177}$ with improvements in efficiency and cost 
savings ${ }^{178}$. The second is the use of new mobile technologies to improve care management, ${ }^{179}$ communicate results, ${ }^{180}$ improve attendance at clinics, ${ }^{181}$ and improve patient self-management for long-term illnesses ${ }^{182}$. The third is the development of novel competency-based curricula, which use distance learning, e-learning and mobile digital education for undergraduate, postgraduate and in-service training of health professionals to enable. This can rapidly enable low-cost, efficient and effective development of a large pool of trained health professionals. ${ }^{183,184}$ The fourth element of a multi-pronged human resource development approach is to introduce incremental licensing, in which gradual upgrades of responsibilities and competence are underpinned by on-the-job training and professional development, with appropriate increases in incentives and rewards.

\section{Innovations in service delivery to scale services for children with cancer}

Integration of childhood cancer services with existing service delivery platforms should be accompanied with innovations to develop new healthcare service models relevant to LMICs. Effective integration and reduction of service duplication could help overcome resource shortages, particularly for human resources which is a major hindrance to expansion of cancer services, remove barriers to efficient and effective care delivery, and help accelerate adoption of existing and new technologies. Integration of strengthened childhood cancer services within the health system can also create positive synergies to improve other services, such as haematology, pathology laboratory medicine, and infection control, by enhancing quality. 
When developing innovative service delivery LMICs do not necessarily need to replicate models of care from high-income countries, which are based on narrow specialists and expert-led systems and have evolved over many decades. Instead, there is an opportunity to learn from innovative delivery models developed in LMICs for managing chronic conditions ${ }^{185}$, HIV ${ }^{186,187}$ and tuberculosis ${ }^{188,189}$. These innovative service delivery models have emphasised the simplification of care, decentralisation of care to primary health centres and communities with strong reliance on a non-physician health workforce (including nurses and community health workers), community involvement, peer support and self-management ${ }^{190}$.

\section{Financing for global scale up of healthcare for childhood cancer}

Global financing is needed to catalyse the response for addressing the childhood cancer burden and for the production of global public goods, such as internationally accepted but contextually-sensitive guidelines for diagnosis, treatment and care; research for the development of effective and efficient care delivery models that coordinate affordable diagnostics, surgery, radiotherapy, medicines and palliative care; harmonized norms and standards for surveillance through development and strengthening of cancer registries in all countries; and, global data for comparative analysis and shared learning. ${ }^{191}$

In most countries, domestic sources will provide most of the funding for scaling up services for better management of childhood cancers. The sources are most likely to be from public financing (government budget allocated to health, or health insurance), perhaps with complementary financing from health insurance. 
At country level, public financing for any sector, including health, is determined by the 'fiscal space' available to the government. ${ }^{192}$ Fiscal space is defined as "...the availability of budgetary room that allows a government to provide resources for a desired purpose without any prejudice to the sustainability of a government's financial position."193

Fiscal space depends on the sources of finance available to a government from (i) improved economic growth that creates favourable macroeconomic conditions for government budget that could be allocated to health (ii) generation of revenues by strengthening tax administration in LMICs, where government revenues from tax are low, ranging from 10$15 \%$ of GDP compared to $30-40 \%$ for high income countries (iii) reprioritization of health within the government budget (iv) borrowing from domestic and international sources to invest in health (v) innovative domestic and international financing, and (vi) more effective and efficient allocation of available health resources. ${ }^{194,195}$

The funding for childhood cancer services and UHC will predominantly come from domestic sources of financing. Expansion of fiscal space for health is therefore critical for governments in LMICs, if the goals of scaling-up cancer services for children and UHC are to be achieved. Each of the six avenues discussed above offers potential for expanding the fiscal space to enable greater investment in health, especially economic growth, new taxes, innovative financing and reduced waste in health systems. We discuss these briefly. 
(i) Improved economic growth: according to the International Monetary Fund (IMF), LMICs are projected to achieve economic growth between 2020 and 2025,196 with potential to expand the fiscal space for health. Estimates suggest that in 2015-40, continued growth of GDP, improved government revenues and expanded government spending on health could help increase per capita health by 5.3\% (UI 4.1-6.8) each year in upper-middleincome countries, $4.2 \%$ (UI 3.8-4.9) in middle-income countries and 1.8\% (UI 1.0-2.8) in low-income countries. ${ }^{197}$

(ii) Generation of revenues by strengthening tax administration: Judicious increase in taxes is a potential source of government revenues to expand the fiscal space. In particular, increased taxes on tobacco and alcohol, which are highly cost-effective public policies, offer potentially large revenues for health. Egypt, the Philippines and Thailand have successfully used tobacco taxes to generate earmarked funding for the health sector. ${ }^{198}$

(iii) Reprioritization of health within government budget: Demonstration of health and economic benefits for health investments could provide the necessary evidence to persuade governments to increase investments in health.

(iv) Borrowing from domestic and international sources: Concessional financing with low interest rates and a generous grace period for repayments could be mobilised from international development banks to invest in health. For interventions that generate substantial health and economic benefits and positive return on investment, such as services for treating childhood cancers, borrowing is justified. 
(v) Innovative financing: A further potential source of new and additional funding for scaling up sustainable care for childhood cancers is innovative financing - funding mobilised from non-traditional mechanisms.

In 2002, the International Conference on Financing for Development in Monterrey, Mexico, identified innovative financing as a promising source of new and additional financing for global health. ${ }^{199}$ Since then, innovative financing mechanisms ${ }^{200}$ (which link different elements of the financing value chain-namely, resource mobilisation, pooling, channelling, resource allocation, and implementation) and innovative financing instruments ${ }^{201}$ (used to mobilise funding) have enabled mobilisation and channeling of substantial funds for health programmes globally. Innovative financing (panel 8) could help augment funding from domestic sources to catalyse scale-up of services for childhood cancer.

\section{Panel 8: Innovative financing for funding investments in childhood cancers}

To date, three innovative financing mechanisms (which mobilise funding from multiple sources, and pool, allocate and channel these funds health programmes in LMICs) have reached a global scale, namely the Global Fund to Fight AIDS, Tuberculosis and Malaria (the Global Fund, established in 2002) ${ }^{202}$, GAVI (established in 2000) ${ }^{203}$, and Unitaid (established in 2006). ${ }^{204}$ By June 2019, the Global Fund had disbursed US\$ 41.4 billion for HIV/AIDS, tuberculosis, malaria and health systems, ${ }^{202}$ GAVI had disbursed US $\$ 13.4$ billion for vaccines by November 2018, ${ }^{203}$ and by 2017 UNITAID had invested more than US $\$ 2$ billion, in 
medicines, diagnostics and health products for HIV/AIDS, drug resistant tuberculosis, malaria, and Hepatitis $\mathrm{C}^{204}$.

Several innovative financing instruments have been developed to generate and mobilise funds totaling around US $\$ 8.9$ billion in $2002-15 .{ }^{201}$ For example, the Airline Solidarity Levy, ${ }^{201}$ which involves a small tax (levy) on airline tickets in participating countries, has generated regular funding for Unitaid. Financial transaction taxes ${ }^{205}$, introduced to reduce excessive speculation in financial markets, are potentially large source of innovative financing. Countries, such as South Korea, India, Brazil, Taiwan, South Africa and Switzerland have already introduced a financial transaction tax to generate general tax revenues.

Long-term pledges by donors have been used as security to issue bonds in capital markets. The International Finance Facility for Immunisation, established in 2006, has successfully mobilised donor pledges to launch immunization bonds, and to channel $\$ 6$ billion in 200618 to Gavi to accelerate introduction of new vaccines and expand immunization programmes in LMICs. ${ }^{206}$

Debt conversion has been used to convert loans to grants with conditions of meeting a health or social target. For example, with Debt2Health, a creditor country forgoes a portion of a debt on the condition that the debtor country invests an agreed counterpart amount by contributing to the Global Fund according to a schedule established as a part of a debt swap agreement which is then provided as a grant to expand national health programs.$^{207}$ 
The Affordable Medicines Facility for Malaria (AMFm) 208,209 has pooled donor funds and negotiated with drug manufacturers price reductions for malaria medicines in return for predictable and increased volumes of medicines purchased by countries funded by the Global Fund. AMFm then funded both public and private sector institutions to make available to the public affordable and effective malaria medicines and displace less-effective treatments from the market. 210,211

Similarly, the Advanced Market Commitments Pilot for Pneumococcal Disease ${ }^{210}$ used donor funding or pledges to establish legally-binding long-term purchase commitments for new vaccines for diseases affecting children in LMIC at pre-negotiated prices and predictable volumes for purchasing vaccines.

A promising funding instrument is a Social Impact Bond, which is created by a government agency that wishes to achieve a desired social or health outcome. ${ }^{211}$ The agency engages an external organization to achieve the outcome. A third-party investor provides upfront working capital to the external organization as an at-risk investment. If the desired social outcome is achieved, the government releases payment to the external organization, based on terms specified in an upfront contract, which repays its investors their principal, plus a return on the investment. If the outcome is not met, the government disburses no payment. A Development Impact Bond is a variation on the social impact bond, where the payment comes from an external funder (e.g. a development agency or a charitable foundation), rather than a government. ${ }^{212}$ 
(vi) More effective and efficient allocation of available health resources: The World Health Organisation has estimated that worldwide around $20-40 \%$ of all health spending in health systems is not used efficiently or effectively. ${ }^{213}$ With priority setting, which enables more efficient allocation of resources, governments could use the available fiscal space more optimally. The potential savings are substantial. This could help release funds for investing in scale-up of services for childhood cancers. 


\section{SECTION 6: SUSTAINABLE CARE FOR CHILDHOOD CANCERS: MAKING IT HAPPEN}

The Commission has presented compelling evidence to show the large burden of cancer in children, poor access to care in countries where those services are most needed, and wide inequities in outcome. It also identified real opportunities to address the childhood cancer burden globally, through cost-effective interventions and strengthened health systems that could prevent needless deaths and realise very substantial health gains, at the same time as generating substantial economic benefits.

We explore in this section critical success factors with stakeholder roles that could help translate these solutions into actions, and to realise the vision of scaling up effective and sustainable healthcare for children with cancer.

\section{Critical success factors for scaling up childhood cancer interventions}

The challenges and opportunities in the global fight against cancer and critical success factors have been discussed in multiple fora. ${ }^{214}$

The first critical success factor is strong global and country-level leadership, which is currently lacking for childhood cancers. This is currently lacking for childhood cancers. There is a need for more visible commitment and funding from the UN and international development agencies, as well as global and country level leaders to halt a very large number of needless deaths from childhood cancer. The recent WHO Global Initiative for Childhood Cancer $^{39}$ is commendable. It could mark the beginning of a global movement to 
raise awareness among international agencies and governments about the importance of addressing the problem of childhood cancer and advocate for strengthening health systems to provide optimal and sustainable care for children with cancer. Given the magnitude of the problem, however, much more needs to be done. A recent study which re-examined the ranking of cancer burden suggest childhood cancers rank sixth globally in terms of total number of DALYs after cancers of the lung, liver, stomach, colon and rectum, and breast, with greater burden than cancers of oesophagus, pancreas, and cervix. ${ }^{215}$ Despite this, the attention childhood cancers receive in the global health agenda is vanishingly small.

The second critical success factor relates to the development of a clear narrative for childhood cancers - a narrative that communicates a clear sense of urgency and ambition, and articulates a clear sense of mission, hope and actions to achieve success. Globally, there is a lack of awareness of the true burden of childhood cancer, the burgeoning inequities, the extent of the crisis, and the availability of solutions that would produce great health and economic returns. Instead, the cancer narrative is clouded by myths that it is 'complex', 'expensive', 'difficult to diagnose', 'complicated to treat', and the narrative on childhood cancers is drowned by the broader discourse on non-communicable diseases that focuses almost entirely on adults.

The third critical success factor is the creation of a diverse and inclusive global social movement that brings together a coalition of partnerships and networks, involving civil society, affected individuals and communities, health professionals, researchers, funders, international agencies, private sector, and innovators. Instead, the global efforts for 
childhood cancer are highly fragmented, with no clear overarching global strategy, and characterised by a multitude of twinning relationships, which usually remain at project level. The fragmentation is compounded by the many short-term initiatives, which morph into one-off 'pilot projects', but fail to seriously address the needs of children with cancer. The fragmented landscape needs to change. It should be replaced by an inclusive, strategic, and large-scale global response to address the large burden of childhood cancer. In particular, the empowerment of civil society, communities and people will be critical for galvanizing locally-led effective response and sustained change.

The fourth critical success factor relates to alignment. Scale -up of services for children with cancer should capitalise on the global momentum for achieving SDGs, and in particular UHC. In particular, it is critical to ensure that scale-up of services for childhood cancer are fully integrated with actions to strengthen health systems. This alignment will enable more optimal use of available resources, enable provision of better services, and help with sustainability of scale-up.

The fifth critical success factor is innovation - with investment in research, development and translation to develop technology-enabled service delivery models for providing care to children with cancer. Innovation is critical to rapidly address gaps in human resources, infrastructure, diagnostics, treatment, care and data, and generate local solutions for global ambitions and shared priorities. 


\section{A global coalition for childhood cancers}

A multisectoral global coalition of partnerships and networks is critical for the development of a rapid and impactful response for effectively addressing childhood cancers at global and country level. This partnership should be inclusive and involve governments, civil society, affected individuals, groups and communities, health professionals, professional associations, researchers, funders, international agencies, the private sector and innovators. Each of these actors has a role to play. Each brings strengths and capabilities that could be harnessed to create synergies for expanding access to care for children with cancer, in order to reduce inequities and improve outcomes (panel 9).

\section{Panel 9: Multisectoral collaboration and partnership to develop an effective response for childhood cancers}

Governments

Governments can provide leadership, by convening and empowering stakeholders to catalyse a coordinated multisectoral response for effective management of childhood cancers.. Governments make political and fiscal decisions to allocate resources to priority areas and invest in health in order to meet current and emerging health needs and ensure wellbeing of their citizens. Governments have the opportunity to use the evidence generated by the Commission to invest in the expansion of services for childhood cancers as part of UHC, to improve health and wellbeing of children, and help generate substantial economic returns for communities and countries.

International Organizations 
As with governments, international organizations can play a convening role to develop multisectoral responses at global and country level with meaningful targets, establish guidance on incorporating appropriate services and cost-effective interventions as part of UHC expansion in countries, and help mobilise sustainable funding. Childhood cancers have not featured prominently in the global discussions on financing and prioritisation of health challenges. For example, the Global NCD Action Plan for the Prevention and Control of NCDs 2013-2020 does not mention childhood cancers as a priority area, nor does it have any targets specific to childhood cancer. ${ }^{216}$ Similarly, the SDG 3 target 3.4, "by 2030 reduce by one-third pre-mature mortality from non-communicable diseases (NCDs) through prevention and treatment, and promote mental health and wellbeing", has no indicators specific to childhood cancer. ${ }^{217}$ Nor do the WHO 'Best Buys” for NCDs, which comprise 88 cost-effective interventions and policy actions, have any interventions specifically aimed at childhood cancers. ${ }^{218}$

Childhood cancer has been increasingly embedded into WHO priority activities on cancer following the mandate of the 2017 World Health Assembly resolution. ${ }^{38}$ In September 2018 WHO announced the launch of WHO Global Initiative for Childhood Cancer, which aims to double the global cure rate for children with cancer, improving average 5-year survival of the six commonest childhood cancers (namely, acute lymphoblastic leukaemia, Hodgkin lymphoma, Wilms tumour, Retinoblastoma, Low Grade Glioma and Burkitt lymphoma) to $60 \%$ by 2030 , and to save one million lives. ${ }^{39}$ However, targets need to be revised in the light of the new modelling and estimates developed by the Commission which indicates 
substantial underreporting of childhood cancers in LMICs, where one in two cases of new cases of childhood cancer are missed.

The International Atomic Energy Agency (IAEA) (https://www.iaea.org) has played an important role in expanding worldwide access to radiotherapy and nuclear medicine. Through its Programme of Action for Cancer Therapy (PACT) ${ }^{219}$ IAEA is working with UN Member States to reduce global inequities in cancer care ${ }^{220}$, and with WHO and the International Agency for Research on Cancer (IARC https://www.iarc.fr ) has undertaken imPACT reviews ${ }^{221}$ in around 100 countries. These reviews assess country capacity, identify priority interventions to address current and future needs for cancer and future work needed to support countries in developing national cancer control plans, strengthen cancer registries, identify funding and improve cancer services.

Stronger cancer registries are critical for estimating the true burden of childhood cancers. IARC is working with countries to develop and strengthen cancer registries, and to establish standardized methods to better measure the incidence, and mortality for childhood cancers. The registry data collated by IARC for use in its analyses, publications and in the Global Cancer Observatory ${ }^{222}$ should be publicly available to stimulate the development of innovative methods of measurement and comparison. These data will underpin the development and implementation of monitoring accountability frameworks to measure regularly and compare country-by-country progress in expanding access to high-quality diagnosis, treatment and care, for children's cancers. 


\begin{abstract}
Civil Society
Concerted action and advocacy from civil society has been instrumental in catalysing global movements, such as that for AIDS, which led to the convening of the UN General Assembly special session in 2001 and the UN Declaration on AIDS. ${ }^{223}$ In addition to bringing a voice for affected children, families and communities, mobilising support and building awareness at country level, civil society can help accelerate capacity development and programme implementation, and hold governments to account.
\end{abstract}

Civil society can help shape the narrative on childhood cancers to frame childhood cancer as an integral part of global commitments to UHC and health rights to influence policy for expanding worldwide access to effective services for childhood cancers. There are good examples of civil society initiatives that are providing a voice for childhood cancers. For example, Childhood Cancer International (https://www.childhoodcancerinternational.org), which is a global, parent-driven, not-for-profit entity for grassroots and national parent support organizations for childhood cancer. It represents 188 parent organizations, childhood cancer survivor associations, childhood cancer support groups and cancer societies in 96 countries. The Union for International Cancer Control (UICC) (https://www.uicc.org) has played an increasingly important global advocacy and leadership role in strengthening the global response to cancer by bringing together more than 1,000 non-governmental organizations involved in cancer, mobilising global leaders at the World Cancer Summit, and by updating the World Cancer Declaration with a call to action to reduce the global cancer burden. ${ }^{224}$ 


\begin{abstract}
Professional Associations
Professional associations play an important role in establishing professional standards, developing capacity and expanding access to high-quality healthcare services for children with cancer. For example, the International Society of Paediatric Oncology (SIOP; https://siop-online.org), which has affiliated societies in different regions of the world such as SIOP-Africa, SIOP-Asia, SIOP-Oceania and the Latin American Pediatric Oncology Group (GALOP), as well as International Society of Pediatric Surgical Oncology (IPSO https://ipsoonline.org) is working with international and country-level partners to develop muchneeded human resource capacity through education and training to expand services in LMICs. Professional associations have also helped to establish or strengthen regional collaborations to raise the level of available expertise in LMICs through shared resources to improve care and outcomes for children with cancer (appendix pp. 45-48) - platforms which could further advance management of children with cancer in low-resource settings.
\end{abstract}

\title{
Philanthropic Organizations and Academic Cancer Centers
}

In LMICs, philanthropic organisations have played an instrumental role in mobilising donations and public funding to establish centres to care for children with cancer. These centres, which have established twinning arrangements with cancer centres in high-income countries, provide high quality services to those who are fortunate enough to access these services (Section 2). There is an opportunity in LMICs to operationally better integrate the centres involved in twinning activities with existing cancer networks and health systems. Such integration will help to create synergies to more optimally expand access to care for children with cancer. 


\section{The private sector}

The private for-profit sector has played an important role in expanding services for children with cancer, but generally for the few who can afford to pay for the services. However, in many LMICs, the private for-profit healthcare provider sector is not well regulated, and there are no data on the quality of services provided or the outcomes achieved. The private sector is a major funder of research and development for diagnostics, medicines and health technologies for management of cancer in children, but mostly for high-income and middle-income countries, where profitable markets exist. Public-private collaborations could help develop affordable solutions for countries that need them.

Wide-ranging activities by many committed stakeholders have generated an extensive collection of initiatives for childhood cancers to grow capacity, increase know-how and establish research and service-delivery platforms to benefit those able to access them. However, many of these initiatives have remained as projects and have not always produced noticeable differences in access to cancer services for all children or have had an equitable impact on cancer outcomes at population-level. Despite these shortcomings, these initiatives, which have helped, provide valuable lessons for scale-up of services for childhood cancers. They can be used as a foundation for scale-up of effective care for children for cancer. ${ }^{225}$ Hence, it is an imperative to better coordinate and combine global activities of international agencies, professional associations, civil society, foundations and the private sector in order to expand worldwide access to care, reduce inequities and improve outcomes for children with cancer. 


\section{SECTION 7: A CALL TO ACTION}

We present, for the first time, new estimates that quantify country-specific and worldwide incidence, mortality and survival for childhood cancers. We also provide new estimates for the coverage of healthcare services for childhood cancers. The results point to worldwide inequities and a stark picture for children with cancer in LMICs. Yet, childhood cancer is not complex, expensive, difficult to diagnose, or complicated to treat.

There will be an estimated 413,000 incident cases of childhood cancer worldwide in 2020, but 181,000 of these cases, almost one half, will go undiagnosed. We estimate that globally there will be 13.7 million cases of childhood cancer between 2020 and 2050, of whom around 3.4 million will be in low-income countries, and an estimated 6.9 million in lowermiddle-income countries. Our projections show that at current levels of health system performance (access and referral), 6.1 million cases, accounting for $44.9 \%$ of total cases of childhood cancers during 2020 to 2050, will not even be undiagnosed. In low-income and lower-middle income countries, the number of children with cancer who are never diagnosed will exceed the number of those who are diagnosed.

In 2020, there would be 328,000 deaths from childhood cancers globally, projected to rise to 390,000 by 2050 . The largest number of deaths is projected to be in lower-middleincome countries, reaching 208,000 in 2050 , but the largest proportionate increase is projected to be in low-income countries, rising from 82,000 to 128,000 . Unaddressed, we 
estimate that between 2020 and 2050, cumulatively, 11,108,000 children will die from childhood cancer if no additional investments are made to improve access to healthcare services or childhood cancer treatment. Of these a staggering 9,344,000 children, accounting for $84.1 \%$ of children who die from cancer, will be in low-income and lowermiddle-income countries.

As with incidence and mortality, there are substantial variations in 5-year net survival between countries by World Bank income group. While in 2015-2019 average global 5year net survival was $37.4 \%$, it ranged from $11.6 \%$ in Africa to $83.0 \%$ in North America. There was a huge difference in the modelled estimates of 5-year net survival for all cancers combined, from $7.4 \%$ estimated for low-income countries to $79.8 \%$ in high-income countries.

There is very substantial underreporting of childhood cancers in LMICs, where one in two cases of new cases of childhood cancer are missed. Our findings indicate that the targets set by the Global Initiative for Childhood Cancer to double the global cure rate for children with cancer, to improve globally the 5 -year survival from childhood cancers to $60 \%$ by 2030 and to save one million lives ${ }^{39}$, need to be revised

However, our results also show that this burden can be largely addressed with new and additional funding for the application and scale-up of interventions, which are known to be cost-effective. 
There are substantial health and economic benefits of investing in interventions to effectively manage childhood cancers. Simultaneous comprehensive scale up of interventions could avert 6,235,086 deaths in children with cancer in 2020 to 2050 , representing more than half (56.1\%) of the total number of deaths otherwise projected to occur. With excess mortality risk taken into account, this reduction in the number of deaths is projected to produce undiscounted 318.4 million life-years gained.

A with health benefits, the economic benefits of Comprehensive Scale-up are substantial. Cumulative productivity gains would exceed the cumulative costs in lower-middle income countries, middle-income countries and high-income countries in the period 2020 to 2050, and beyond 2050 for low-income countries. The global lifetime productivity gains of $\$ 2,580$ billion in 2020 to 2050 would be four-times greater than the cumulative treatment costs of $\$ 594.4$ billion, producing a net benefit of $\$ 1,986.1$ billion on the global investment. This would represent a net return of $\$ 3$ for every $\$ 1$ invested.

For all country income groups, the overall lifetime productivity gains would exceed cumulative treatment costs to generate very substantial net benefits and a positive return on investment.

We provide compelling new evidence that investment for comprehensive scale-up of interventions not only enables treatment of children with cancer worldwide to avert more than 6 million deaths, save in excess of 300 million life years, but also brings almost $\$ 2$ trillion in positive economic benefits. 
Our findings also suggest that successful implementation of effective childhood cancer services is feasible, even in low-income countries to achieve the goal of improving outcomes for children with cancer.

We propose six major actions, with targets to achieve this important goal.

Action 1: incorporate childhood cancers in essential benefits packages when expanding universal health coverage

Care for childhood cancers must be incorporated into national essential benefits packages when expanding UHC, with explicit targets for comprehensive scale-up of capacity in health systems to expand the coverage of effective services for childhood cancers.

Target: by 2030, as part of the efforts to expand UHC, at least $80 \%$ of LMICs should incorporate appropriate level of effective services for childhood cancers in their essential benefits packages and ensure their financing and provision to expand access to all children with cancer in their country.

Action 2: develop national cancer control plans and provide predictable financing to ensure expansion of sustainable care for children with cancer

Predictable financing is critical for comprehensive scale-up, both for sustaining services and for preventing interruptions to care. Countries of low-income and middle-income should develop fully costed national cancer plans that articulate how sustainable cancer care for children could be progressively developed and funded. 
Target: By 2030 at least $80 \%$ of LMICs should have national cancer control plans that articulate specific actions and targets for achieving sustainable care for children with cancer, with defined processes for creating the necessary fiscal space for funding this.

\section{Action 3: eliminate out-of-pocket expenditures for children with cancer to halt catastrophic expenditures and abandonment of treatment}

Countries should eliminate co-payments and out-of-pocket expenditures for direct and indirect costs incurred by children with cancer when they are receiving care to prevent catastrophic expenditures and to eliminate treatment abandonment. Countries should also work with partners, such as local NGOs and foundations, to address needs of children and their families beyond direct cancer services (including transportation, housing and meals), especially for vulnerable families where these unmet needs contribute to treatment abandonment risk.

Target: At least $80 \%$ of LMICs should eliminate out-of-pocket expenditures for children's cancer services by 2030 .

\section{Action 4: expand access to effective services for childhood cancers by establishing cancer networks}

We urge immediate action in all LMICs to create national and regional cancer networks or expand them where they exist, in order to establish appropriate capacity for providing packages of effective services based on evidence-based guidelines to at least $80 \%$ of children with cancer. 
Target: by 2030, increase the capacity of human resources, diagnostics, treatment, surgery, radiotherapy and social support in LMICs to expand coverage of effective services and palliative care to $80 \%$ of children with cancer, and pain control to $100 \%$ of children with cancer.

\section{Action 5: invest in the development of cancer registries that incorporate childhood}

\section{cancers}

Data and evidence are important for guiding country priorities and actions to address childhood cancers. Yet, reliable data on childhood cancers are all but absent in LMICs. Population-based cancer registries are essential for quantifying the determinants, the incidence and survival for cancer in children. To estimate survival, cancer registries must also be able to link their tumour registrations to national or regional databases of deaths from any cause on a routine basis. Efficient vital statistics systems on births, deaths and populations are also required.

Target: by 2030 , at least $80 \%$ of LMICs should establish data systems and population based cancer registries, with the requisite legislative and financial support, to collect data on childhood cancers, including incidence, stage and survival, and to link their data routinely with data on all deaths.

\section{Action 6: invest in research, development and innovation}

Currently, research funding related to childhood cancers is small, highly fragmented and largely inaccessible to researchers outside high-income countries. Lack of available solutions, suboptimal care and the absence of affordable interventions hinder the 
achievement of health outcomes for children with cancer. Investments in research infrastructure, research based in LMICs, and innovation is needed to expand the use of available interventions. This will help create affordable and accessible solutions, to translate research outputs into scalable and impactful solutions for children with cancer, but importantly to develop novel innovative service delivery models that are appropriate for LMICs and do not necessarily replicate models of care from high-income countries. Target: The United Nations should spearhead the establishment of a global coalition to achieve the goal of sustainable care and an 'Innovation Fund for Childhood Cancer'. This fund should have the mission to pool and improve coordination of disparate funding streams, and to fund research and innovation in LMICs, with a target of mobilising $\$ 100$ million per year. In particular the funding should be used for the development of affordable solutions for children with cancer in LMICs, implementation studies, and multicentre prospective studies to elucidate effect of treatment in different contexts with varying socio-economic and genetic backgrounds.

No one can doubt the huge challenges that many countries face in relation to childhood cancer. However, the improved outcomes for childhood cancer achieved in many countries over the last five decades bring hope. The availability of cost-effective interventions, evidence for the feasibility of scaling up their application at a global level, and the compelling economic case for investment, for investment in improving the survival from childhood cancer, provide inspiration for further progress over the next generation. 
Success will be realised through political leadership, global solidarity, collective action, inclusive participation of all major stakeholders, and alignment of country-level and global efforts to expand access to effective and sustainable care for children with cancer.

Only then can all children who are diagnosed with cancer be able to enjoy equitable access to optimal care, better health, the chance to reach a fulfilling and productive adulthood, and the dignity that they deserve. 


\section{References}

${ }^{1}$ Farmer P, Frenk J, Knaul F, Shulman L, et al. Expansion of cancer care and control in countries of low and middle income. Lancet 2010; 376: 1186-93.

${ }^{2}$ Knaul FM, Gralow JR, Atun R, Bhedelia A. Bridging the cancer divide: an equity imperative. Harvard Global Equity Initiative, Harvard University. Distributed by Harvard University Press. Boston, USA; 2012.

${ }^{3}$ Allemani C, Matsuda T, Di Carlo V, et al: Global surveillance of trends in cancer survival 2000-14 (CONCORD-3): analysis of individual records for 37513025 patients diagnosed with one of 18 cancers from 322 population-based registries in 71 countries. Lancet 2018; 391:1023-1075.

${ }^{4}$ Shah A, Coleman MP. Increasing incidence of childhood leukaemia: a controversy re-examined. $\mathrm{Br}$ J Cancer 2007; 97: 1009-1012.

${ }^{5}$ Rodriguez-Galindo C, Friedrich P, Alcasabas P, et al. Toward the cure of all children with cancer through collaborative efforts: pediatric oncology as a global challenge. J Clin Oncol 2015; 33(27): 3065-73.

6 Wilson ML, Atun R, DeStigter K, et al; Commissioners of The Lancet Commission on diagnostics. Lancet 2019 May 18; 393 (10185):2018-2020.

${ }^{7}$ Cohen P, Friedrich P, Lam C, et al. Global access to essential medicines for childhood cancer: a cross-sectional survey. JGO 2019; 4: 1-11.

${ }^{8}$ Sullivan R, Alatise OI, Anderson BO, et al. Global cancer surgery: delivering safe, affordable, and timely cancer surgery. The Lancet Oncology 2015;16:1193-224

${ }_{9}^{9}$ Atun R, Jaffray DA, Barton MB, et al. Expanding global access to radiotherapy. Lancet Oncol 2015; 16: $1153-86$. 
10 Rodriguez-Romo L, Olaya Vargas A, Gupta S, Shalkow J, et al. Delivery of Paediatric Cancer Care in Mexico: A National Survey. J Glob Oncol. American Society of Clinical Oncology, June 2018;(4):1-12. doi:10.1200/JG0.17.00238)

${ }^{11}$ Friedrich P, Lam CG, Itriago E, Perez R, Ribeiro RC, Arora RS. Magnitude of treatment abandonment in childhood cancer. PLoS One 2015; 10: e0135230.

12 Israels T, Renner L, Hendricks M, Hesseling P, Howard S, Molyneux E. SIOP PODC: recommendations for supportive care of children with cancer in a low-income setting. Pediatr Blood Cancer 2013; 60: 899-904.

13 GBD 2015 Healthcare Access and Quality Collaborators. Healthcare Access and Quality Index based on mortality from causes amenable to personal health care in 195 countries and territories, 1990-2015: a novel analysis from the Global Burden of Disease Study 2015. Lancet 2017; 390: 23166.

${ }^{14}$ Howard SC, Zaidi A, Cao X, et al. The My Child Matters programme: effect of public-private partnerships on paediatric cancer care in low-income and middle-income countries. The Lancet Oncology 2018;19:e252-e66.

15 Rodriguez-Galindo C, Friedrich P, Morrissey L, Frazier L. Global challenges in pediatric oncology. Current Opinion in Pediatrics 2013;25:3-15 0.1097/MOP.0b013e32835c1cbe.

16 Leal-Leal CA, Dilliz-Nava H, Flores-Rojo M, Robles-Castro J. First contact physicians and retinoblastoma in Mexico. Pediatric Blood \& Cancer 2011;57:1109-12.

17 De Angelis C, Pacheco C, Lucchini G, et al. The experience in nNicaragua: childhood leukemia in low income countries-the main cause of late diagnosis may be "medical delay". Int J Pediatr 2012;2012:129707. Epub 2012 Feb 12. 
18 Gupta S, Yeh S, Martiniuk A, et al. The magnitude and predictors of abandonment of therapy in paediatric acute leukaemia in middle-income countries: a systematic review and meta-analysis. Eur J Cancer 2013 Jul;49(11):2555-64

${ }^{19}$ Seah T, Zhang C, Hilbert J, Prabha S, Gupta S. The magnitude and predictors of therapy abandonment in pediatric central nervous system tumors in low- and middle-income countries: Systematic review and meta-analysis. Pediatr Blood Cancer.2019;66:e27692.

${ }^{20}$ Friedrich P, Lam CG, Kaur G, Itriago E, Ribeiro RC, Arora RS. Determinants of Treatment Abandonment in Childhood Cancer: Results from a Global Survey. PLoS ONE 2016;11:e0163090. ${ }^{21}$ Friedrich P, Ortiz R, Fuentes S, et al. Barriers to effective treatment of pediatric solid tumors in middle-income countries: Can we make sense of the spectrum of nonbiologic factors that influence outcomes? Cancer 2014;120:112-25.

22 Israëls T, van de Wetering MD, Hesseling P, van Geloven N, Caron HN, Molyneux EM. Malnutrition and neutropenia in children treated for Burkitt lymphoma in Malawi. Pediatric Blood \& Cancer $2009 ; 53: 47-52$.

${ }^{23}$ Sala A, Rossi E, Antillon F, et al. Nutritional status at diagnosis is related to clinical outcomes in children and adolescents with cancer: A perspective from Central America. European Journal of Cancer 2012;48:243-52.

${ }^{24}$ Gupta S, Antillon FA, Bonilla M, et al. Treatment-related mortality in children with acute lymphoblastic leukemia in Central America. Cancer 2011;117:4788-95.

25 Gupta S, Bonilla M, Gamero M, Fuentes SL, Caniza M, Sung L. Microbiology and Mortality of Pediatric Febrile Neutropenia in El Salvador. Journal of Pediatric Hematology/Oncology $2011 ; 33: 276-80$ 
${ }^{26}$ Gupta S, Bonilla M, Valverde P, et al. Treatment-related mortality in children with acute myeloid leukaemia in Central America: Incidence, timing and predictors. European Journal of Cancer 2012;48:1363-9.

${ }^{27}$ Roberts DJ, Field S, Delaney M, Bates I. Problems and Approaches for Blood Transfusion in the Developing Countries. Hematology/oncology clinics of North America 2016;30:477-95.

28 Organization WH. Blood safety and availability.

http://wwwwhoint/mediacentre/factsheets/fs279/en/indexhtml. (accessed July 6, 2019)

${ }^{29}$ Ladas EJ, Marjerrison S, Arora B, et al. Traditional and Complementary Medicine in Pediatric Oncology and Low-Middle Income Countries: Recommendations from the International Society of Pediatric Oncology (SIOP), T\&CM Collaborative. Journal of the National Cancer Institute Monographs 2017;2017.

${ }^{30}$ Delgado E, Barfield RC, Baker JN, et al. Availability of palliative care services for children with cancer in economically diverse regions of the world. European Journal of Cancer 2010;46:2260-6.

31 Connor SR, Downing J, Marston J. Estimating the Global Need for Palliative Care for Children: A Cross-sectional Analysis. Journal of pain and symptom management 2017;53:171-7.

32 Knaul FM, Atun R, Farmer P, Frenk J. Seizing the opportunity to close the cancer divide. Lancet 2013; Published Online February 4, 2013.

33 Howitt P, Darzi A, Guang-Zhong Y, Ashrafian H, Atun R et al. Technologies for Global Health. Lancet 2012; 380(9840): 507-35.

34 Horton S, Gauvreau CL. Cancer in Low- and Middle-Income Countries: An Economic Overview. In: Disease Control Priorities (third edition): Volume 3, Cancer, edited by H. Gelband, P. Jha, R. Sankaranarayanan, S. Horton. Washington, DC: World Bank. http://dcp3.org/sites/default/files/chapters/DCP3\%20Cancer Ch\%2016.pdf (accessed June 1, 2019) 
35 Jamison DT, Alwan A, Mock CN, and others. Universal Health Coverage and Intersectorial Action for Health: Key Messages from Disease Control Priorities, 3rd Edition. The Lancet 2017. Published online 24 November, 2017.

${ }^{36}$ Jamison DT, Summers LH, Alleyne G, et al. Global health 2035: a world converging within a generation. Lancet 2013; 382: 1898-1955.

${ }^{37}$ United Nations. Sustainable development goals-goal 3: ensure healthy lives and promote wellbeing for all at all ages. New York: United Nations; 2017. http://www.un. org/sustainabledevelopment/health/ [accessed 2019 Apr 30]

${ }^{38}$ WHO. Seventieth World Health Assembly. Resolutions and Decisions. WHA70/2017/REC/1. Geneva, 2017. http://apps.who.int/gb/ebwha/pdf_files/WHA70-REC1/A70_2017_REC1en.pdf\#page=27 (accessed August 8, 2019)

39 WHO. Global Initiative for Childhood Cancer, https://www.who.int/cancer/childhoodcancer/en/ (accessed May 27, 2019)

40 Meheus F, Atun R, Ilbawi A. The role of health systems in addressing inequalities in access to cancer control. In: Reducing social inequalities in cancer: evidence and priorities for research / edited by S. Vaccarella, J. Lortet-Tieulent, R. Saracci, D.I. Conway, K. Straif, C.P. Wild. IARC Scientific Publications; 168. International Agency for Research on Cancer. WHO. Lyon, France; 2019. $\underline{\text { http://publications.iarc.fr/580 }}$

41 United Nations Population Division. World Population Prospects 2017. Data Query. https://population.un.org/wpp/DataQuery/ (accessed May 27, 2019)

42 Murray, Christopher J. L, Lopez, Alan D, World Health Organization, World Bank \& Harvard School of Public Health. (1996). The Global burden of disease: a comprehensive assessment of mortality and disability from diseases, injuries, and risk factors in 1990 and projected to 2020 : summary / 
edited by Christopher J. L. Murray, Alan D. Lopez. World Health

Organization. https://apps.who.int/iris/handle/10665/41864 (Accessed June 16 2019).

43 Bhakta N, Force LM, Allemani C, et al. Childhood cancer burden: a review of global estimates. Lancet Oncol 2019; 20: e42-53

${ }^{44}$ IICC-3. Steliarova-Foucher E, Colombet M, Ries LAG, et al: International incidence of childhood cancer, 2001-10: a population-based registry study. Lancet Oncology 2017; 18:719-731

45 WHO. International incidence of childhood cancer 3. 2018.

http://iicc.iarc.fr/results/comparative.php (accessed June 2, 2019).

46 Ferlay J, Soerjomataram I, Dikshit R, et al. Cancer incidence and mortality worldwide: sources, methods and major patterns in GLOBOCAN 2012. Int J Cancer 2015; 136: e359-86.

47 Global Burden of Disease Cancer Collaboration, Fitzmaurice C, Akinyemiju TF, et al. Global, regional, and national cancer incidence, mortality, years of life lost, years lived with disability, and disability adjusted life-years for 29 cancer groups, 1990 to 2016: a systematic analysis for the Global Burden of Disease study. JAMA Oncol 2018; published online June 2.

DOI:10.1001/jamaoncol.2018.2706.

48 Pohar Perme M, Stare J, Estève J. On estimation in relative survival. Biometrics 2012; 68: 113-20.

${ }^{49}$ Allemani C, Weir HK, Carreira H, et al. Global surveillance of cancer survival 1995-2009: analysis of individual data for 25676887 patients from 279 population-based registries in 67 countries (CONCORD-2). Lancet 2015; 385: 977-1010.

${ }^{50}$ Bonaventure A, Harewood R, Stiller CA, et al: Worldwide comparison of survival from childhood leukaemia for 1995-2009, by subtype, age, and sex (CONCORD-2): a population-based study of individual data for 89828 children from 198 registries in 53 countries. Lancet Haematology 2017; 4:e202-e217. 
51 Global Initiative for Cancer Registry Development. https://gicr.iarc.fr (accessed May 2, 2019)

52 IARC. Global Cancer Observatory (GLOBOCAN). https://gco.iarc.fr (accessed May 2, 2019)

53 IARC. Global Initiative for Cancer Registry Development (GICR). Making cancer data count. (n.d.). Retrieved June 10, 2019. http://gicr.iarc.fr/en/.

${ }^{54}$ Global Burden of Disease Cancer Collaboration. Fitzmaurice C, Allen C, et al. Global, Regional, and National Cancer Incidence, Mortality, Years of Life Lost, Years Lived With Disability, and DisabilityAdjusted Life-years for 32 Cancer Groups, 1990 to 2015: A Systematic Analysis for the Global Burden of Disease Study. JAMA Oncol 2017; 3(4): 524-48.

55 Ellis L, Belot A, Rachet B, Coleman MP. The mortality-to-incidence ratio is not a valid proxy for cancer survival. J Global Oncol 2019; 5: 1-9.

${ }^{56}$ Ward ZJ, Yeh JM, Bhakta N, Frazier AL, Atun R. Estimating the total incidence of global childhood cancer - a simulation-based analysis. Lancet Oncology 2019. Published Online February 26, 2019 http://dx.doi.org/10.1016/ S1470-2045(18)30909-4

57 The World Bank. World Bank Country and Lending Groups 2018. https://datahelpdesk.worldbank.org/knowledgebase/articles/906519 (accessed August 8, 2018)

${ }^{58}$ Ward ZJ, Yeh JM, Bhakta N, Frazier ALFabio Girardi F, Atun R. Global childhood cancer survival estimates and priority-setting - a simulation-based analysis. Lancet Oncology 2019. Published Online May 22, 2019 http://dx.doi.org/10.1016/S1470-2045(19)30273-6

59 WHO. Global Health Expenditure Database. Available at URL https://apps.who.int/nha/database (accessed June 14, 2019)

60 OECD Health Statistics 2018. http://www.oecd.org/els/health-systems/health-data.htm (accessed June 14, 2019 
${ }^{61}$ OECD. Development Finance Data. http://www.oecd.org/dac/financing-sustainabledevelopment/development-finance-data/ (accessed June 14, 2019) 62 World Health Organization. National cancer control programmes. https://www.who.int/cancer/nccp/en/(accessed July 1, 2019)

${ }^{63}$ WHO. World Health Assembly, 70. (2017). Cancer prevention and control in the context of an integrated approach.. http://www.who.int/iris/handle/10665/275676 (accessed July 1, 2019)

${ }^{64}$ Romero Y, Trapani D, Johnson S, et al. National cancer control plans: a global analysis. Lancet Oncol 2018; 19: e546-55. Published Online September 26, 2018 http://dx.doi.org/10.1016/ S14702045(18)30681-8

${ }^{65}$ Weaver MS, Yao AJ, Renner LA, Harif M, Lam CG. The prioritisation of paediatrics and palliative care in cancer control plans in Africa. Br J Cancer 112(12):1845-56, 2015. doi: 10.1038/bjc.2015.158 ${ }^{66}$ Sirohi B, Chalkidou K, Pramesh CS, et al. , Developing institutions for cancer care in low-income and middle-income countries: from cancer units to comprehensive cancer centres. Lancet Oncol 2018; 19: e395-406

${ }^{67}$ Goss PE, Strasser-Weippl K, Lee-Bychkovsky BL, et al. Challenges to effective cancer control in China, India, and Russia. Lancet Oncol 2014; 15: 489-538.

${ }^{68}$ Loucaides EM, Fitchett EJA, Sullivan R, Atun R. Global public and philanthropic investment in childhood cancer research: systematic analysis of research funding over nine years, 2008 - 2016. Lancet Oncology 2019

${ }^{69}$ ICRP Report 2005-08_International Cancer Research Partnership | Library. https://www.icrpartnership.org/library?nodeId=2 (accessed July 20, 2018). 
70 US Department of Health \& Human Services. The National Institutes of Health Estimates of Funding for Various Research, Condition, and Disease Categories. Table Published: April 2019 https://report.nih.gov/categorical spending.aspx (accessed Sept 18, 2019)

${ }^{71}$ Denburg AE, Ramirez A, Pavuliri S, et al. Political priority and pathways to scale-up of childhood cancer care in five nations. PLOS One 2019 Aug 19;14(8):e0221292. doi:

10.1371/journal.pone.0221292. eCollection 2019.

72 Maser B, Force LF, Friedrich P, et al. Paediatric Oncology System Integration Tool (POSIT) for Joint Analysis of the Performance of Childhood Cancer Programs and Health Systems. In Press 73 Ministerio de Salud. Plan Estrategico 2010-2014 Programa Nacional de Promoción de la Salud: Prevencion y Control de las Enfermedades Crónicas No Transmisibles [Internet]. San Salvador, El Salvador (2010). http://www.iccp-portal.org/system/files/plans. (accessed June 1, 2019)

74 Ministerio de Salud de El Salvador. Política Nacional de Atención Integral a Las Personas con Cáncer. San Salvador, El Salvador (2015). http://www.iccpportal.org/system/files/plans/politica cancer 0.pdf. (accessed June 1, 2019)

75 Fuentes-Alabi S, Bhakta N, Vasquez RF, Gupta S, Horton SE. The Cost and Cost-Effectiveness of Childhood Cancer Treatment in El Salvador, Central America: A report from the Childhood Cancer 2030 Network. Cancer 2018; 124(2): 391-397.

76 Ministerio de Salud de El Salvador. Política Nacional de Atención Integral a Las Personas con Cáncer. San Salvador, El Salvador (2015). Accessed 21April 2017. http://www.iccpportal.org/system/files/plans/politica cancer 0.pdf. (accessed June 1, 2019)

77 Ministerio de Salud Publica y Asistencia Social. Guia de Prevencion y Atencion Integral de Cancer. (2016) Guatemala, Guatemala. Accessed 20 May 2017. http://www.iccpportal.org/system/files/plans/GTM B5 GuiaCancer2016.pdf. (accessed June 1, 2019) 
${ }^{78}$ Ministerio de Salud Publica y Asistencia Social. Politica Nacional Contra El Cancer (Plan Nacional 2010-2015): Consejo Nacional de Lucha Contra El Cancer. (2010) Guatemala, Guatemala. Accessed 23 May 2017. http://www.iccpportal.org/system/files/plans/GTM B5 4POLITICAS\%20NACIONAL\%20CONTRA\%20EL\%20CÁNC ER.pdf. (accessed June 1, 2019)

${ }^{79}$ Ribeiro RC, Antillon F, Pedrosa F, Pui CH. Global pediatric oncology: Lessons from partnerships between high-income countries and low-to mid-income countries. J Clin Oncol 2016; 34(1): 53-61.

80 Lecciones JA. The global improvement of childhood cancer care in the Philippines. Cancer Control 2015; 138-144.

81 Ribeiro RC, Steliarova-Foucher E, Magrath I, et al. Baseline status of pediatric oncology care in ten low-income or mid-income countries receiving My Child Matters support: a descriptive study. Lancet Oncol 2008; 9: 721-729.

82 Ho BLC. Mapping of Medicine Entitlement Programs of the National Government. Medicines Transparence Alliance, World Health Organization, Geneva: 2015. http://apps.who.int/medicinedocs/documents/s21772en/s21772en.pdf. (accessed June 1, 2019) 83 World Health Organization. The Philippines health system review. Manila: WHO Regional Office for the Western Pacific, 2011. http://www.who.int/iris/handle/10665/207506 (accessed June 1, 2019)

${ }^{84}$ Ho BLC. Mapping of Medicine Entitlement Programs of the National Government. Medicines Transparence Alliance, World Health Organization, Geneva: 2015. http://apps.who.int/medicinedocs/documents/s21772en/s21772en.pdf. (accessed June 1, 2019) 
85 Philippine Health Insurance Corporation. Strengthening the implementation of the no balance billing policy. Philippine Health Insurance Corporation, 2017. Accessed 1 June 2017.:

https://www.philhealth.gov.ph/circulars/2017/circ2017-0006.pdf

${ }^{86}$ Senate of the Philippines. An Act institutionalizing national integrated cancer control and appropriating funds therefor. Congress of the Republic of the Philippines, 2017. S.B. No 1570. Accessed 1 June 2017. https://www.senate.gov.ph/lisdata/2660322877!.pdf.

${ }^{87}$ Sarin R. Indian National Cancer Control Programme: Setting sight on shifting targets. J Can Res Ther 2005; 1:240-8.

88 Jatia S, Prasad M, Paradkar A, Bhatia A, Narula G, Chinnaswamy G, Vora T, Gomle S, Sankaran H, Banavali S. Holistic support coupled with prospective tracking reduces abandonment in childhood cancers: A report from India. Pediatr Blood Cancer. 2019 Jun;66(6):e27716.

${ }^{89}$ Saleh K. The Health Sector in Ghana: A Comprehensive Assessment. Washington, DC: World Bank, 2013. DOI: 10.1596/978-0-8213-9599-8. Accessed 14 July 2017.

90 The National Health Insurance Authority. Benefits. NHIA, Government of Ghana, 2018. Accessed 20 July 2017. Retrieved from: http://www.nhis.gov.gh/benefits.aspx.

${ }^{91}$ Ghana Ministry of Health. National Cancer Plan: 2012-2016. July 2011. Accessed 18 July 2017.

Retrieved from: https://www.iccp-

portal.org/sites/default/files/plans/Cancer\%20Plan\%20Ghana\%202012-2016.pdf

92 Ghana Ministry of Health. Health Sector Medium Development Plan 2014-2017. October 2014. Accessed 1 July 2017. Retrieved from: http://www.moh.gov.gh/wpcontent/uploads/2016/02/2014-2017-Health-sector-medium-term-dev-plan.pdf. 
${ }^{93}$ Rodriguez-Galindo C, Friedrich P, Alcasabas P et al. Toward the cure of all children with cancer through collaborative efforts: Pediatric oncology as a global challenge. J Clin Oncol 2016; 33: 30653073.

94 Gupta S, Rivera-Luna R, Ribeiro RC, Howard SC. Pediatric oncology as the next global child health priority: the need for national childhood cancer strategies in low-and middle-income countries. PLoS Med 2014; 11(6): e1001656.

${ }^{95}$ Denburg AE, Wilson MG, Johnson S, Kutluk T, Torode J, Gupta S. Advancing the development of national childhood cancer care strategies in Latin America. Journal of Cancer Policy 2017; 12: 7-15.

${ }^{96}$ Salaverria C, Rosell N, Hernandez A, et al. Interventions targeting absences increase adherence and reduce abandonment of childhood cancer treatment in El Salvador. Pediatr Blood Cancer 2015; $62: 1609-15$

${ }_{97}$ Alvarez E, Seppa M, Rivas S, et al. Improvement in treatment abandonment in pediatric patients with cancer in Guatemala. Pediatr Blood Cancer 2017 Oct. Epub 2017 Apr 19

98 Jatia S, Prasad M, Paradkar A, et al. Holistic support coupled with prospective tracking reduces abandonment in childhood cancers: A report from India. Pediatr Blood Cancer. 2019 Jun;66(6):e27716. doi: 10.1002/pbc.27716. Epub 2019 Mar 22.

${ }^{99}$ Morrissey L, Lurvey M, Sullivan C, et al. Disparities in the delivery of pediatric oncology nursing care by country income classification: International survey results. Pediatr Blood Cancer. 2019 Jun;66(6):e27663. doi: 10.1002/pbc.27663. Epub 2019 Feb 20.

100 Day SW, Garcia J, Antillon F, et al. A sustainable model for pediatric oncology nursing education in low-income countries. Pediatric Blood \& Cancer 2012;58:163-6 
${ }^{101}$ McGoldrick SM, Mutyaba I, Adams SV, et al. Survival of children with endemic Burkitt lymphoma in a prospective clinical care project in Uganda. Pediatr Blood Cancer. 2019 Sep;66(9):e27813. doi: 10.1002/pbc.27813. Epub 2019 Jun 3.

102 Hesseling P, Molyneux E, Kamiza S, Israels T, Broadhead R. Endemic Burkitt lymphoma: a 28-day treatment schedule with cyclophosphamide and intrathecal methotrexate. Annals of Tropical Paediatrics: International Child Health 2009;29:29-34.

${ }^{103}$ Denburg AE, Laher N, Mutyaba I, et al. The cost effectiveness of treating Burkitt lymphoma in Uganda. Cancer. 2019 Jun 1;125(11):1918-1928.

${ }^{104}$ Rodriguez-Galindo C, Friedrich P, Alcasabas P, et al. Toward the Cure of All Children With Cancer Through Collaborative Efforts: Pediatric Oncology As a Global Challenge. Journal of Clinical Oncology 2015;33:3065-73.

105 Rodriguez-Galindo C, Friedrich P, Morrissey L, Frazier L. Global challenges in pediatric oncology. Current Opinion in Pediatrics 2013;25:3-15

106 Howard SC, Zaidi A, Cao X, et al. The My Child Matters programme: effect of public-private partnerships on paediatric cancer care in low-income and middle-income countries. Lancet Oncol. 2018 May;19(5):e252-e266.

107 Ribeiro RC, Steliarova-Foucher E, Magrath I, et al. Baseline status of paediatric oncology in ten low-income or mid- income countries receiving My Child Matters support: a descriptive study. Lancet Oncol. 2008; 9(8): 721-729.

108 Ribeiro RC. Impact of the Mexican government's System of Social Protection for Health, or Seguro Popular, on pediatric oncology outcomes. Pediatr Blood Cancer 2013; 60(2): 171-172. 109 Atun R. Transforming Turkey’s Health System — Lessons for Universal Coverage. N Engl J Med 2015; 373 (14): 1285-89. 
110 Atun R, Aydın S, Chakraborty S, et al. Universal health coverage in Turkey: enhancement of equity. Lancet 2013; 382: 65-99.

${ }^{111}$ Pui CH, Tang JY, Yang JJ, Chen SJ, Chen Z. International Collaboration to Save Children With Acute Lymphoblastic Leukemia. J Glob Oncol. 2019 May;5:1-2.

112 Chilean National Childhood Cancer Program.

https://www.paho.org/hq/index.php?option=com docman\&view=download\&category slug=child hood-cancer-working-group-meeting-2-3-feb-2017-9011\&alias=38150-chilean-national-

childhood-cancer-program-150\&Itemid=270\&lang=en (accessed August 8, 2019)

${ }^{113}$ Castellanos EM, Barrantes JC, Baez LF, Gamboa Y, Pena A, Alabi S, et al. A chemotherapy only therapeutic approach to pediatric Hodgkin lymphoma: AHOPCA LH 1999. Pediatr Blood Cancer 2014; 61(6): 997-1002.

${ }^{114}$ Navarrete M, Rossi E, Brivio E, Carrillo JM, Bonilla M, Vasquez RF, et al. Treatment of childhood acute lymphoblastic leukemia in Central America: A lower-middle income countries experience. Pediatr Blood Cancer 2014; 61: 803-809.

115 Gupta A, Kapoor G, Jain S, Bajpai R. Absolute lymphocyte count recovery independently predicts outcome in childhood acte lymphoblastic leukemia: Experience from a tertiary care center of a developing country. J Pediatr Hematol Oncol 2015; 37(3): e143-149.

116 Gao YJ, Qian XW, Lu FJ, Zhai XW, Wang HS, Li J. Improved outcome for children with non high risk actue lymphoblastic leukemia after using an ALL IC-BFM 2002-based protocol in Shanghai, China. Br J Haematol 2012; 160(3): 363-367.

117 Traore F, Coze C, Atteby JJ, Andre N, Moreira C, Doubme P, et al. Cyclophosphomide monotherapy in children with Burkitt lymphoma: a study fromt eh French-African Pediatric Oncology Group (GFAOP). Pediatr Blood Cancer 2011; 56(1): 70-76. 
118 Ngoma T, Adde M, Durosinmi M, Githang'a J, Aken'Ova Y, Kaijage J, et al. Treatment of Burkitt lymphoma in equatorial Africa using asimple three-drug combination followed by a salvage regimenfor patients with persistent or recurrent disease. Br J Haematol 2012; 158: 749-762.

${ }^{119}$ Israels T, Borgstein E, Pidini D, Chagaluka G, de Kraker J, Kamiza S, et al. Management of children with a Wilms tumor in Malawi, sub-Saharan Africa. J Pediatr Hematol Oncol 2012; 34: 606-610.

${ }^{120}$ Howard SC, Pedrosa M, Lins M, et al. Establishment of a pediatric oncology program and outcomes of childhood acute lymphoblastic leukemia in a resource-poor area. JAMA. 2004; 291:2471-75. [PubMed: 15161898]

${ }^{121}$ Antillon F, Baez FL, Barr R, et al. AMOR: a proposed cooperative effort to improve outcomes of childhood cancer in Central America. Pediatr Blood Cancer. 2005; 45:107-10. [PubMed: 15806545]

${ }^{122}$ Hesseling P, Broadhead R, Mansvelt E, et al. The 2000 Burkitt lymphoma trial in Malawi. PediatrBlood Cancer. 2005; 44:245-50.

${ }^{123}$ Harif M, Barsaoui S, Benchekroun S, et al. Treatment of childhood cancer in Africa. Preliminary results of the French-African Paediatric Oncology Group. Arch Pediatr. 2005; 12:851-53. [PubMed: 15904826]

124 Magrath I, Shanta V, Advani S, et al. Treatment of acute lymphoblastic leukaemia in countries with limited resources; lessons from use of a single protocol in India over a twenty year period [corrected]. Eur J Cancer. 2005; 41:157-83.

125 Howard SC, Ribeiro RC, Pui CH. Strategies to improve outcomes of children with cancer in lowincome countries. Eur J Cancer. 2005; 41:1584-87. [PubMed: 15979305]

126 Bonilla M, Moreno N, Marina N, et al. Acute lymphoblastic leukemia in a developing country: preliminary results of a nonrandomized clinical trial in El Salvador. J Pediatr Hematol Oncol. 2000; 22:495-501. [PubMed: 11132215] 
${ }^{127}$ Masera G, Baez F, Biondi A, et al. North-South twinning in paediatric haematooncology: the La Mascota programme, Nicaragua. Lancet. 1998; 352:1923-26.

${ }^{128}$ Seidman G, Atun R. Aligning values and outcomes in priority-setting for health. J Glob Health. 2016 Dec;6(2):020308.

129 Daniels N, Sabin JE. Accountability for reasonableness: an update. BMJ. 2008;337:a1850. doi: 10.1136/bmj.a1850.

${ }^{130}$ Russell HV, Panchal J, Von Ville H, Franzini L, Swint JM. Economic Evaluation of Pediatric Cancer Treatment: A Systematic Literature Review. Pediatrics 2012; 131: e273-277.

${ }^{131}$ Bhakta N, Martiniuk ALC, Gupta S, Howard SC. The Cost-Effectiveness of Treating Paediatric Cancer in Low-Income and Middle-Income Countries: A Case-Study Approach using Acute Lymphocytic Leukaemia in Brazil and Burkitt Lymphoma in Malawi. Arch Dis Child 2013; 98(2): $155-160$.

${ }^{132}$ Hesseling PB, Broadhead R, Molyneux E, Borgstein E, Schneider JW, Louw M, et al. Malawi pilot study of Burkitt lymphoma treatment. Med Pediatr Oncol 2003; 41(6): 532-540.

133 Liu Y, Chen J, Tang J, Ni S, Xue H, Pan C. Cost of childhood acute lymphoblastic leukemia care in Shanghai, China. Pediatr Blood Cancer 2009; 53(4): 557-562.

${ }^{134}$ Luo XQ, Ke ZY, Huang LB, Guan XQ, Zhang YC, Zhang XL. Improved Outcome for Chinese Children with Acute Promyelocytic Leukemia: A Comparison of Two Protocols. Pediatr Blood Cancer 2009; 53: $325-328$.

135 Luo XQ, Ke ZY, Guan XQ, Zhang YC, Huang LB, Zhu J. The comparison of outocme and cost of three protocols for childhood non-high risk acute lymphoblastic leukemia in China. Pediatr Blood Cancer 2008; 51(2): 204-209. 
136 Stefan DC, Stones D. How much does it cost to treat children wtih Hodgkin lymphoma in Africa. Leuk Lymphoma 2009; 50(2): 196-199.

${ }^{137}$ Hendricks M, Davidson A, Pillay K, Desai F, Millar A. Carboplatin-based chemotherapy and surgery: a cost effective treatment strategy for malignant extracranial germ cell tumours in the developing world. Pediatr Blood Cancer 2011; 57(1): 172-174.

138 Ji X, Xuan Y, Li J, Zhao J, Lu S, Zhang J, et al. Direct costs for retinoblastoma treatment during the first year of comprehensive therapy in China. J Pediatr Ophthalmol Strabismus 2012; 49(6): 353358.

${ }^{139}$ Denburg AE, Laher N, Mutyaba I et al. The cost effectiveness of treating Burkitt lymphoma in Uganda. Cancer 2019; 125 (11); 1918-28.

140 Schrappe M, Reiter A, Zimmerman M, Harbott J, Ludwig WD, Henze G, et al. Long-term results of four consecutive trials in childhood ALL performed by the ALL-BFM study group from 1981 to 1995. Leukemia 2000; 14: 2205-2222.

141 Gaynon PS, Angiolillo A, Carroll WL, Nachman JB, Trigg ME, Sather H, et al. Long term results of the Children's Cancer Group studies for childhood acute lymphoblastic leukemia 1983-2002: a Children's Oncology Group Report. Leukemia 2010; 24(2): 285-297.

142 Miles RR, Arnold S, Cairo MS. Risk factors and treatment of childhood and adolescent Burkitt lymphoma/leukemia. Br J Haematol 2012; 156(6): 730-743.

143 Traore F, Coze C, Atteby JJ, Andre N, Moreira C, Doubme P, et al. Cyclophosphomide monotherapy in children with Burkitt lymphoma: a study fromt eh French-African Pediatric Oncology Group (GFAOP). Pediatr Blood Cancer 2011; 56(1): 70-76. 
144 Department of Information, Evidence and Research. WHO methods and data sources for life tables 1990-2016. Geneva: World Health Organization; 2018.

https://www.who.int/healthinfo/statistics/LT method.pdf (accessed June 19, 2019)

145 World Health Organization. Global Health Observatory data repository. 2018.

https://www.who.int/gho/en/ (accessed June 19, 2019)

${ }^{146}$ Armstrong GT, Chen Y, Yasui Y, Leisenring W, Gibson TM, Mertens AC, et al. Reduction in Late Mortality among 5-Year Survivors of Childhood Cancer. N Engl J Med. 2016; 374(9):833-42.

147 Yeh JM, Nekhlyudov L, Goldie SJ, Mertens AC, Diller L. A model-based estimate of cumulative excess mortality in survivors of childhood cancer. Ann Intern Med. 2010; 152(7):409-17, W131-8.

148 Rice D.P. Estimating the costs of illness. Am J Public Health 1967; 57: 424-440.

${ }^{149}$ Shillcutt SD, Walker DG, Goodman CA, Mills AJ. Cost effectiveness in low- and middle-income countries: a review of the debates surrounding decision rules. Pharmacoeconomics 2009; 27: 90317.

150 The World Bank. Age dependency ratio (\% of working-age population) https://datacatalog.worldbank.org/age-dependency-ratio-working-age-population-3 (accessed June 17, 2019)

151 WHO Commission on Macroeconomics and Health, World Health Organization. Macroeconomics and health: Investing in health for economic development. Report of the Commission on Macroeconomics and Health. World Health Organization 2001.

https://apps.who.int/iris/handle/10665/42435

(accessed June 17, 2019) 
152 International Monetary Fund. World Economic Outlook Database 2018.

https://www.imf.org/external/pubs/ft/weo/2018/02/weodata/index.aspx (accessed June $17,2019)$

153 Moucheraud C, Sparkes S, Nakamura Y, Gage A, Atun R, Bossert TJ. PEPFAR Investments In Governance And Health Systems Were One-Fifth Of Countries' Budgeted Funds, 2004-14. Health Aff (Millwood). 2016;35(5):847-55.

${ }^{154}$ Warren AE, Wyss K, Shakarishvili G, Atun R, de Savigny D. Global health initiative investments and health systems strengthening: a content analysis of global fund investments. Global Health 2013;9(1):30.

155 Howard SC, Davidson A, Luna-Fineman S, et al. A framework to develop adapted treatment regimens to manage pediatric cancer in low- and middle-income countries: The Pediatric Oncology in Developing Countries (PODC) Committee of the International Pediatric Oncology Society (SIOP). Pediatric blood \& cancer 2017;64 Suppl 5.

156 Anderson BO. Evidence-based methods to address disparities in global cancer control: the development of guidelines in Asia. The Lancet Oncology 2013;14:1154-5.

157 Yeoh AEJ, Tan D, Li C-K, Hori H, Tse E, Pui C-H. Management of adult and paediatric acute lymphoblastic leukaemia in Asia: resource-stratified guidelines from the Asian Oncology Summit 2013. The Lancet Oncology 2013;14:e508-e23.

${ }^{158}$ Lewin J, Puri A, Quek R, et al. Management of sarcoma in the Asia-Pacific region: resourcestratified guidelines. The Lancet Oncology 2013;14:e562-e70.

${ }^{159}$ American Academy of Pediatrics Committee on F, Newborn. Levels of neonatal care. Pediatrics 2012;130:587-97.

160 Hoyt DB, Coimbra R. Trauma systems. The Surgical clinics of North America 2007;87:21-35. 
161 Phibbs CS, Baker LC, Caughey AB, Danielsen B, Schmitt SK, Phibbs RH. Level and volume of neonatal intensive care and mortality in very-low-birth-weight infants. The New England journal of medicine 2007;356:2165-75.

162 Profit J, Gould JB, Bennett M, et al. The Association of Level of Care With NICU Quality. Pediatrics $2016 ; 137$.

${ }^{163}$ Schubert FD, Gabbe LJ, Bjurlin MA, Renson A. Differences in trauma mortality between ACS-verified and state-designated trauma centers in the US. Injury 2019;50:186-91.

${ }^{164}$ American Academy of Pediatrics Committee on F, Newborn. Levels of neonatal care. Pediatrics 2012;130:587-97.

165 Hoyt DB, Coimbra R. Trauma systems. The Surgical clinics of North America 2007;87:2135.

166 Ghebreyesus TA. All roads lead to universal health coverage. Lancet Glob Health. 2017; 5: e839e840.

167 Ramirez O, Aristizabal P, Zaidi A, Gagnepain-Lacheteau A, Ribeiro RC, Bravo LE. On behalf of VIGICANCER working group. Childhood cancer survival disparities in a universalized health system in Cali, Colombia. Pediatric Hematology Oncology Journal 2018; 3:79-87

168 WHO. Making fair choices on the path to universal health coverage. Final report of the WHO Consultative Group on Equity and Universal Health Coverage.

https://apps.who.int/iris/bitstream/handle/10665/112671/9789241507158 eng.pdf?sequence=

1 (Accessed June 18,2019)

169 Jamison DT, Alwan A, Mock CN, et al. Universal health coverage and intersectoral action for health: key messages from Disease Control Priorities, 3rd edition. Lancet 2017; published online Nov 24. http://dx.doi.org/10.1016/ S0140-6736(17)32906-9. 
170 Knaul FM, Farmer PE, Krakauer EL, et al. Alleviating the access abyss in palliative care and pain relief-an imperative of universal health coverage: the Lancet Commission report. Lancet. 2017 Oct 11. pii: S0140-6736(17)32513-8. doi: 10.1016/S0140-6736(17)32513-8. [Epub ahead of print] ${ }^{171}$ Paintsil V, David H, Kambugu J, et al. The Collaborative Wilms Tumour Africa Project; baseline evaluation of Wilms tumour treatment and outcome in eight institutes in sub-Saharan Africa. European journal of cancer (Oxford, England : 1990) 2015;51:84-91.

172 Israels T, Moreira C, Scanlan T, et al. SIOP PODC: Clinical guidelines for the management of children with Wilms tumour in a low income setting. Pediatric Blood \& Cancer 2012:n/a-n/a. 173 Wilson ML, Fleming KA, Kuti MA, Looi LM, Lago N, Ru K. Access to pathology and laboratory medicine services: a crucial gap. Lancet (London, England) 2018;391:1927-38.

174 Sullivan R, Alatise OI, Anderson BO, et al. Global cancer surgery: delivering safe, affordable, and timely cancer surgery. The Lancet Oncology 2015;16:1193-224.

175 World Health Organization. First Global Conference on Task Shifting. 2008. http://www.who.int/healthsystems/task shifting/en/. (accessed June 20, 2019) ${ }^{176}$ Joshi R, Alim M, Kengne AP, Jan S, Maulik PK, Peiris D, Patel AA. Task shifting for noncommunicable disease management in low and middle income countries-a systematic review. PLoS One. 2014;9(8):e103754.

177 Penazzato M, Davies MA, Apollo T, Negussie E, Ford N. Task shifting for the delivery of pediatric antiretroviral treatment: a systematic review. J Acquir Immune Defic Syndr. 2014;65(4):414-22.

178 Seidman G, Atun R. Does task shifting yield cost savings and improve efficiency for health systems? A systematic review of evidence from low-income and middle-income countries. Human Resources for Health 2017; 15:29 DOI 10.1186/s12960-017-0200-9 
179 Hall CS, Fottrell E, Wilkinson S, Byass P. Assessing the impact of mHealth interventions in lowand middle-income countries - what has been shown to work?, Global Health Action, 2014;

7:1, DOI: $\underline{10.3402 / g h a . v 7.25606}$

180 Gurol-Urganci I, de Jongh T, Vodopivec-Jamsek V, Car J, Atun R. Mobile phone messaging for communicating results of medical investigations. Cochrane Database Syst Rev 2012: 6: CD007456.

181 Car J, Gurol-Urganci I, de Jongh T, Vodopivec-Jamsek V, Atun R. Mobile phone messaging reminders for attendance at healthcare appointments. Cochrane Database Syst Rev 2012; 7: CD007458.

182 de Jongh T, Gurol-Urganci I, Vodopivec-Jamsek V, Car J, Atun R. Mobile phone messaging telemedicine for facilitating self-management of long-term illnesses. Cochrane Database Syst Rev 2008; 4: CD007459.

183 World Health Organization. eLearning for undergraduate health professional education: a systematic review informing a radical transformation of health workforce development. WHO, 2015. edited by Najeeb Al-Shorbaji, Rifat Atun, Josip Car, Azeem Majeed, Erica Wheeler. https://www.who.int/hrh/documents/14126-eLearningReport.pdf (accessed June 19,2019) ${ }^{184}$ Dunleavy G, Nikolaou CK, Nifakos S, Atun R, Law GCY, Tudor Car L. Mobile digital education (mLearning) for health professions: a systematic review and meta-analysis by the Digital Health Education collaboration. Journal of Medical Internet Research 2019 Feb 12;21(2):e12937. doi: $10.2196 / 12937$.

185 Atun R, Jaffar S, Nishtar S, et al. Improving responsiveness of health systems to noncommunicable diseases. Lancet 2013; 381: 690-97 
186 Schouten EJ, Jahn A, Midiani D, et al. Prevention of mother-to-child transmission of HIV and the health-related Millennium Development Goals: time for a public health approach. Lancet 2011; 378: $282-84$

187 van Olmen J, Schellevis F, Van Damme W, Kegels G, Rasschaert F. Management of chronic diseases in Sub-Saharan Africa: cross-fertilisation between HIV/AIDS and diabetes care. J Trop Med 2012; 2012: 349312.

188 Bloom BR, Atun R. Back to the future: Rethinking global control of tuberculosis. Sci. Transl. Med. 2016; 8: 329ps7 DOI: 10.1126/scitranslmed.aaf2944

${ }^{189}$ Atun R, Weil DE, Eang MT, Mwakuysa D. Health-system strengthening and tuberculosis control. Lancet 2010; 375: 2169-78.

190 Atun R, Davies JI, Gale EAM, et al. Diabetes in sub-Saharan Africa: from clinical care to health policy. Lancet Diabetes and Endocrinology Commission Report. Lancet Diabetes and Endocrinology $2017 ; 5$ (8) 622-667.

191 Blanchet N, Thomas M, Atun R, Knaul F, Jamison D, Hecht R. Global Collective Action in Health: the WDR+20 Landscape of Core and Supportive Functions. UNU-WIDER, Helsinki, Finland (2014) 25 pp. [WIDER Working Paper No. 2014/011] https://www.wider.unu.edu/publication/global$\underline{\text { collective-action-health }}$

192 Heller PS. Understanding fiscal space. IMF Policy Discussion Paper. PDP 05/4, March 2005. International Monetary Fund, 2005; Washington D.C., USA.

193 Heller PS. Understanding fiscal space. IMF Policy Discussion Paper. PDP 05/4, March 2005. International Monetary Fund, 2005; Washington D.C., USA.

${ }^{194}$ Heller PS. The prospects of creating 'fiscal space' for the health sector. Health Policy and Planning 2006;21(2):75-9. 
195 Tandon A, Cashin C. Assessing Public Expenditure on Health From a Fiscal Space Perspective: World Bank, 2010; Washington D.C. USA.

196 International Monetary Fund. IMF Data Mapper. World Economic Outlook. Real GDP Growth. https://www.imf.org/external/datamapper/NGDP_RPCH@WEO/OEMDC/ADVEC/WEOWORLD (accessed June 7, 2019)

197 Dieleman JL, Sadat N, Chang AY, et al. for Global Burden of Disease Health Financing Collaborator Network. Future and potential spending on health 2015-40: development assistance for health, and government, prepaid private, and out-of-pocket health spending in 184 countries. Lancet 2019. Published Online April 19, 2017 http://dx.doi.org/10.1016/S0140-6736(17)30873-5 198 WHO. Earmarked tobacco taxes: lessons learnt from nine countries. World Health Organization. Geneva, 2015. http://apps.who.int/iris/bitstream/10665/206007/1/9789241510424 eng.pdf?ua=1 199 UN. Report of the International Conference on Financing for Development. Monterrey, Mexico, 2002. http://www.un.org/esa/ffd/monterrey/MonterreyConsensus.pdf (accessed June 7, 2019). ${ }^{200}$ Atun R, Knaul FM, Akachi Y, Frenk J. Innovative financing for health: what is truly innovative? Lancet 2012; 380: 2044-49.

201 Atun R, Silva S, Knaul FM. Innovative financing instruments for global health 2002-15: a systematic analysis. Lancet Glob Health 2017; 5: e720-26.

202 The Global Fund. Financials. https://www.theglobalfund.org/en/financials/ (accessed June 7, 2019).

203 Gavi, the Vaccine Alliance. Disbursements and commitments. http://www.gavi.org/results/disbursements/ (accessed June 7, 2019). 204 UNITAID. Strategy 2017-2021. https://unitaid.eu/assets/Unitaidstrategy-2017-2021 Dec- 
2017.pdf (accessed June 7, 2019).

205 Griffith-Jones S, Persaud A. Financial Transaction Taxes. http://stephanygi.net/papers/FTT.pdf (accessed June 2, 2019)

206 The International Finance Facility for Immunisation. https://www.iffim.org (accessed June 7, 2019).

207 Debt2Health. The Global Fund. https://www.uhc2030.org/fileadmin/uploads/ihp/Documents/Results Evidence/HAE results lessons/Taskforce\%20factsheet - global fund debt2health initiative EN.pdf (accessed June 2, 2019).

${ }^{208}$ Adeyi O, Atun R. Innovating for impact: the Affordable Medicines Facility-malaria (AMFm). Nat Med 2009; 15: 991.

${ }^{209}$ Adeyi O, Atun R. Universal access to malaria medicines: innovation in financing and delivery. Lancet 2010; 376: 1869-71.

210 GAVI Alliance. Pneumococcal AMC. AMC annual reports.

http://www.gavialliance.org/funding/pneumococcal-amc/ (accessed June 21, 2017).

${ }^{211}$ Social Finance. Social Impact Bonds. http://www.socialfinance.org.uk/wpcontent/uploads/2016/07/SIBs-Early-Years Social-Finance 2016 Final3.pdf (accessed June 26, 2017)

212 Social Finance. Investing in Social Outcomes: Development Impact Bonds http://www.socialfinance.org.uk/investing-in-social-outcomes-development-impact-bonds/ (accessed June 26, 2017)

213 The World Health Report 2010. Financing for universal coverage. WHO, 2010, Geneva. 
${ }^{214}$ Atun R, Cavalli F. The global fight against cancer: challenges and opportunities. Lancet $2018 ; 391: 412-413$

215 Force L M, GBD 2017 Childhood Cancer Collaborators, Fitzmaurice C, Bhakta N. The global burden of childhood cancer: results from the Global Burden of Disease 2017

Study. Lancet Oncology 2019 (in press)

216 WHO. Global NCD Action Plan for the Prevention and Control of NCDs 2013-2020.

https://apps.who.int/iris/bitstream/handle/10665/94384/9789241506236 eng.pdf?sequence=1 accessed June 192019

217 United Nations Sustainable Development Goals. Goal 3: Ensure healthy lives and promote wellbeing for all at all ages. Goal 3 targets. https://www.un.org/sustainabledevelopment/health/ accessed June 19, 2019

218 WHO. Tackling NCDs. 'Best buys' and other recommended interventions for the prevention and control of noncommunicable diseases.

https://apps.who.int/iris/bitstream/handle/10665/259232/WHO-NMH-NVI-17.9-

eng.pdf?sequence=1 (accessed June 19, 2019)

219 IAEA. Programme of Action for Cancer Therapy. Available at https://www.who.int/cancer/childhood-cancer/en/ (accessed June 19, 2019)

220 International Atomic Energy Agency. IAEA Human Health Reports. Inequity in cancer care: a global perspective. Vienna: International Atomic Energy Agency, 2011.

221 IAEA. impact Review. https://www.iaea.org/services/review-missions/impact-review (accessed June 19, 2019)

222 IARC. Global Cancer Observatory. http://gco.iarc.fr (accessed June 19, 2019)

223 UN. Declaration of commitment on HIV/AIDS. "Global Crisis-Global Action." 
http://www.un.org/ga/aids/coverage/FinalDeclarationHIVAIDS.html (accessed June 5, 2019).

224 Union for International Cancer Control.

https://www.uicc.org/sites/main/files/private/131119 UICC WorldCancerDeclaration 2013 1.pd $\underline{\mathrm{f}}$ (accessed June 20, 2019)

${ }^{225}$ Lam CG, Howard SC, Bouffet E, Pritchard-Jones K Science and health for all children with cancer. Science $2019 ; 363,1182-1186$. 